\title{
Determination of Power Losses in Solar Panels Using Artificial Neural Network
}

\section{Kian Jazayeri}

Submitted to the

Institute of Graduate Studies and Research

in partial fulfillment of the requirements for the Degree of

Master of Science

in

Electrical and Electronic Engineering

Eastern Mediterranean University

September 2012

Gazimağusa, North Cyprus 
Approval of the Institute of Graduate Studies and Research

\section{Prof. Dr. Elvan Y1lmaz \\ Director}

I certify that this thesis satisfies the requirements as a thesis for the degree of Master of Science in Electrical and Electronic Engineering.

Assoc. Prof. Dr. Aykut Hocanın

Chair, Department of Electrical and Electronic

Engineering

We certify that we have read this thesis and that in our opinion it is fully adequate in scope and quality as a thesis for the degree of Master of Science in Electrical and Electronic Engineering.

Prof. Dr. Şener Uysal

Supervisor

1. Prof. Dr. Şener Uysal

2. Assoc. Prof. Dr. Aykut Hocanın

3. Asst. Prof. Dr. Rasime Uyguroğlu 


\begin{abstract}
The world's traditional energy resources remain insufficient with respect to the increasing energy requirements of the modern era. In recent decades the threats and limitations associated with energy resources such as fossil fuels have motivated researches to find alternative clean and sustainable energy resources. Concentrated solar power is considered as one of the most competitive and rapidly growing renewable energy resources which emerge to meet the modern world's increasing energy requirements. Along with the rising demand for alternative energy resources, the technologies and methods regarding utilization of solar energy have been the subject of many scientific works recently.
\end{abstract}

Solar panels made of solar cells generate electrical power from sun's radiations and developing management and controlling techniques for solar panels plays a major role in benefitting from solar energy. The purpose of this study is to develop an intelligent fault detection system which provides possibilities of real time monitoring and fault detection of solar panels.

Utilizing artificial neural network technology, the intelligent solar panel fault detection system is capable of perceiving sun's position in the sky and estimating the corresponding output power of a solar panel based on algorithms derived by the artificial neural network which has been trained on solar data at several time intervals. The system being capable of operating in any geographical location provides possibilities of 24-hour monitoring and fault detection as well as future power estimations for solar panels. 
Keywords: Renewable Energy, Photovoltaic, Solar Energy, Solar Panel/Cell, Intelligent Fault Detection, Artificial Neural Network, Output Power Estimation 


\section{$\ddot{O} \mathbf{Z}$}

Modern asrın artan enerji ihtiyaçları dikkate alındığında dünyanın geleneksel enerji kaynaklarının yetersiz kaldığı görülmektedir. Son yıllarda özellikle fosil yakıtlar ve buna benzer enerji kaynaklarına yönelik olan sınırlamalar ve tehditler, araştırmaların alternatif temiz ve sürdürülebilir enerji kaynakları üzerinde yoğunlaşmasına neden olmuştur. Yoğunlaştırılmuş güneş enerjisi, modern dünyanın artan enerji ihtiyaçlarını karşılamak üzere alternatif olarak düşünülen, rekabet gücü en yüksek olan ve hızlı bir şekilde büyüyen yenilenebilir bir enerji kaynağı konumundadır. Alternatif enerji kaynaklarına yönelik olan taleplerin artması ile birlikte, güneş enerjisinin kullanımı ile ilgili olan teknoloji ve yöntemler de birçok bilimsel çalışmaya konu olmuştur.

Güneş hücrelerinden oluşan güneş panelleri, güneş 1şınlarından elektrik enerjisi üretmekte olup bu panellere yönelik gelişme yönetimi ve kontrol teknikleri güneş enerjisinden yararlanma yönünde önemli bir rol oynamaktadır. Bu çalışmada güneş panelleri için gerçek zamanlı izleme ve hata belirleme olanaklarını sağlayan akıllı bir hata belirleme sisteminin geliştirilmesi amaçlanmaktadır.

Yapay zeka ağları teknolojisinden yararlanılarak güneş panelleri için tasarlanan akıllı hata blirleme sistemi, güneşin gökyüzündeki konumunu algılama ve çeşitli zaman aralıklarında toplanan solar bilgiler ile eğitilmiş olan yapay zeka ağları tarafından elde edilen algoritmalara dayanarak ilgili çıkış güçlerini tahmin etme kabiliyetine sahip olmaktadır. Herhangi bir coğrafi konumda çalışma kabiliyetine sahip olan 
sistem, güneş panellerine yönelik 24 saat izleme ve hata belirleme olanaklarının yanısıra güç tahmin olanaklarını da sağlamaktadır.

Anahtar Kelimeler : Yenilenebilir Enerji, Güneş Enerjisi, Güneş Paneli/Hücresi, Akıllı Hata Belirleme, Yapay Zeka Ağları, Güç Tahmini 


\section{ACKNOWLEDGEMENTS}

First and foremost, I would like to express my sincere appreciation to my supervisor Prof. Dr. Şener Uysal for his professional and kind guidance and assistance through the various stages of this study.

It is a great pleasure to acknowledge the advice and support of the Head of Electrical and Electronic Engineering Department Assoc. Prof. Dr. Aykut Hocanın and my examining committee member Asst. Prof. Dr. Rasime Uyguroğlu.

Words are not enough to extend my gratitude to my dear father and mother for their limitless love, motivation and support throughout my life.

I would like to give my endless thanks to my dear brother and best friend Moein, whom this study could not have been completed without his absolute support.

Finally I would like to thank my dear friend Reza Abrishambaf for his helps through this study. 


\section{TABLE OF CONTENTS}

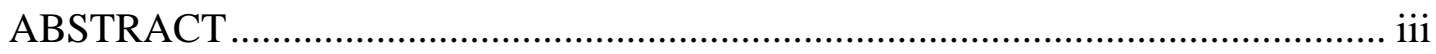

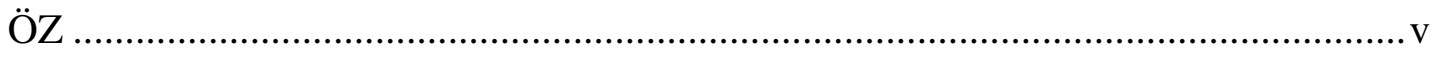

ACKNOWLEDGEMENTS ........................................................................... vii

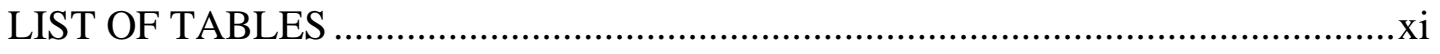

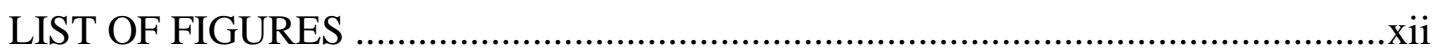

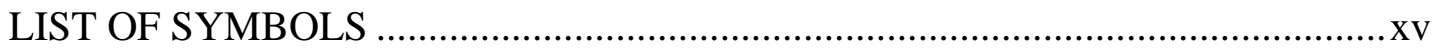

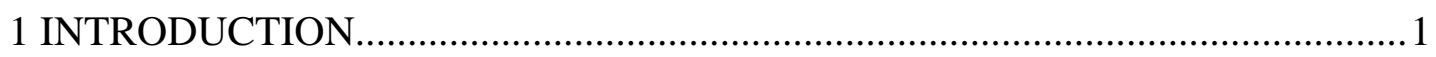

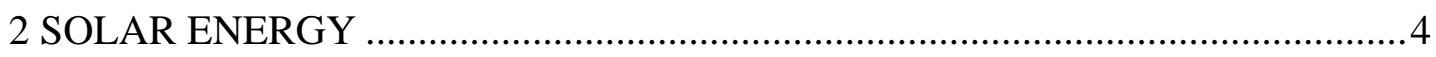

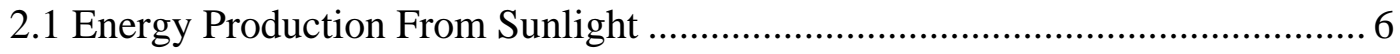

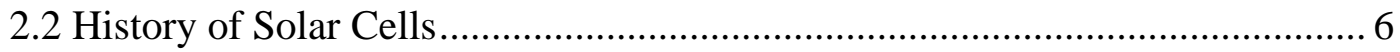

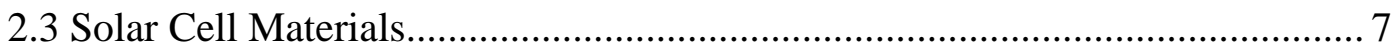

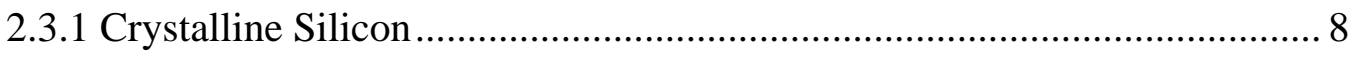

2.3.2 Thin Film Solar Cells ....................................................................... 8

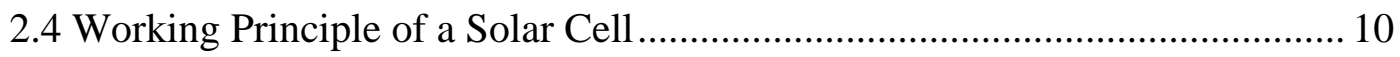

2.5 Mathematical Model of a Solar Cell ......................................................... 11

2.6 Characteristic Factors of a Solar Cell......................................................... 13

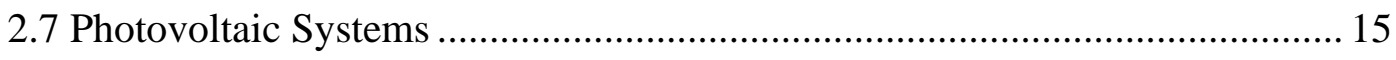

2.7.1 Grid-Interactive Systems (PV Systems Without Battery Backups).......... 15

2.7.2 Grid-Interactive Systems With Battery Backups .................................. 16

2.7.3 Effects of External Factors on PV System Power Output........................ 17

2.8 Current Applications of Solar Systems ........................................................ 19

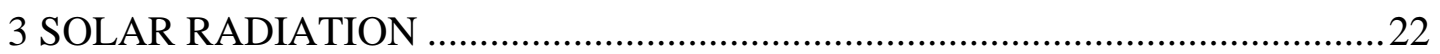

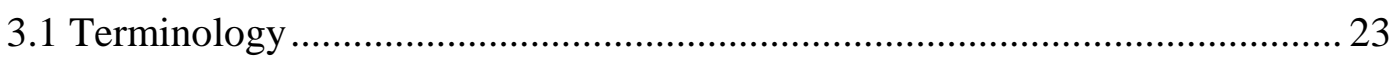


3.2 Solar Spectrum 25

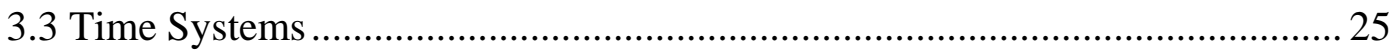

3.4 Extraterrestrial Radiation From the Sun ................................................... 27

3.5 Behavior of Sunlight Beams at the Surface of the Earth ............................... 30

4 SUN`S POSITION IN THE SKY AS SEEN FROM THE EARTH .......................33

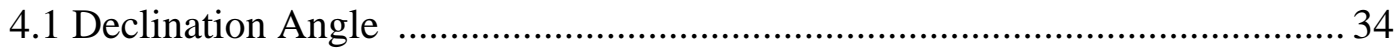

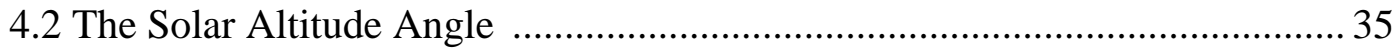

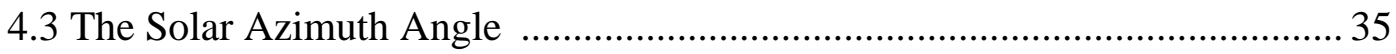

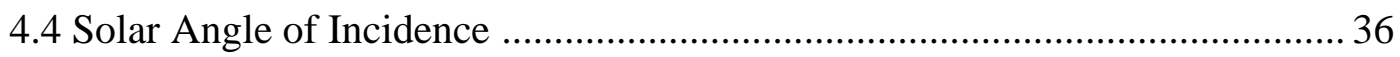

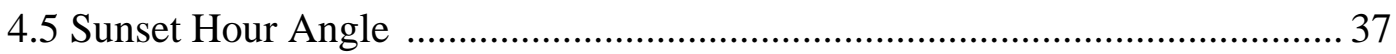

5 BASIC CONCEPTS OF ARTIFICIAL NEURAL NETWORK THEORY ............39

6 ENERGY CONSUMPTION PROFILE AND SOLAR ENERGY

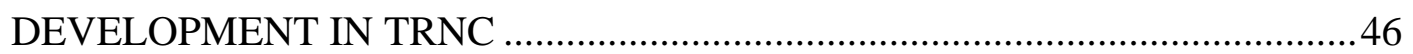

6.1 Geographical Characteristics and Climate in TRNC ................................... 46

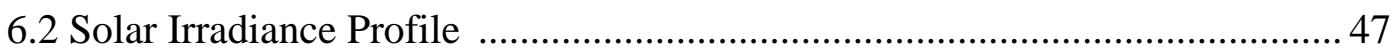

6.3 Energy Production and Consumption Profile in TRNC ................................. 48

7 EXPERIMENTAL INTELLIGENT SOLAR PANEL FAULT DETECTION

SYSTEM BASED ON ARTIFICIAL NEURAL NETWORKS ...........................50

7.1 Solar Data Collection Procedures ............................................................... 51

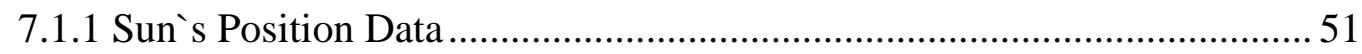

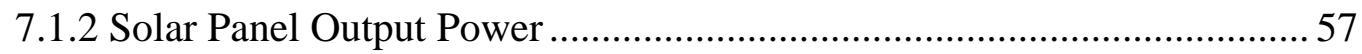

7.2 Artificial Neural Network Training Process ................................................. 63

8 EXECUTION RESULTS OF INTELLIGENT SOLAR PANEL FAULT

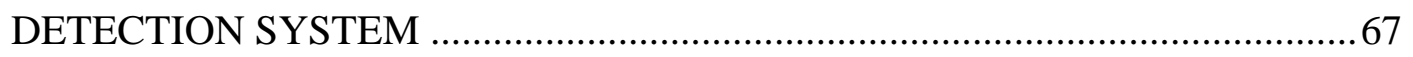

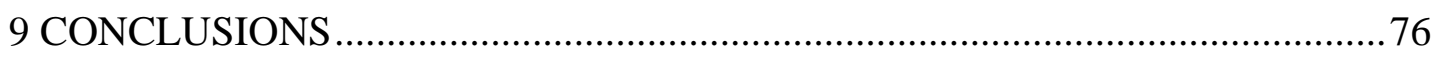


REFERENCES. 


\section{LIST OF TABLES}

Table 4.1 : Relationship between the Julian Day And the $i^{\text {th }}$ Day of a Month .33

Table 8.1 : Average Percent RMSE between the Measured and the Estimated

Output Power Values of a 50x60 Monocrystalline Silicon Solar

Panel for Different Daylight Time Intervals on July $6^{\text {th }}, 2012$ 


\section{LIST OF FIGURES}

Figure 2.1 : Global Photovoltaics Market Growth......................................................5

Figure 2.2 : Solar Cell, Solar Module, Solar Array .............................................6

Figure 2.3 : Energy Band Structure in a Semiconductor Material ............................ 11

Figure 2.4 : Electronic Equivalent Circuit of a Solar Cell ...................................... 11

Figure 2.5 : Grid Interactive PV System without Battery Backups .......................... 15

Figure 2.6 : A Grid-Interactive PV System with Battery Backups .......................... 17

Figure 2.7 : Grid-Connected and Stand Alone Connected PV Systems ...................20

Figure 3.1 : Annual Mean Insolation in Europe ................................................... 24

Figure 3.2 : Annual Mean Insolation in Cyprus.....................................................24

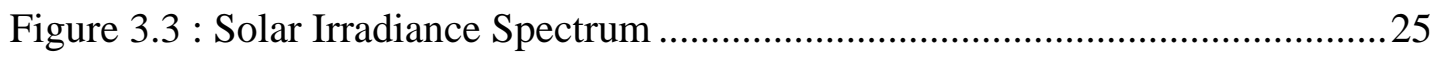

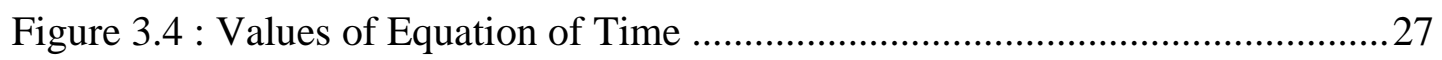

Figure 3.5 : Earth - Sun Movement Pattern....................................................... 28

Figure 3.6 : The Variations in $\mathrm{G}_{\mathrm{od}}$ as a Function of the Julian Day Number and Latitude

Figure 3.7 : The Average Irradiance Hitting the Earth`s Atmosphere ........................30

Figure 3.8 : The Direct, Diffuse and Albedo Components of Solar Radiation........... 31

Figure 4.1 : The Position of the Earth and the Sun as Seen from any Point on

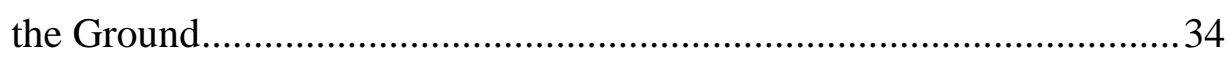

Figure 4.2 : The Position of The Sun at a Specific Time of a Day ............................36

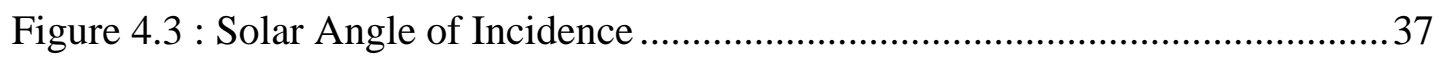

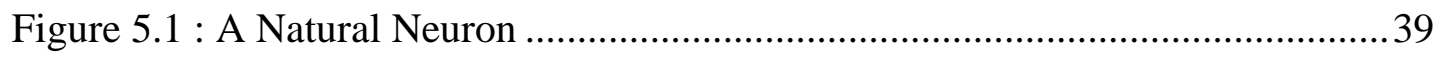

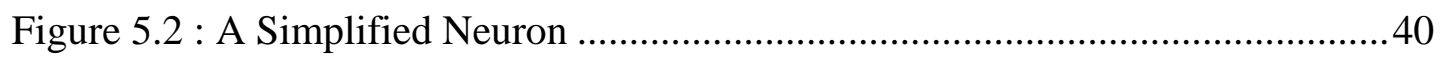

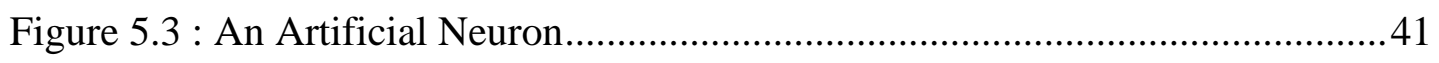


Figure 5.4 : Sigmoid Function With Different Steepness Factors 42

Figure 5.5 : A Multilayer Feed Forward Network .................................................4

Figure 6.1 : Mean Daily Solar Irradiance in Cyprus .............................................48

Figure 6.2 : Energy Consumprion Profile in TRNC …........................................ 48

Figure 6.3 : Direct Normal Irradiance Map of Cyprus .............................................49

Figure 7.1 : The Solar Altitude Angle Calculations over a 24-H Period on July $1^{\text {st }}, 2012$ .53

Figure 7.2 : The Solar Azimuth Angle Calculations over a 24-H Period on July $1^{\text {st }}, 2012$ 55

Figure 7.3 : The Solar Angle of Incidence Calculations over a 24-H Period on July $1^{\text {st }}, 2012$ .57

Figure 7.4 : The Solar Panel Used For Data Collection .58

Figure 7.5 : The Circuit Connection between the Solar Panel and the Power Resistor

Figure 7.6 : The Circuit Used for the Output Power Measurement of the Solar Panel .60

Figure 7.7 : Output Power Measured with 1 Sample per Minute for a 50x60 cm Monocrystalline Silicon Solar Panel over a 24-Hour Period on July $3^{\text {rd }}, 2012$ 61

Figure 7.8 : Output Power Measured with 12 Samples per Minute for a 50x60 cm Monocrystalline Silicon Solar Panel over a 24-Hour Period on July $3^{\text {rd }}, 2012$. 62

Figure 7.9 : Artificial Neural Network Training Data Set .64

Figure 7.10 : The Artificial Neural Network Architecture Utilized in the Solar

Panel Fault Detection System .66 
Figure 7.11: The Execution Window of The Training Process of the Artificial Neural Network .66

Figure 7.12 : Output Power Values (Measured vs. Estimated) for a 50x60 cm Monocrystalline Silicon Solar Panel over a 24-Hour Period on July $6^{\text {th }}, 2012$

Figure 7.13 : The Root Mean Square Error between the Measured and the Estimated Output Power Values for a 50x60 cm Monocrystalline Silicon Solar Panel on July $6^{\text {th }}, 2012$ .70

Figure 7.14 : Output Power Values (Measured vs. Estimated) for a 50x60 cm Monocrystalline Silicon Solar Panel over a 24-Hour Period on August $3^{\text {rd }}, 2012$ .71

Figure 7.15 : The Root Mean Square Error between the Measured and the Estimated Output Power Values for a 50x60 cm Monocrystalline Silicon Solar Panel on August $3^{\text {rd }}, 2012$ .72 


\section{LIST OF SYMBOLS}

\begin{tabular}{|c|c|}
\hline $\mathrm{cm}$ & : Centimeter \\
\hline$I$ & : Current \\
\hline$I_{0}$ & : The Reverse Saturation Current \\
\hline$I_{D}$ & : The Current Passing through the Diode \\
\hline$I_{L}$ & : The Photogenerated Current \\
\hline$I_{S C}$ & : The Short Circuit Current \\
\hline$I_{S H}$ & : The Current Passing through the Shunt Resistor \\
\hline$j^{\prime}$ & : The Day Angle \\
\hline $\mathrm{J}$ & : Joule \\
\hline$J$ & : The Julian Day Number \\
\hline $\mathrm{m}$ & : Meter \\
\hline$P_{\text {Output }}$ & : Output Power \\
\hline$R_{L}$ & : Power Resistor \\
\hline$R_{S H}$ & : The Shunt Resistor \\
\hline$s$ & : Steepness Parameter \\
\hline$S_{\text {od }}$ & : The Astronomical Daylength \\
\hline$t$ & : The Shift Value from the Centre of the Activation Function \\
\hline$V$ & : Voltage at the Output Terminals \\
\hline$V_{j}$ & : The Voltage Across the Diode and the Shunt Resistor \\
\hline$V_{O C}$ & : The Open Circuit Voltage \\
\hline $\mathrm{W}$ & : Watt \\
\hline Wh & : Watt Hour \\
\hline$w_{i}$ & : Weights of Inputs \\
\hline$x_{i}$ & : The Input Dendrites \\
\hline$y(x)$ & : The Output Axon \\
\hline
\end{tabular}




\begin{tabular}{|c|c|}
\hline$Z_{S}$ & Zenith Angle of the Sun \\
\hline$\alpha_{M}$ & Azimuth Angle of the Panel \\
\hline$\alpha_{\mathrm{S}}$ & The Solar Azimuth Angle \\
\hline$\beta$ & Tilt Angle of the Panel \\
\hline$\gamma_{\mathrm{S}}$ & The Solar Altitude Angle \\
\hline$\varepsilon$ & : The Correction to Mean Solar Distance \\
\hline$\theta_{\mathrm{i}}$ & : The Solar Angle of Incidence \\
\hline$\lambda_{\mathrm{R}}$ & : The Longitude of the Selected Time Zone \\
\hline$\omega$ & : The Hour Angle \\
\hline$\omega_{\mathrm{SR}}$ & : The Sunrise Hour Angle \\
\hline$\omega_{\mathrm{SS}}$ & : The Sunset Hour angle \\
\hline$\mu$ & Micro \\
\hline$\delta$ & The Declination angle \\
\hline$\lambda$ & : Longitude (Degrees) \\
\hline$\varphi$ & : The Latitude \\
\hline $\mathrm{AC}$ & : Alternative Current \\
\hline ANN & The Artificial Neural Networks \\
\hline A-Si & Amorphous Silicon \\
\hline BOS & Balance of System Equipment \\
\hline $\mathrm{C}$ & The Summer Time Correction Factor \\
\hline CdTe & Cadmium Telluride \\
\hline CET & The Central Europe Time \\
\hline CIGS & : Copper Indium Gallium Selenide \\
\hline $\mathrm{C}-\mathrm{Si}$ & : Mono Crystalline Silicon \\
\hline DC & Direct Current \\
\hline ET & : The Equation of Time \\
\hline FANN & Fast Artificial Neural Network Library \\
\hline
\end{tabular}




$\begin{array}{ll}\text { FF } & : \text { Fill Factor } \\ \text { GaAs } & : \text { Gallium Arsenide } \\ \text { GMT } & : \text { The Mean Greenwich Time } \\ \text { God }_{\text {LAT }} & : \text { The Extraterrestrial Radiation on a Horizontal Surface Over a Day } \\ \text { LMT } & : \text { The Local Apparent Time } \\ \text { Mc-Si } & : \text { Mono Crystalline Silicon } \\ \text { Poly-Si } & : \text { Poly Crystalline Silicon } \\ \text { PV } & : \text { Photovoltaic } \\ \text { RMSE } & : \text { Root Mean Square Error } \\ \text { SHS } & : \text { Stand Alone Solar System } \\ \text { U.T. } & : \text { The Universal Time }\end{array}$




\section{Chapter 1}

\section{INTRODUCTION}

Back in 1970s, the subject of earth's energy resources was not being taken into enough consideration. The industrial world had used to the idea of producing electricity in fossil fuel power plants far from factories and homes. Fossil fuels that had been taken millions of years to form and store underground were being widely used up for electricity generation. Few people were aware of the environmental threats of burning coal, oil and gas. The global warming and the air, water and land pollutions are just a few of these threats. Carbon dioxide, which is the most significant gas emitted when fossil fuels are burned, traps heat in earth's atmosphere. During the last 150 years the amount of carbon dioxide in earth's atmosphere is \%25 increased as a result of burning fossil fuels. Inundation of wetlands, river deltas, and even populated areas due to the warming of the oceans is predicted to be one of the most important consequences of the global warming. Besides the global warming, the pollution blended into air, water and land when fossil fuels burned forms another major environmental threat. The most important fossil fuel pollutants which mix with the air are carbon monoxide, nitrogen oxides, sulfur oxides, and hydrocarbons. On the other hand, the extraction, transportation and use of oil and coal cause in water and land pollutions. The offshore oil spills and the waters coming through coal mines, leaves the entire surrounding shores and rivers inhabitable and cause in loss of plant and animal life. The same happens to the mined lands since the wastes of mining remains and makes the land barren. 
In particular, humans were failing to figure out the fact that the fossil fuels are counted as the capital components of the earth's resources, not the income components, which means that even if using these kinds of resources was environmentally safe, it still would not change the fact that they are limited and are going to run out one day.

Now, it is of prior importance to put effort into developing techniques of gaining benefit from renewable energy resources. The term renewable refers to the sustainability of the energy resource. According to Lynn (2010), "The Sun's radiation beamed at us day by day, year by year, and century by century, is effectively free income to be used or ignored as we wish. This income is expected to flow for billions of years. Nothing is wasted or exhausted if we don't use it because it is there anyway" [1]. The free and sustainable solar energy will be available for human use through the next centuries without causing any environmental damage to the planet earth.

Solar panels made of solar cells generate electrical power from sun's radiations and developing management and controlling techniques for solar panels plays a major role in benefitting from solar energy. The purpose of this study is to develop an intelligent fault detection system which provides possibilities of real time monitoring and fault detection of solar panels.

The intelligent fault detection system utilizes the artificial neural network technology to immediately detect solar panel output power losses due to damaged cells, shadows etc. by estimating the output power with respect to sun's position in the sky. 
Utilizing such a fault detection system increases the efficiency of the solar power stations and decreases the maintenance and support costs in long terms. 


\section{Chapter 2}

\section{SOLAR ENERGY}

Half a century ago, few people had any idea about the photovoltaics (PV), which is the technique of producing electricity from the solar radiations. Although PV was successful in its early missions of powering the space satellites, even the pioneers of this technology could hardly imagine that their works will lead to a worldwide industry and replace the traditional methods of electricity generation. Lynn (2010) indicates that "More recently it would have taken courage to suggest that terrestrial PV would move into a multi - gigawatt era and start rivalling conventional methods

of electricity generation in the developed world" [1]. Figure 2.1 shows the global photovoltaics market growth based on the collected and the predicted data. 


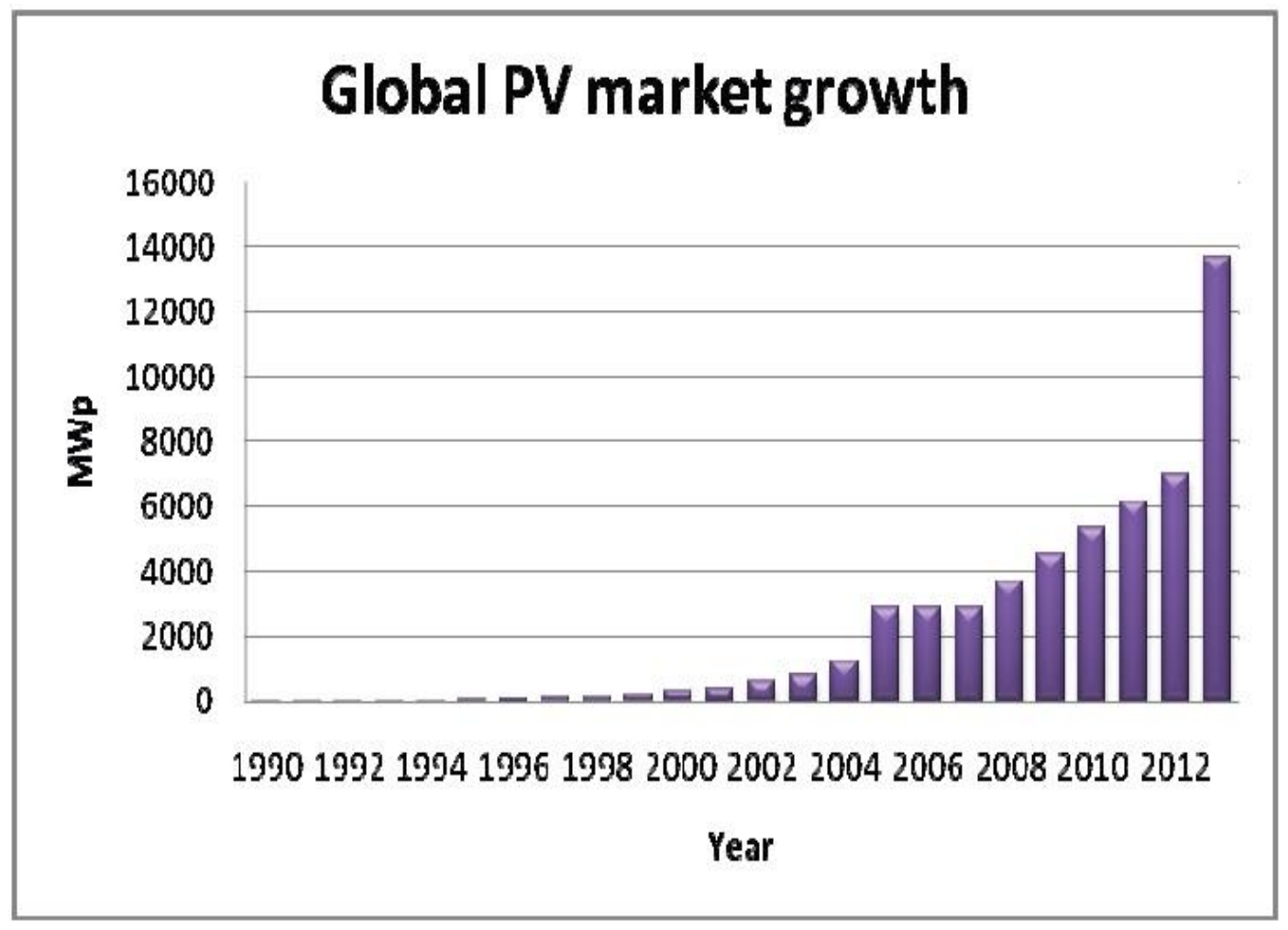

Figure 2.1.Global Photovoltaics Market Growth [2]

As it is obvious from Figure 2.1, the photovoltaics technology shows a dramatic market growth in recent years. One of the most important reasons for such a growth is elegance and simplicity. PV technology produces electricity noiselessly without moving parts or wastes, unlike the traditional electricity production techniques in which electricity is produced by a turbine which is driven by high pressure steam produced by fossil fuel or nuclear reactions. Such complex procedures are associated with many waste productions and environmental threats. Compared to the disadvantages regarding traditional technologies, there is not any major downside in photovoltaic technology. The most important matters with this technology may be its negative contribution to aesthetics of buildings covered by solar panels, or the space required for such a technology to produce the same amount of electricity a fossil fuel or nuclear power plant produce without taking up huge amounts of space. But considering that the space taken up by solar panels can be unproductive areas like 
desserts, and also the truth that solar panels are not visually aggressive or unattractive, it seems that there are no major problems regarding deployment of PV technology for electricity productions.

\subsection{Energy Production from Sunlight}

Solar cells are defined as devices that generate DC current directly from sunlight. Solar cells are combined and interconnected in order to form a solar panel (module) and a solar array consists of a number of interconnected solar panels. Solar cells, Solar Panels and Solar Arrays are shown in Figure 2.2.

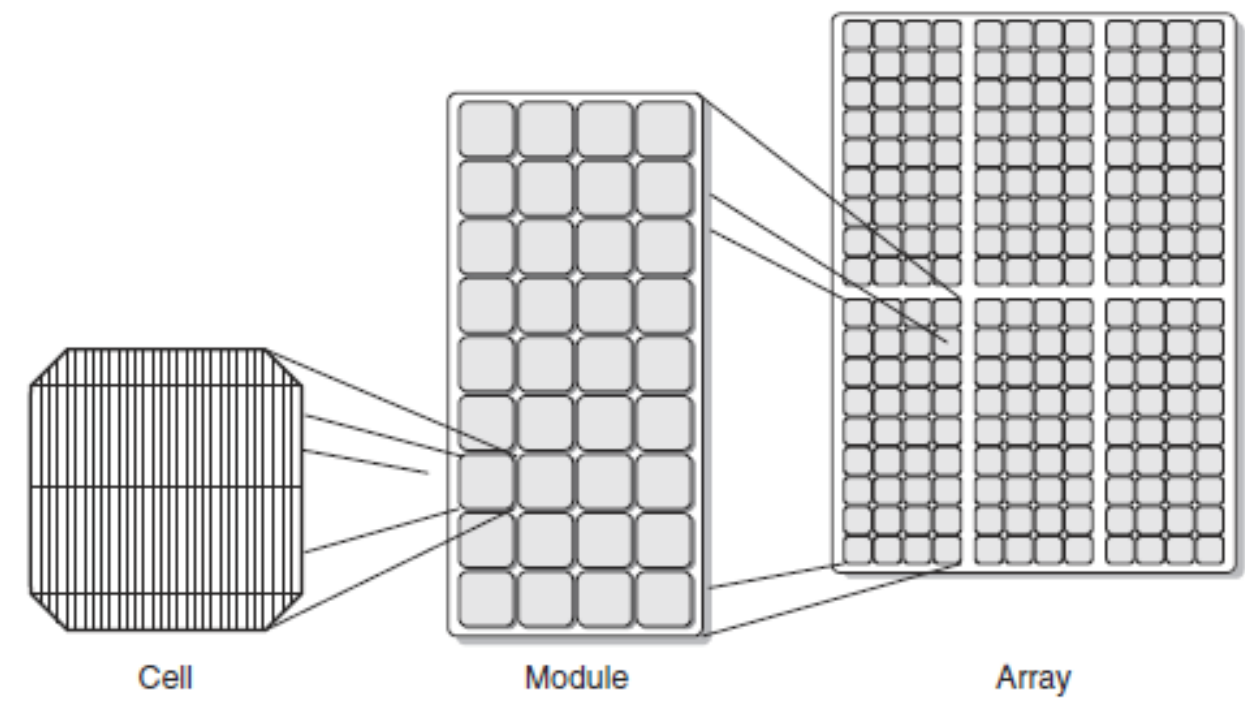

Figure 2.2.Solar Cell, Solar Module and Solar Array [3]

\subsection{History of Solar Cells}

The first experimental demonstration of photovoltaic effect was made by French physicist A.E.Becquerel in 1839 who made the world`s first photovoltaic cell. In 1883 the first solid state photovoltaic cell was made by Charles Fritts. He coated the semiconductor selenium by a very thin layer of gold to form the junctions. The first photoelectric cell based on outer photoelectric effect was made by Russian physicist Aleksander Stoletov in 1888. The underlying mechanism of light instigated carrier 
excitation was explained by Albert Einstein in 1905 and he received the Nobel prize in Physics for that in 1921. The modern junction semiconductor solar cell was patented by Russel Ohl in 1946. The first practical photovoltaic cell was developed in Bell Laboratories in 1954. Solar cells were first added to Vanguard I satellite in 1958. Elliot Barmen had managed to produce solar cells with lower costs in 1973 as a result of his researches. After this the productions costs have either been reduced as a result of recent improvements. [4]

\subsection{Solar Cell Materials}

There are various semiconductor materials used in solar cells. The efficiency and costs of solar cells varies depend on the materials used. It is desired that the material which is used has the appropriate characteristics to match the spectrum of the available sunlight. Some of the solar cells are designed to convert the wavelengths of the sunlight reaching the Earth`s surface while some other types of solar cells are capable of light absorbing beyond the Earth`s atmosphere. Also light absorber materials can be used in multiple physical configurations in order to take the advantage of different light absorption and charge separation mechanisms.

The materials which are currently used for solar cells include monocrystalline silicon, polycrystalline silicon, amorphous silicon, Cadmium telluride and copper indium selenide/sulfide. A big amount of currently available solar cells are made from bulk materials which are cut into 180-240 mm thick wafers and then processed like the other semiconductor materials. 
Some other materials are made as thin film layers, organic dyes and organic polymers. A third group of materials are made from nanocrystals and used as quantum dots. [4]

\subsubsection{Crystalline Silicon}

Crystalline silicon is the most prevalent bulk material used in solar cells. Silicon Wafers and Silicon Ribbons are two main structures of Crystalline Silicon cells. The energy conversion efficiency of these kind of solar cells are reported to be $\% 12-\% 18$ while the record efficiency for some laboratory cells has been \%24.7 [5]. The main disadvantage of this kind of cells is their high production costs while the reliability and stability of them is proven under outdoor working conditions. The high cost is a result of a combination of factors such that the small number of production and manufacturing units, complexities in solar cell manufacturing and module assembly and the needs to highly purified silicon. This material is divided into the following sub-categories according to crystallinity and crystal size;

- Monocrystalline Silicon (C-si)

- Polycrystalline Silicon or Multycrystalline Silicon (Poly -Si or mc-Si)

- Ribbon Silicon

- Mono-like-multi-silicon

\subsubsection{Thin Film Solar Cells}

Using thin film technology the amount of material which is required to create the active material of a solar cell is reduced. Thin film solar cells are approximately twice as heavy as crystalline cells and have lower efficiencies and larger corresponding area per watt production compared to crystalline silicon cells. Cadmium Telluride (CdTe), Copper Indium Gallium Selenide (CIGS) and 
Amorphous Silicon (A-Si) form three thin-film technologies generally used for outdoor solar power generation.

- Cadmium Telluride Solar Cells: These types of cells use a Cadmium Telluride (CdTe) thin film as a semiconductor layer to absorb and convert sunlight into electricity.

- Copper Indium Gallium Selenide: Copper Indium Gallium Selenide has the best efficiency among thin film materials.

- Gallium Arsenide Multijunction: Multijunction cells with high efficiencies were originally developed for satellite and space exploration application. These cells offer the lowest cost alternative at the present when used in terrestrial concentrators and consist of multiple thin films. Each semiconductor material used in a multijunction cell has a band gap energy which causes it to absorb a specific portion of the spectrum of sunlight. When the materials in a multijunction cell are selected based on specific needs and criteria the produced cells will be able to absorb nearly most of the sunlight spectrum and as a result the efficiency of the cell will be improved.

- Other Solar Cell Technologies: Along with the above mentioned solar cell technologies, there are other technologies used in solar cell production in order to provide solar cells with higher efficiencies and lower costs. Among them, organic cells, dye-sensitized cells and light-concentration based GaAs cell can be mentioned. The GaAs cells have announced to have more than $\% 40$ efficiencies when being used under concentrated sunlight. But the main disadvantage of them is their high production costs. 


\subsection{Working Principle of a Solar Cell}

The generation of electricity in a solar cell is based on the photovoltaic effect. The photovoltaic effect is defined as the generation of a potential difference between the junctions of different materials which happens as a response to some visible or other radiation. The processes during the photovoltaic effect can briefly be explained as follows:

- Generation of charge carriers as a result of absorption of photons in semiconductor material

- Separation of photo-generated charge carriers in the junction

- Collection of charge carriers at the terminals of the junction

The photons contained in sunlight have different amounts of energy corresponding to different wavelengths of solar spectrum. When the sunlight hits the surface of a solar cell the photons may be reflected back, absorbed or may pass through the material. The energy of the absorbed photons is then transferred to electrons in the semiconductor material. These electrons are generally in valence band of energy. This energy excites the electron into the conduction band of energy and makes it able to freely move within the semiconductor material. Moving of electrons from the valence band to conduction band creates the electron holes which are able to move through the material. As a result of researches it is found that most of the solar radiation reaching the earth consists of photons with energies higher the band gap and thus these photons are able to excite the electrons to move from the valence band into conduction band and create the opportunity for photogeneration to be possible. The energy bands in a semiconductor material are shown in Figure 2.3. 


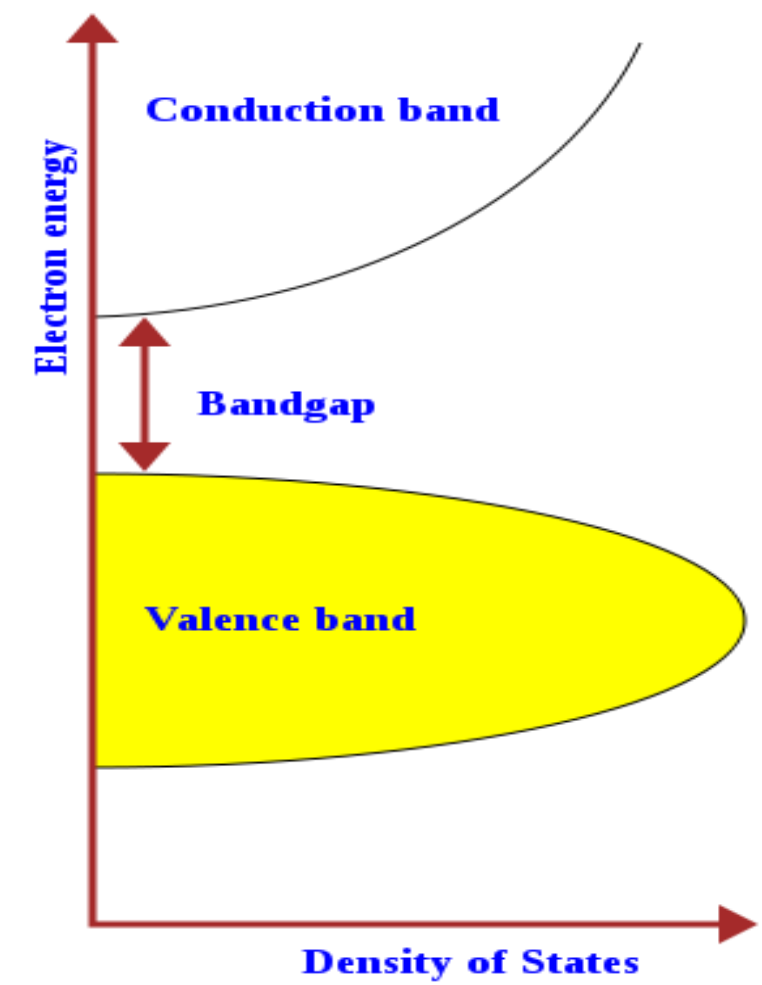

Figure 2.3.Energy Band Structure in a Semiconductor Material [4]

\subsection{Mathematical Model of a Solar Cell}

Each solar cell can be mathematically modeled in order to better understand its electronic behavior. The mathematical model (equivalent electronic circuit) of a solar cell is shown in Figure 2.4.

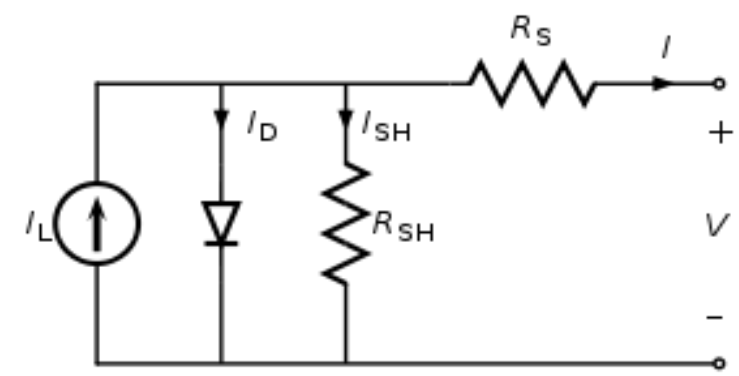

Figure 2.4.Electronic Equivalent Circuit of a Solar Cell [4]

Ideally each solar cell can be modeled as a current source which is connected to a diode in parallel. Referring to the results of practical tests it is seen that solar cells are 
not practically ideal. Thus to complete the model a shunt and a series resistor are added to the mathematical model.

As it is obvious from the figure the electrical current which is produced by the solar cell is equal to the current produced by the current source minus the current passing through the diode and the shunt resistor.

$$
I=I_{L}-I_{D}-I_{S H}
$$

Where;

I $\quad$ : Total output current (A)

$I_{L} \quad:$ The photogenerated current (A)

$I_{D} \quad$ : The current passing through the diode

$I_{S H} \quad$ : The current passing through the shunt resistor

The voltage equation also can be defined by the following equation;

$$
V_{j}=V+I R_{s}
$$

Where;

$V_{j} \quad:$ The voltage across the diode and the shunt resistor

V : The voltage at the output terminals

I : The output current

The current passing through the diode can be described as;

$$
I_{D}=I_{0}\left\{\left\{\exp \left[\frac{q\left(V+I R_{S}\right)}{n K T}\right]-1\right\}-\frac{V+I R_{S}}{R_{S H}}\right.
$$

Where;

$I_{0} \quad$ : The reverse saturation current (A)

$n \quad$ : Diode ideality factor 
$q \quad$ : Elementary charge (the electric charge carried by a single proton)

$k \quad$ : Boltzman`s constant

T : The absolute temperature

Also the current diverted through the shunt resistor $\left(I_{S H}\right)$ can be described as;

$$
I_{S H}=\frac{V_{J}}{R_{S H}}
$$

Taking the above mentioned into the consideration, the characteristic equation of a solar cell can be re-written as;

$$
I=I_{L}-I_{0}\left\{\exp \left[\frac{q\left(V+I R_{S}\right)}{n K T}\right]-1\right\}-\frac{V+I R_{S}}{R_{S H}}
$$

\subsection{Characteristic Factors of a Solar Cell}

There are several factors and limitations for solar cells that should be taken into the consideration during solar cell design procedure. These factors also are called as characteristics of solar cells. Short circuit current, open circuit voltage and fill factor are some of these characteristics. During this section the main characteristic factors of solar cells are briefly described.

- Short Circuit Current ( $\left.\mathbf{I}_{\mathbf{S C}}\right)$ : Short circuit current can be explained as the maximum possible current which is produced by the solar cell when the terminals are shorted. As it was explained before the energy of photons contained in the sunlight will excite the electrons inside the semiconductor material and give them the opportunity to move freely through the material. Therefore it can be estimated that the maximum short circuit current will be 
produced when each photon in the sunlight contributes to one electron flow to the load. Again as it was previously explained, the energy of the photons must be greater than the band gap energy of the material to be able to excite the electrons. Thus it implies that the produced short circuit current depends on the band gap of the semiconductor material. A large band gap will cause less number of photons to be absorbed and so a smaller amount of produced short circuit current. Thus it can be predicted that solar cells which are made of materials with larger band gaps will produce a smaller amount of short circuit current compared to the cells made of materials with smaller band gap energies.

- Open Circuit Voltage $\left(\mathbf{V}_{\mathbf{O C}}\right)$ : Open circuit voltage of a solar cell is defined as the maximum voltage obtained from a cell when the terminals are open circuited. When the photons with energies higher than the band gap energy are absorbed they excite electrons from the valence band to the conduction band and cause their potential to be increased. The maximum amount of open circuit voltage in a solar cell depends on the band gap energy of the semiconductor material. The larger amount of band gap energy will cause the higher amount of open circuit voltage and the smaller band gap energies yield to smaller amounts of open circuit voltages.

- Fill Factor : The Fill Factor of a solar cell is a measure of squareness of the I-V curve of the cell and can be defined using the following equation;

$$
F F=\frac{V_{O C}-\ln \left(V_{O C}+0,72\right)}{V_{O C}+1}
$$

Where;

$V_{O C}=V_{O C} /\left(\frac{k T}{q}\right) \quad:$ Normalized open circuit voltage 


\subsection{Photovoltaic Systems}

Photovoltaic (PV) systems are designed and installed for several applications and the goal is to produce some or all of the electrical energy requirements. These kinds of systems are connected to the applications along with the main electric utility. Thus in the cases that all of the needs to electrical energy cannot be met by the PV system the required energy can be supplied by the utility.

In general PV systems have two main design concepts: PV Systems with Battery Backups and PV systems without Battery Backups. In this part brief information is given regarding each of the mentioned systems and their components.

\subsubsection{Grid-Interactive Systems (PV systems without Battery Backups)}

These kinds of systems are generally connected to the main power utility. The users of these systems supply their energy needs from the PV system during daylight and the energy requirements during nights and cloudy days are met by the utility. A general system view of PV systems without battery backup is shown in Figure 2.5.

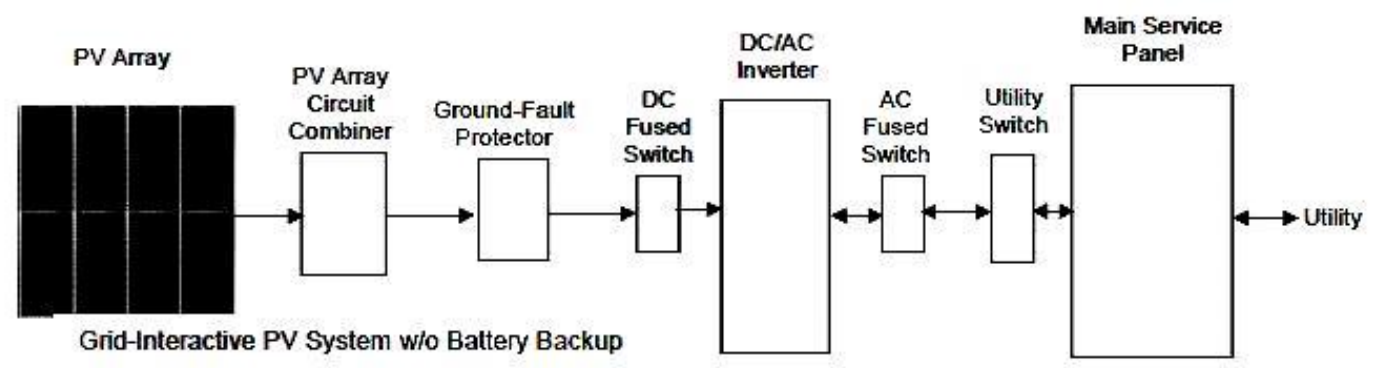

Figure 2.5.A Grid Interactive PV System without Battery Backups [6] 
The main components of such a system are PV Arrays, Balance of System Equipment (BOS), DC-AC inverters, Meters and Switches.

- PV Arrays: A combination of some interconnected solar modules (panels). PV arrays are one of the most important components of the system which converts sunlight directly to DC current.

- Balance of System Equipment (BOS) : BOS includes mounting and wiring systems. These components are used to connect the solar modules and arrays to the systems of the application area. The wiring system consists of disconnects for DC-AC sides of the inverter, ground-fault protection elements and over current protection elements.

- DC-AC Inverter: The DC-AC inverters are used in order to convert the DC current produced by PV arrays into the AC current which is used by the applications.

- Metering: Metering elements and equipment are used to indicate the performance of the systems.

- Other Components : Generally some switches are used for switching purposes between PV system and the utility grid depending on the behavior of the local utility.

\subsubsection{Grid-Interactive Systems with Battery Backups}

These kinds of systems benefit of a battery group in order to be able to handle critical load circuits in the case of utility outages. During power outages the systems disconnects from the utility and supplies the critical load circuits from the battery bank. The mentioned critical load circuits are generally connected through a separate subpanel. In the case of happening an outage during daylight the critical load circuits can be supplied by the battery bank and the PV arrays together. In the case of any 
outages at nights, the critical loads will be supplied directly from the charged battery bank. The duration that critical loads are supplied by the battery banks depends on the energy consumption of the loads and the amount of energy saved in the batteries.

The PV system with battery backups may include some additional components compared to the previously discussed systems. These additional components can be summarized as; Batteries and battery enclosures, battery charge controllers, separate subpanels for critical loads.

A general overview of PV systems with battery backups is shown in Figure 2.6.

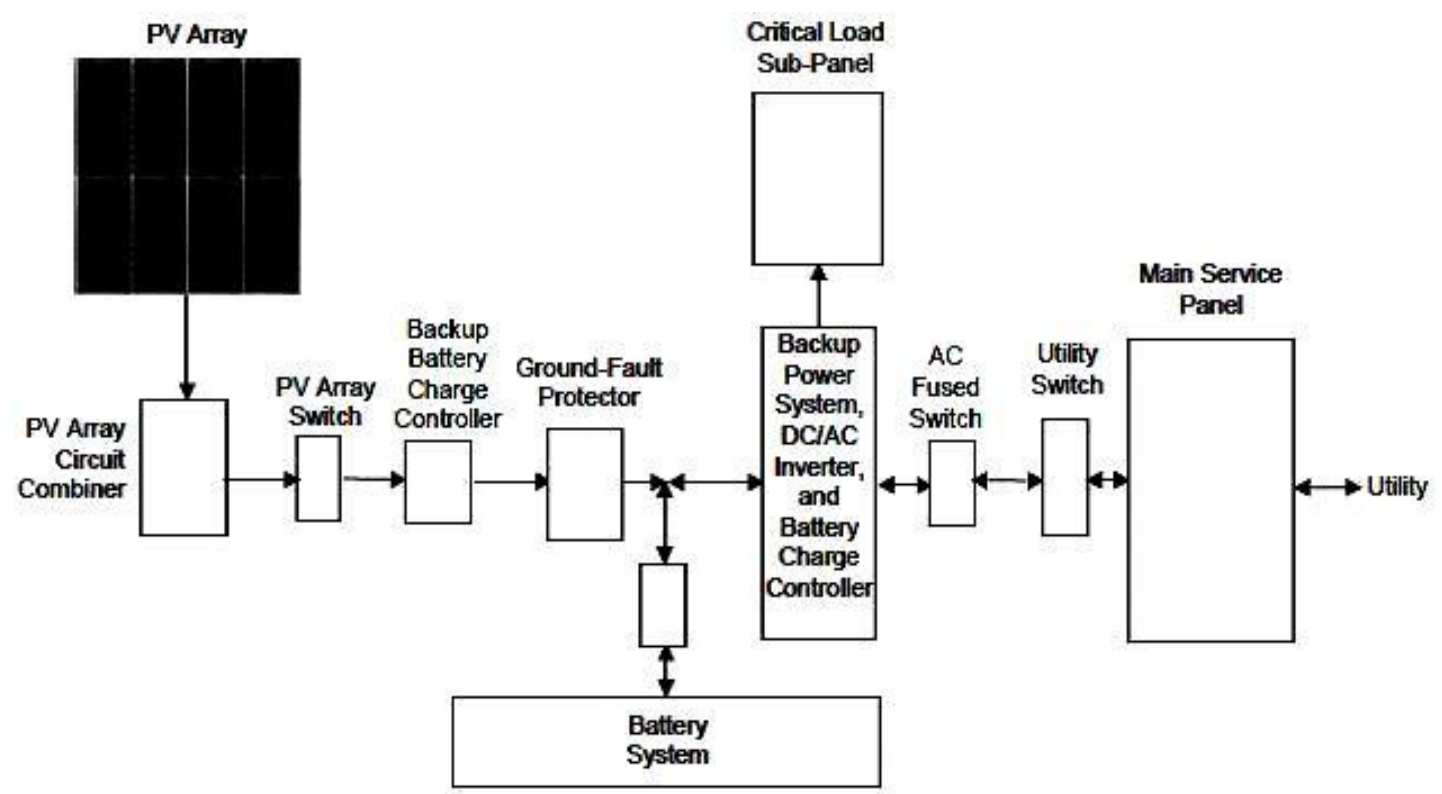

Figure 2.6.A Grid-Interactive PV System with Battery Backups [6]

\subsubsection{Effects of External Factors on PV System Power Output}

The output of any solar panel varies depend on the amount and intensity of the incident sunlight. The sunlight varies depend on the date, time and existence of any obstacles like clouds, etc. Along with the mentioned factors, some other factors also 
affect the power production of a solar panel. The most important factors are standard test conditions, temperature, dirt and dust, mismatch and wiring losses and DC-AC conversion losses.

- Standard Test Condition: The standard test conditions for solar modules are defined as follows; Solar cell temperature $=25^{\circ}$, Solar irradiance $=1000$ $\mathrm{W} / \mathrm{m}^{2}$, solar spectrum as filtered by passing through 1.5 thickness of atmosphere. Under the standard test conditions solar cells are able to produce the rate amounts of power outputs. The standard test conditions can be simulated for indoor applications but as most of the cells and systems are working in outdoor applications there are some losses due to working under non-standard test conditions. These losses are about 5\% [6] of the rated power output for each cell and the power output will be about $95 \%$ of the rated value.

- Temperature: The module power output decreases in parallel with the increases in the temperature. The performance reduces due to temperature effects are approximately to $89 \%$ [6] of power production.

- Dirt and Dust: Dirt and dust may block the surface of the module and hence reduce the amount of the incident sunlight on the module surface. As the dirt and dust is cleaned during rainy seasons it can be predicted that the reductions of power output due to dirt and dust effects increases during dry seasons. The reductive effect of dirt and dust is cause the performance to be reduced to approximately $93 \%$ [6].

- Mismatch and wiring losses: Practically the maximum output power of a PV array is not equal to the sum of the maximum outputs of PV modules contained. This is a result of some differences in module performances and is 
named as module mismatch. Generally the module mismatch approximately causes a $2 \%$ [6] reduction in array output power. Also some losses happen due to resistances of connections and wiring elements which are about $3 \%$.

- DC-AC Conversion Losses: As it is mentioned before, the DC power produced by the PV arrays must be converted to AC to be used in different applications. Inverters are the equipment responsible of DC-AC conversion. In general some losses also happen during the DC-AC conversion procedure and also in wiring from the arrays to the inverters and from the inverters to the other system parts. These losses are named DC-AC conversion Losses and are approximately about $10 \%$ [6] of produced power.

Taking the above mentioned factors into the consideration it can be predicted that a solar module with a rated power output of 100 Watts may experience a loss of approximately 33 Watts in the middle of a clear day due to different factors and effects and produce 67 Watts of output power.

$(100 \times 0.95 \times 0.89 \times 0.93 \times 0.95 \times 0.90=67$ Watts $)$

\subsection{Current Applications of Solar Systems}

The PV systems can be divided into two main categories in sense of their connectivity: Stand-alone systems and Grid-connected systems.

- Stand-alone system: In this system electricity is produced by solar panels which are independent of any electricity grid. The simplest form of this system only contains solar panels which are directly connected to a dc load. Since these solar panels are not equipped with batteries, they do not have the capacity to store electricity and can only supply electricity under day light. 
On the other hand, stand-alone systems (SHSs) equipped with batteries provide the possibility of storing electricity in battery banks to be used at any time needed regardless of day light presence.

- Grid-connected system: In this system the solar panels are connected to an electricity grid. Under regular conditions the solar panels supply their produced surplus electricity which is beyond consumption to the grid.

In Figure 2.7, the left picture shows a photovoltaic power plant with grid-connected solar panels and the right picture shows an independent solar panel powering a parking meter.

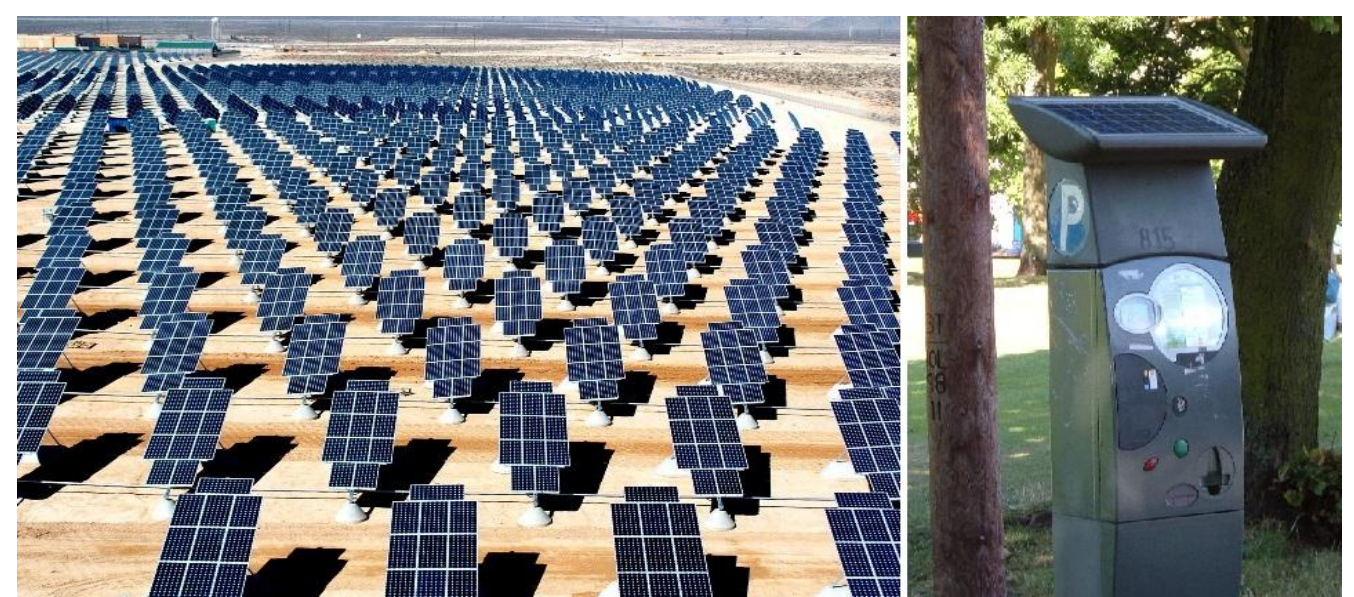

Figure 2.7.Grid-connected (left) and Stand-alone connected (right) PV Systems [4]

Back in 1980s, the PV industry introduced the Stand-alone system (SHS) to families living in sunshine countries. The idea of benefiting from sun power using independent solar panels without any need to be connected to electricity grids caused the first successes for PV industry in global markets. But there were two concerns about the SHSs. Firstly; the SHSs could not generate enough electricity to meet the demands of the modern world for energy. The electricity produced by these systems was in scales of a few $\mathrm{kW}_{\mathrm{p}}$. The second issue which at first glance does not seem to be very important regarding the SHSs is the maintenance costs. Even though a Standalone PV system may only consist of one solar panel, the long term costs regarding 
the maintenance of the panel along with the batteries and other system components may not be easily affordable for individual families. Although the SHS market continues to grow, the above concerns reduce the reliability of these systems and decrease their role in global PV industry.

Although what is covered up to know may give the sense that the science regarding the PV technology is not very complicated, the truth is "solar cells are high-tech products based on more than half a century of impressive research in universities, companies, and government institutes around the world. Their manufacture demands very high standards of precision and cleanliness" [1]. 


\section{Chapter 3}

\section{SOLAR RADIATION}

Almost all of the users of solar energy are interested in prediction of solar radiation amount that can be received at the earth`s surface and transformed into useful energy by solar systems at any instant of time and geographical position. the direction of sunlight beams, mix of diffuse and direct beams in the sunlight, the geographical distribution and the distribution of solar energy with time are all the important factors which are defined by the spectral form of solar energy. The prediction of the amount of solar energy must be made with respect to its spectral form which was briefly discribed.

Interactions of solar radiations with the factros contained in the atmosphere of the earth (aerosols, cloud layers, etc.) makes it more difficult to predict the solar radiation at the earth`s surface in comparison with prediction at the outer edge of the atmosphere.

The most important three factors of each solar radiation prediction procedure can be defind as The Position of Earth and Sun in Solar System, Time Systems and the behaviour of solar radiation beams when passing through the atmosphere and hitting the surface of the Earth. Time Systems and the behaviour of solar radiation beams when passing through the atmosphere and hitting the surface of the Earth are briefly explained within this section while solar geometry with respect to Earct is separately 
contained in chapter 4 due to its high importance and effects on the experimental part of the study.

\subsection{Terminology}

Solar radiation, Insolation, solar constant and annual mean insolation, are some of the main terminologies regarding solar energy and will be covered briefly.

- Solar Radiation: The general name for the entire spectrum of electromagnetic radiation emitted by sun.

- Insolation: "A measure of solar radiation energy received on a given surface area and recorded during a given time" [4]. The insolation which is also called the solar irradiation may be measured quantitatively in units of $\mathrm{J} / \mathrm{cm}^{2}$ or $\mathrm{Wh} / \mathrm{m}^{2}$. If the insolation measured in $\mathrm{Wh} / \mathrm{m}^{2}$ units which is widely used by solar energy practitioners is divided into hours, it gives the power called irradiance measured in $\mathrm{W} / \mathrm{m}^{2}$.

- Solar constant: The irradiance before entering earth's atmosphere which is equal to $1366 \mathrm{~W} / \mathrm{m}^{2}$. This amount is reduced to $1000 \mathrm{~W} / \mathrm{m}^{2}$ which is the irradiance at the earth's surface at sea level. Since this is the insolation value measured on a clear day, it is accepted standard for strong sunshine.

- Annual Mean Insolation: The average solar radiation energy received over one year.

The annual mean insolation in Europe and in Cyprus is shown in Figure 3.1 and Figure 3.2 respectively. 


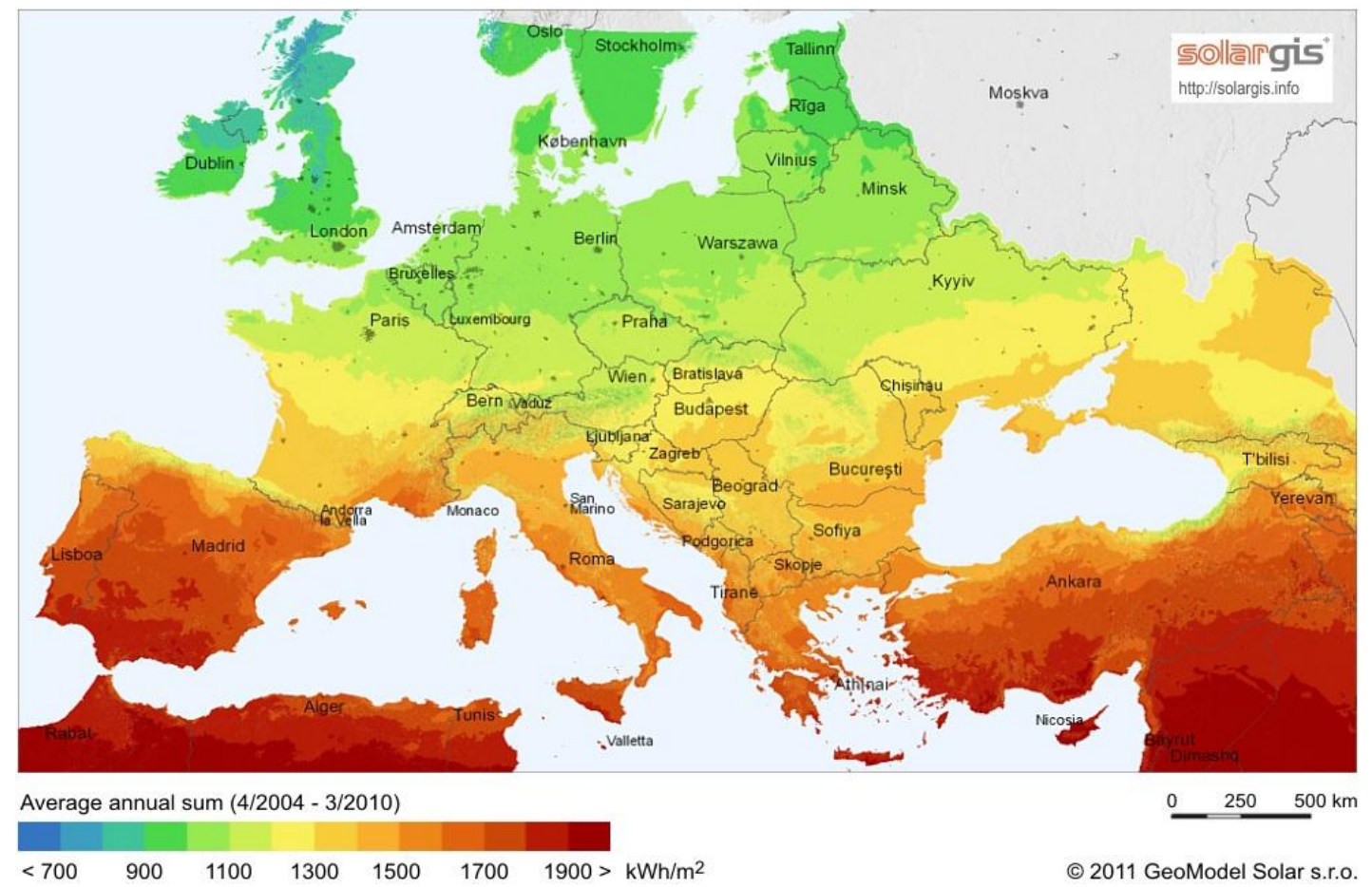

Figure 3.1.Annual Mean Insolation in Europe [4]

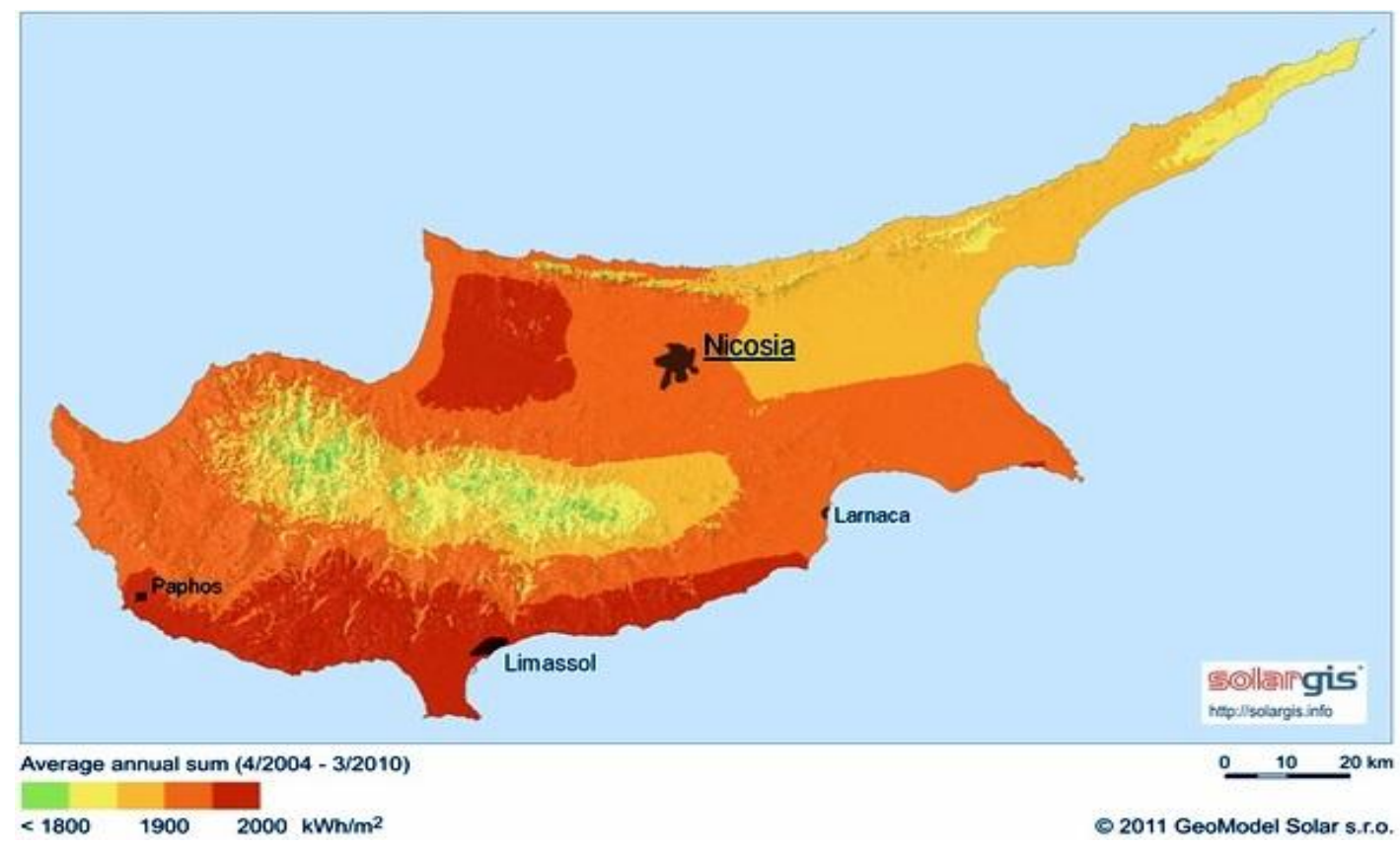

Figure 3.2 Annual Mean Insolation in Cyprus [4] 


\subsection{Solar Spectrum}

The range and intensity of the wavelengths in solar radiations is analyzed through the solar irradiance spectrum. The solar radiation wavelengths spread between $0.2 \mu \mathrm{m}$ and $2.0 \mu \mathrm{m}$, while the visible wavelengths for human eyes vary between $0.4 \mu \mathrm{m}$ and $0.8 \mu \mathrm{m}$ which refer to colors violet and red. Figure 3.3 shows the solar irradiance spectrum. It is obvious from the figure that the solar irradiance shows a peak at about $0.5 \mu \mathrm{m}$.

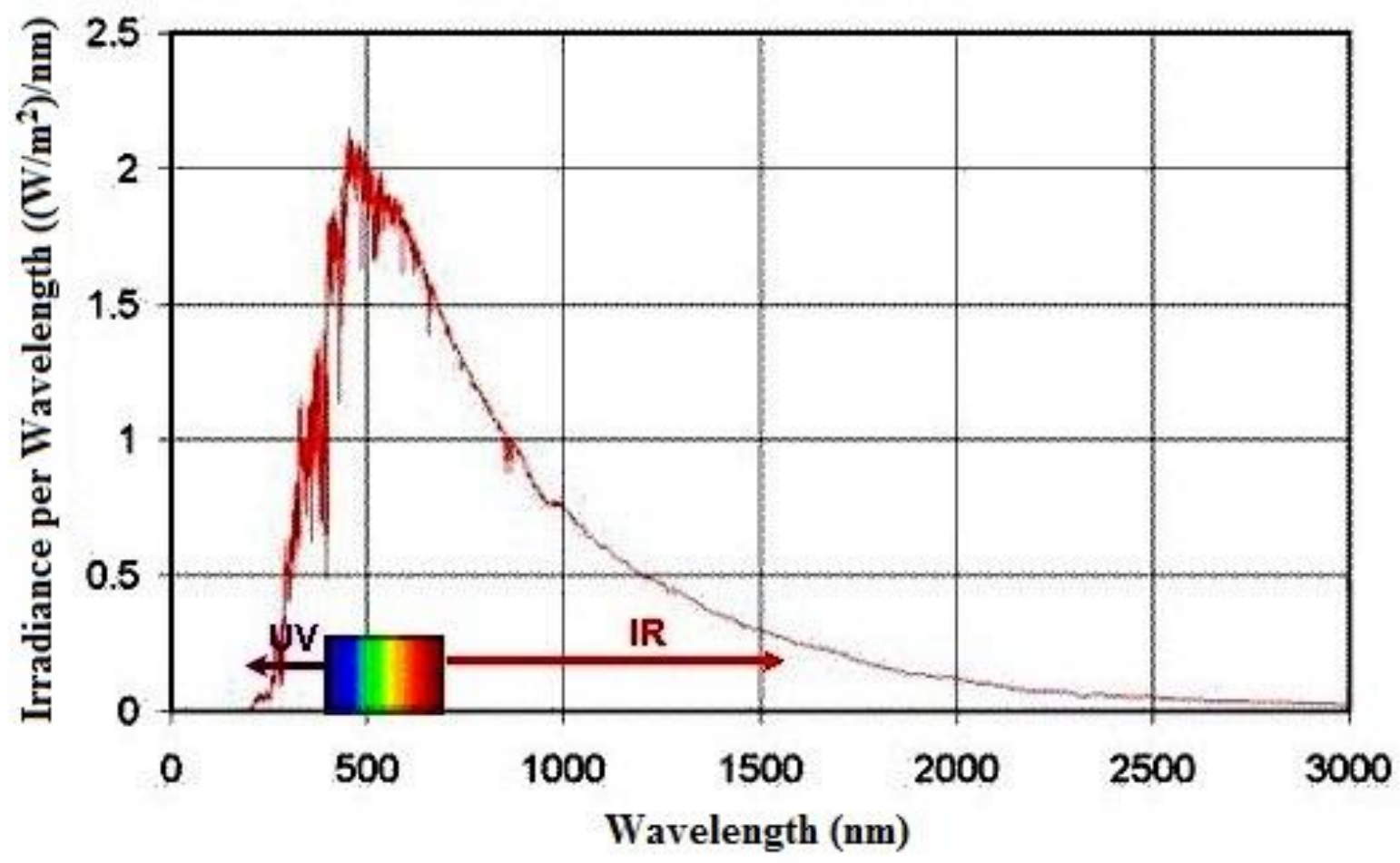

Figure 3.3.Solar Irradiance Spectrum [17]

\subsection{Time Systems}

As it was previously mentioned, Time systems are one of the important parameters during the prediction procedures of solar radiation. It is known that the movements of the sun is a function and depend on the time of the day. There are different time systems defined which can be used during calculation. The most important systems are the Civil Time, the Local Apparent Time (LAT), and the Universal Time (U.T.) 
The Civil Time which is also called as the Local Mean Time (LMT) which is defined to simplify the coverage of large geographical areas is mainly based on both latitude and longitude. The latitude defines the wavelength in civil time while the longitude is used to calculate the sunrise and sunset times.

The solar time which is also called the LAT is another alternative time system widely being used in solar application and calculations. The time at which the sun passes the north-sun axis is defined as solar noon and at this time interval the sun is placed at the highest position of elevation. Different from the Civil Time, the sunrise and sunset times do not depend on the longitude.

In the U.T. the reference longitude is assumed to be at the Greenwich where the longitude is zero. The differences which exist between Solar Time and the Civil Time at Greenwich are happened as the results of the movements of the earth about its north-south axis. These differences can be explained using the time equation. The time equation shows variations according to the Julian day number. These variations are shown in Figure 3.4. Detailed information about the Julian Day Number and the related calculations is given further within the next chapter. Assuming that the observation point is the time zone which is covered by the Greenwich Mean Time the displacement amount corresponding to each degree of longitude toward the west is -4 minutes. The CET is one hour ahead of GMT.

The relationship between these two time zones is given by the following equation,

$$
\text { L.A.T. }=L . M . T+E T+\frac{\lambda-\lambda_{R}}{15}-C(\text { decimal hours })
$$

Where; 
ET : The equation of time

$\lambda \quad$ : Longitude (East Positive)

$\lambda_{R} \quad$ : Time Zone Longitude (East Positive)

C : The summer time improvement parameter normally is set to 1 hours for the countries in which the summer time is applied.

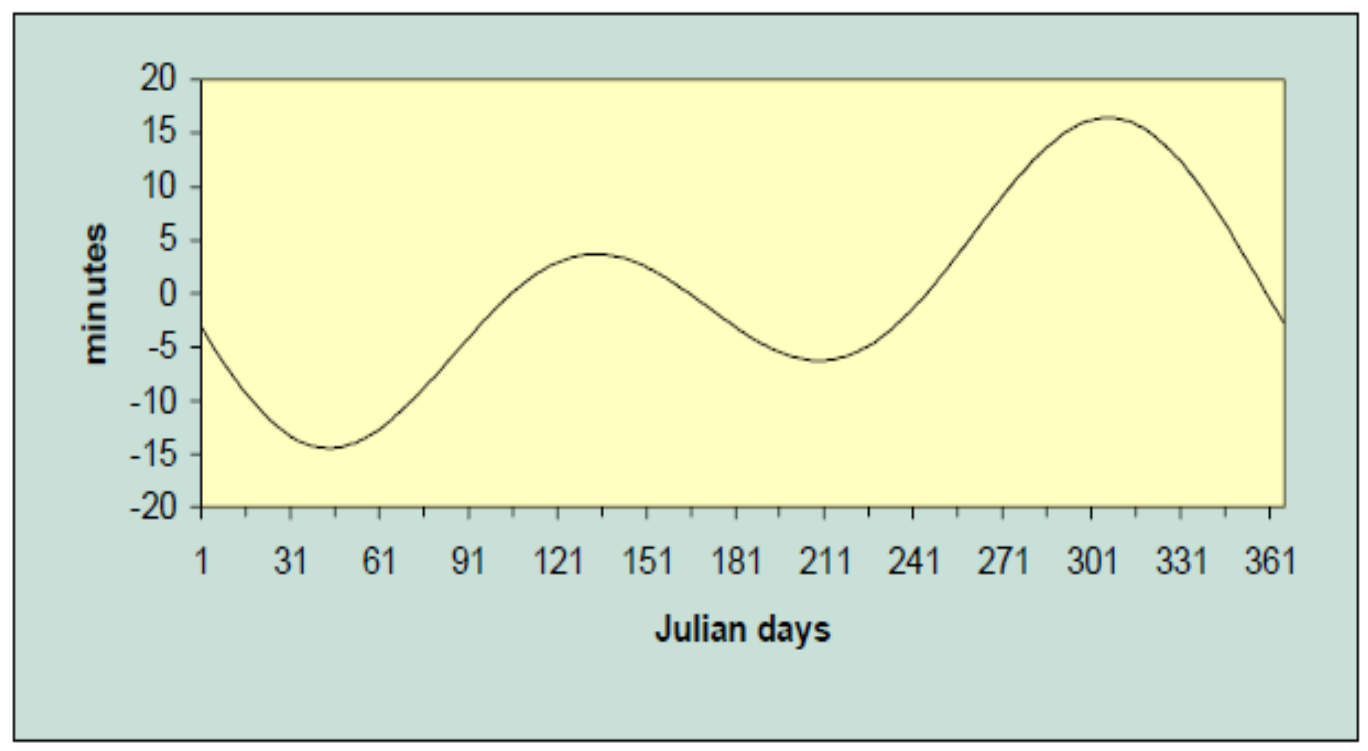

Figure 3.4. Values of the Equation of Time [7]

\subsection{Extraterrestrial Radiation from the Sun}

As mentioned before, the solar constant which can be defined as the irradiance before entering earth's atmosphere is $1367 \mathrm{~W} / \mathrm{m}^{2}$. The earth turns around the sun in an elliptical orbit and for the Northern Hemisphere this fact causes the Earth to be at a closer position from the sun in winter and at a further position in summer. The time in which the earth is at its closet position to the sun is named as the 'Perihelion` and happens about January $2^{\text {nd }}$. The biggest distance difference is known as the 'Aphelion`. The positions of the sun and the earth during the Aphelion and the Perihelion is shown in Figure 3.5. 


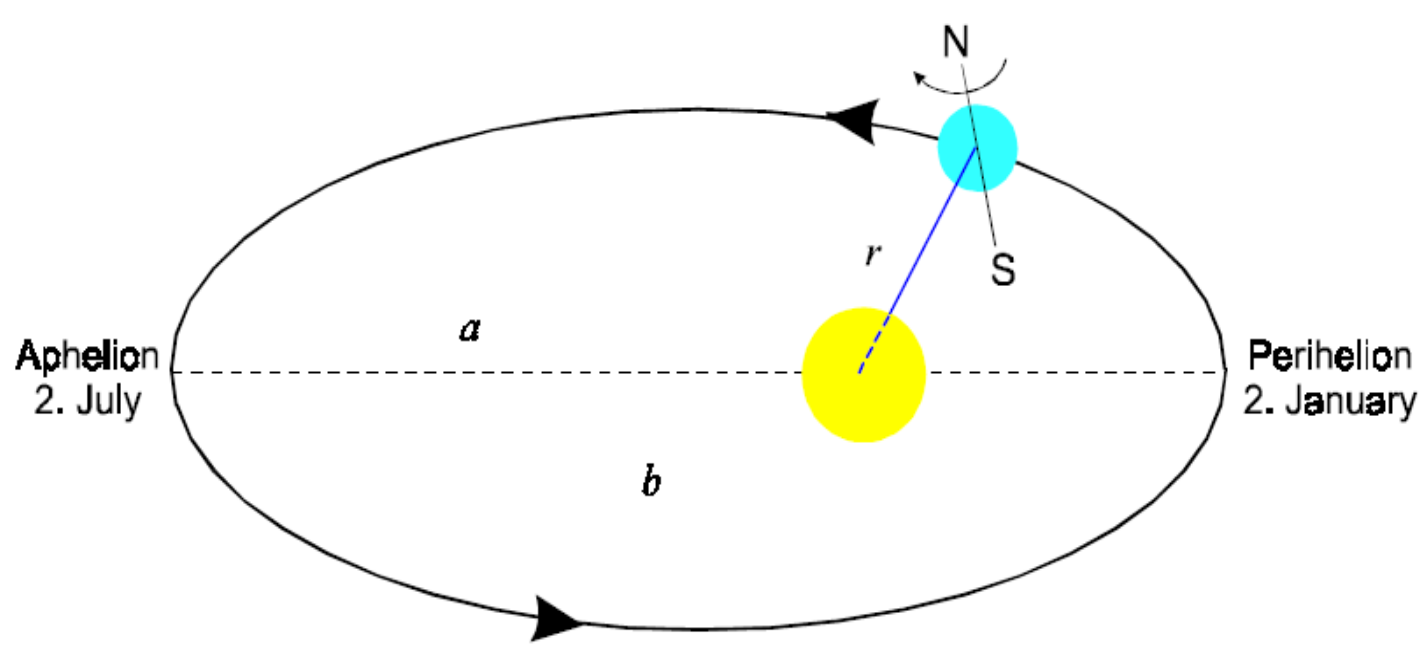

Figure 3.5.Earth - Sun Movement Pattern [7]

The differences between the distances of the earth and the sun changes by $\pm 1.7 \%$. The value of the solar constant also changes about $1 \mathrm{~W} / \mathrm{m}^{2}$ within a period of 11.2 years. $G_{0}$ which represents the amount of irradiance falling on a horizontal plane valid for outside Earth`s atmosphere areas can be calculated using the following equation;

$$
G_{0}=1367 \varepsilon \sin \left(\delta_{s}\right) W / m^{2}
$$

Where;

$\varepsilon:$ The improvement parameter for solar range

$\gamma_{s}:$ Altitude Angle of the sun

The correction factor to mean solar distance, $\varepsilon$, can be obtained using the following formula,

$$
\varepsilon=1+0.0334 \cos \left(j^{\prime}-2.80^{\circ}\right)
$$

Where;

$j^{\prime}: \quad$ The day angle [7] 
The daily irradiation between the sunrise and the sunset, expressed as $\mathrm{Wh} / \mathrm{m}^{2}$, is defined as $G_{\text {od }}$. The variation of $G_{\text {od }}$ against Latitude and the Julian Day number is shown in Figure 3.6 for the Northern Hemisphere.

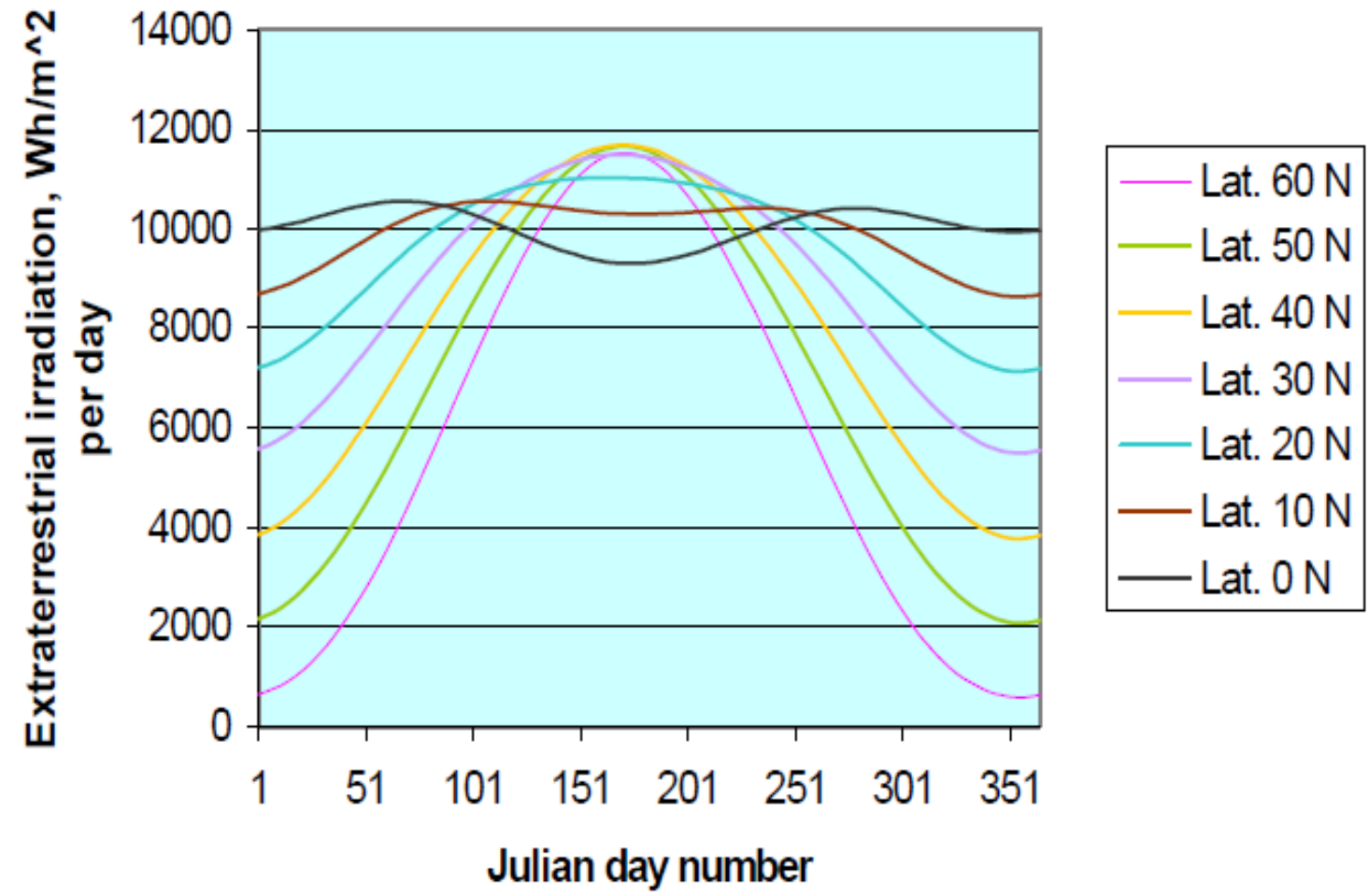

Figure 3.6.The Variations in $\mathrm{G}_{\mathrm{od}}$ as a Function of the Julian Day Number and Latitude [7]

The mean extraterrestrial flux per unit surface area is shown in Figure 3.7. 


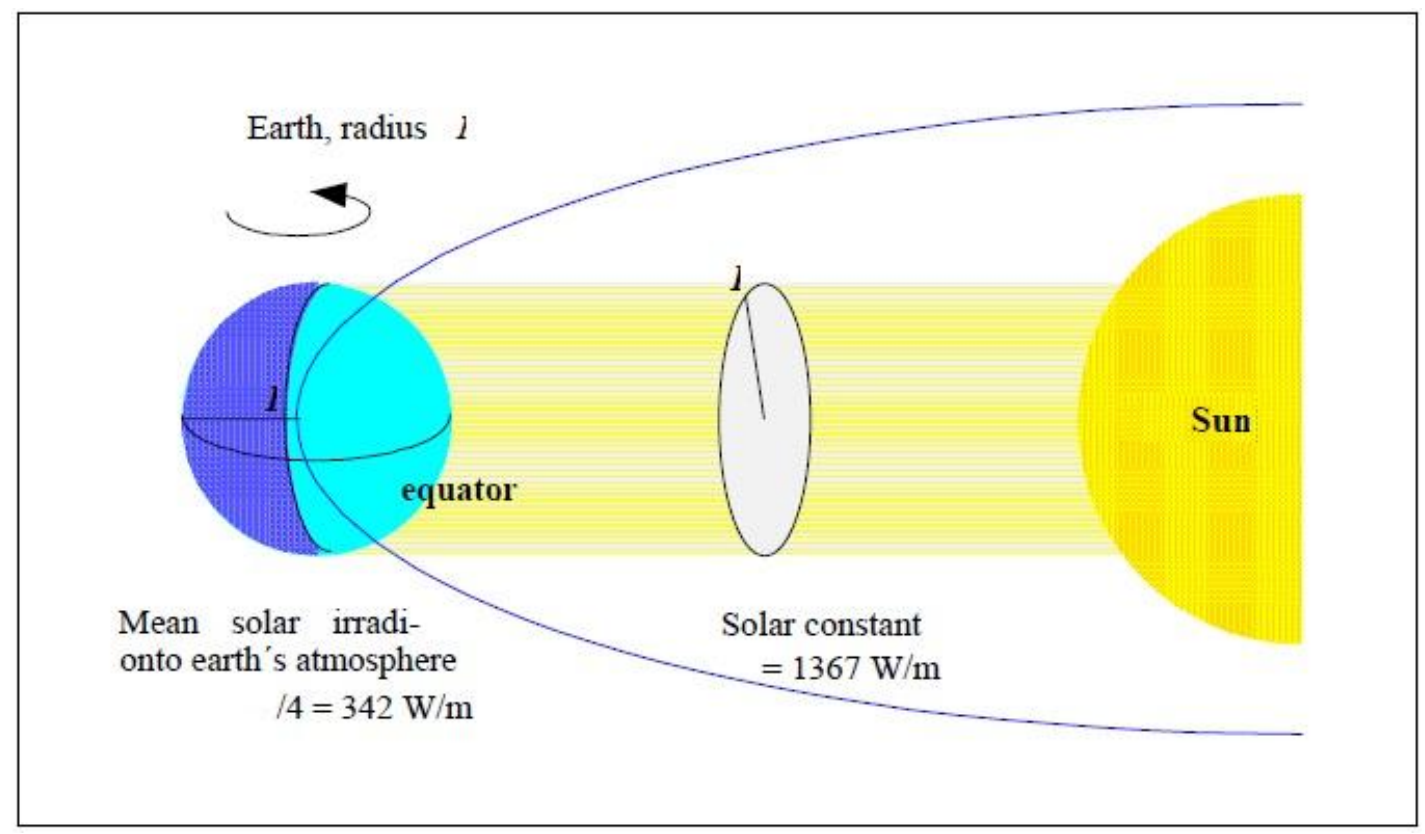

Figure 3.7.The Average Irradiance Hitting the Earth`s Atmosphere [7]

\subsection{Behavior of Sunlight Beams at the Surface of the Earth}

The amount of solar energy which hits a horizontal surface after all of the interactions with the atmosphere is defined as the global irradiation. A very important fact about the sunlight beams is that when solar radiation passes through earth's atmosphere, it divides into direct, diffuse and albedo components. Since the solar cells are placed near to ground, they are affected by all these components of the solar radiations.

The diffuse component of the solar radiation is the radiation scattered by clouds or other particles in the earth's atmosphere. In a cloudy day or when the solar cells are placed somewhere far from the direct sight of the sun, the effect of the diffuse component dominates, despite of when the cells are placed in a direct sight of the sun on a clear day. Another component of the solar radiation is the albedo component, which refers to the radiation reflected from ground or objects on the ground. This component may generally have minor effect on solar cells, but in locations such as 
Swiss Alps its effect becomes remarkable due to the reflections from the snow on the mountains. Figure 3.8 illustrates the three components of the solar radiation after entering earth's atmosphere.

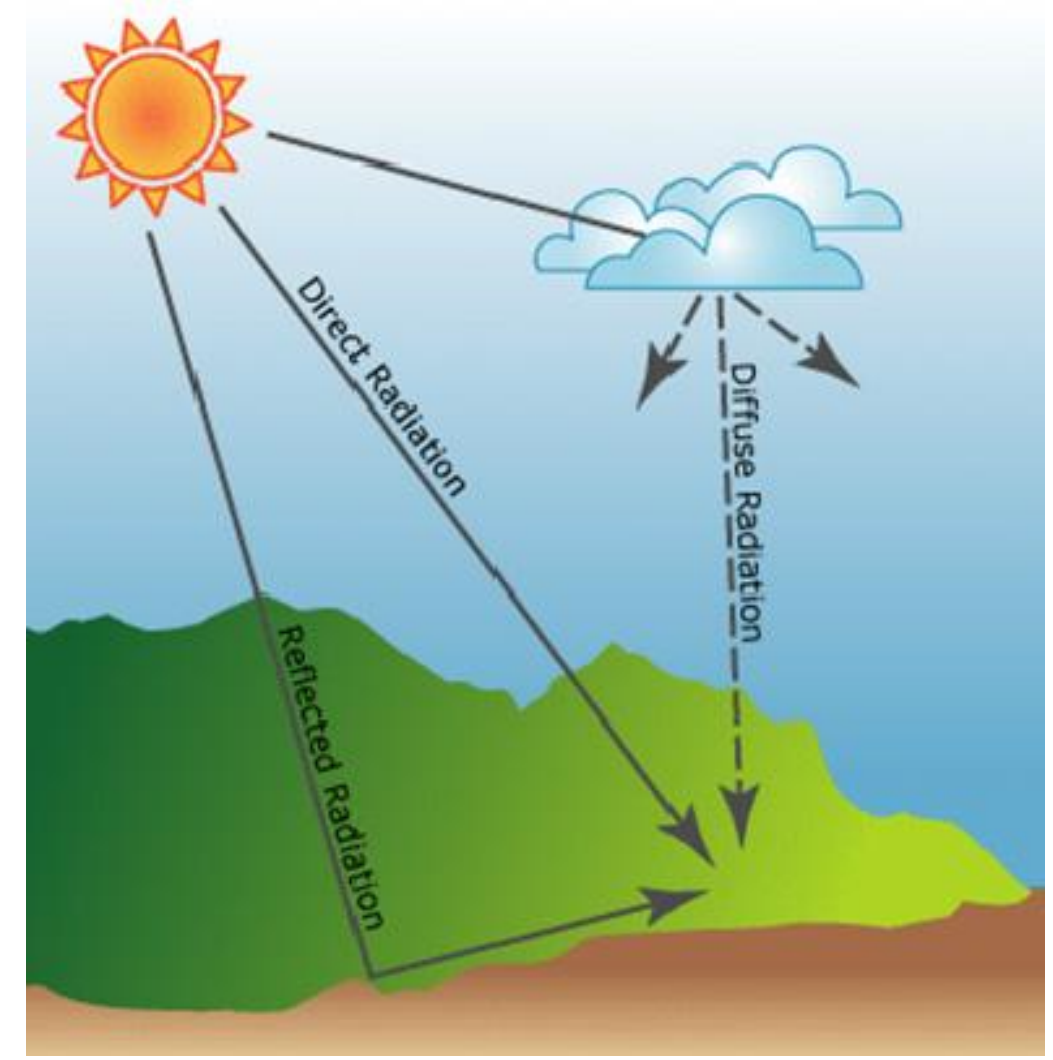

Figure 3.8.The Direct, Diffuse and Albedo Components of Solar Radiation [18]

The prediction of solar parameters under cloudy sky conditions is difficult because of strong effects of clouds on received global radiation. As an opposite, having general information about the Sun and Earth`s positions in the solar system, water vapour amount and the other parameters contained within the Earth`s atmosphere will be enough to make accurate predictions.

The sunlight beams are subjected to some interactions with atmospheric components during their passage through the atmosphere. Some of these components absorb sunlight and some others cause it to be scattered. In general, 
- $\% 20$ of the incoming sunlight beams are absorbed within the atmosphere.

- $\% 23$ of the incoming sunlight beams are back scattered to the space.

- \%57 of the whole incoming sunlight beams can pass the atmosphere and reach the Earth`s surface.

Ground Albedo is defined as the reflection of incoming sunlight beams by the Earth`s surface. In general the effect of ground albedo is about $\% 8$ of the incoming solar irradiation. At the same time an amount of $\% 49$ of the incoming irradiation is absorbed 


\section{Chapter 4}

\section{SUN'S POSITION IN THE SKY AS SEEN FROM THE}

\section{EARTH}

The ability of calculation of the sun`s position in the sky is a requirement during solar energy researches at specified locations and time intervals. The main factors for calculation of the sun`s position in the sky are listed as follows:

- The latitude of the location

- The Julian day

- The hour angle representing the specific time interval

The Julian Day number corresponding to each day of each month is defined in Table

4.1. Table 4.1: Relationship between the Julian Day and the $i^{\text {th }}$ Day of a Month [7]

\begin{tabular}{|l|l|l|}
\hline \multicolumn{1}{|c|}{ Month } & $\begin{array}{c}\text { Julian Day } \\
\text { Number }\end{array}$ & \multicolumn{1}{c|}{ Leap Year } \\
\hline January & I & \\
\hline February & $31+\mathrm{i}$ & \\
\hline March & $59+\mathrm{i}$ & $(+1)$ \\
\hline April & $90+\mathrm{i}$ & $(+1)$ \\
\hline May & $120+\mathrm{i}$ & $(+1)$ \\
\hline June & $151+\mathrm{i}$ & $(+1)$ \\
\hline July & $181+\mathrm{i}$ & $(+1)$ \\
\hline August & $212+\mathrm{i}$ & $(+1)$ \\
\hline September & $243+\mathrm{i}$ & $(+1)$ \\
\hline October & $273+\mathrm{i}$ & $(+1)$ \\
\hline November & $304+\mathrm{i}$ & $(+1)$ \\
\hline December & $334+\mathrm{i}$ & $(+1)$ \\
& &
\end{tabular}


The hour angle, $\omega$, which is used to describe the time of the day is set to zero at solar noon and each hour corresponds to a 15 degrees cycle. $\omega$ can be calculated using the following equation:

$$
\omega=15(t-12)
$$

A general overview of the position of the Sun and the Earth from the viewpoint of an observer is shown in Figure 4.1.

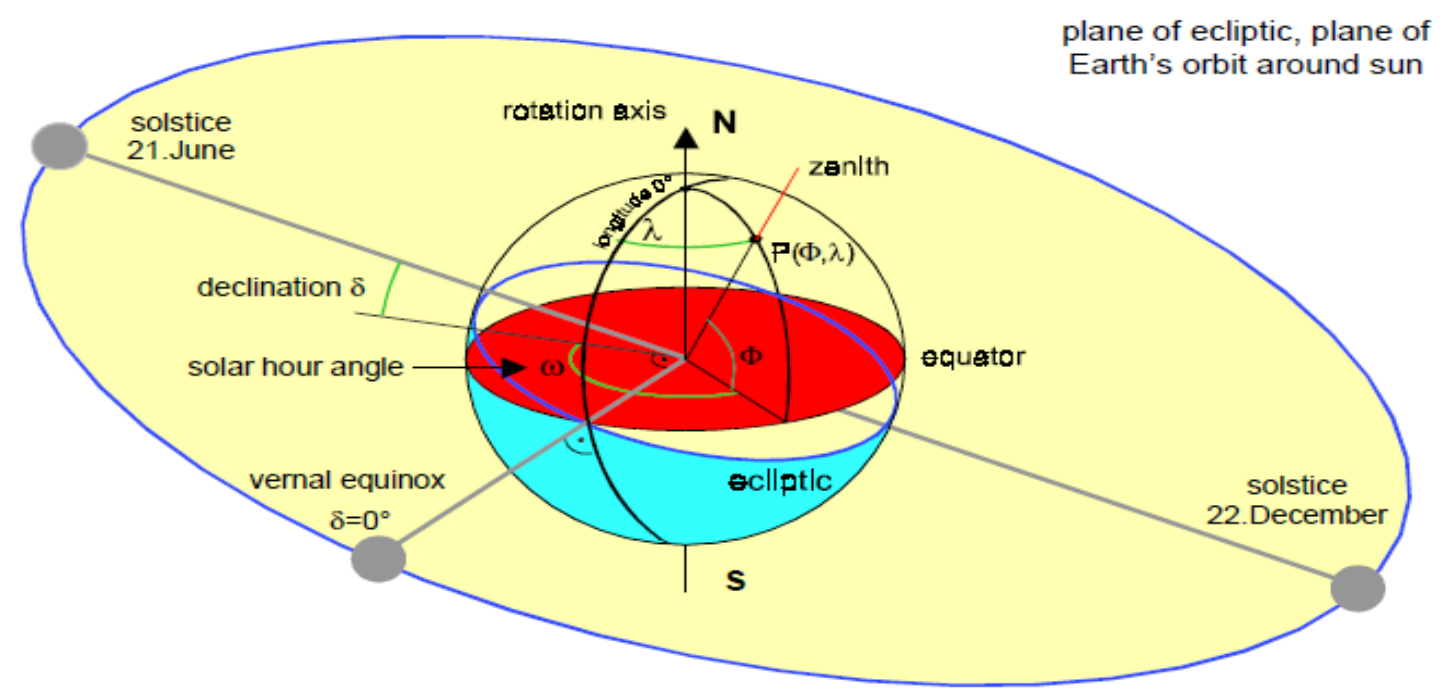

Figure 4.1.The Position of the Earth and the Sun as Seen from any Point on the Ground [7]

\subsection{Declination Angle}

One of the most important parameters to calculate the Sun-Earth position is the declination. The declination angle is represented by $\delta$. The declination of the sun varies continually with time. The amount of variations is small for a specific day. So a constant value for any day can be used as the rate of change. The information of just one parameter, the day number, makes it possible to calculate the solar declination for any time interval. 
The declination angle can simply be calculated using the following equation;

$$
\delta=\sin ^{-1}\left\{0.3978 \sin \left(j^{\prime}-80.2^{0}+1.92\left(\sin \left(j^{`}-2.80^{0}\right)\right)\right)\right\} \text { degree }
$$

Where $j$ is the Julian day angle.

\subsection{The Solar Altitude Angle}

The solar altitude angle, $\gamma_{s}$, also referred to as sun`s height or elevation, is one of the factors required to determine the position of the sun. The solar altitude angle can be calculated using the following equation;

$$
\gamma_{s}=\sin ^{-1}(\sin \varphi \sin \delta+\cos \varphi \cos \delta \cos \omega) \text { Degrees }
$$

Where,

$\varphi \quad$ : The latitude of the observation point

$\delta \quad$ : The solar declination angle, degrees

$\omega \quad$ : The solar hour angle

\subsection{The Solar Azimuth Angle}

The solar Azimuth angle, $\alpha_{s}$, is another factor which is required to determine the position of the sun. The solar azimuth angle can be calculated using the following equations;

$$
\begin{aligned}
& \cos \alpha_{s}=\left(\sin \varphi \sin \gamma_{s}\right) / \cos \varphi \cos \gamma_{s} \\
& \sin \alpha_{s}=\cos \alpha_{s} \sin \omega / \cos \gamma_{s}
\end{aligned}
$$

If $\sin \alpha_{s}<0$

$$
\alpha_{s}=-\cos ^{-1}\left(\cos \alpha_{s}\right)
$$

If $\sin \alpha_{s}>0$

$$
\alpha_{s}=\cos ^{-1}\left(\cos \alpha_{s}\right)
$$

The position of the sun at a specific time at a day is shown in Figure 4.2. 


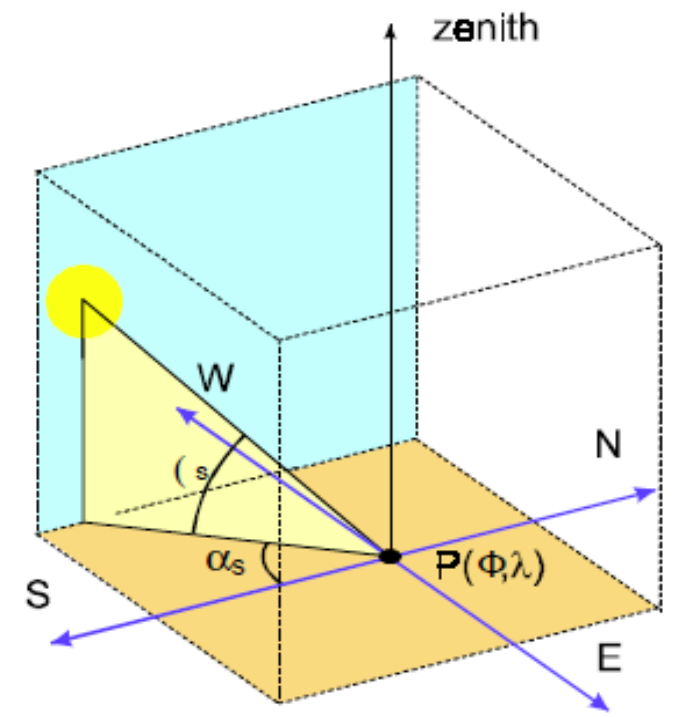

Figure 4.2.The Position of The Sun at a Specific Time of a Day [7]

\subsection{Solar Angle of Incidence}

The angle between the sun`s rays and a vector normal to the surface of solar collector is called the Angle of Incidance. Information about the angle of incidance, $\theta_{i}$, has a great importance for solar system designers as the maximum power output of solar collector is directly proportional to the cosine of this angle. 


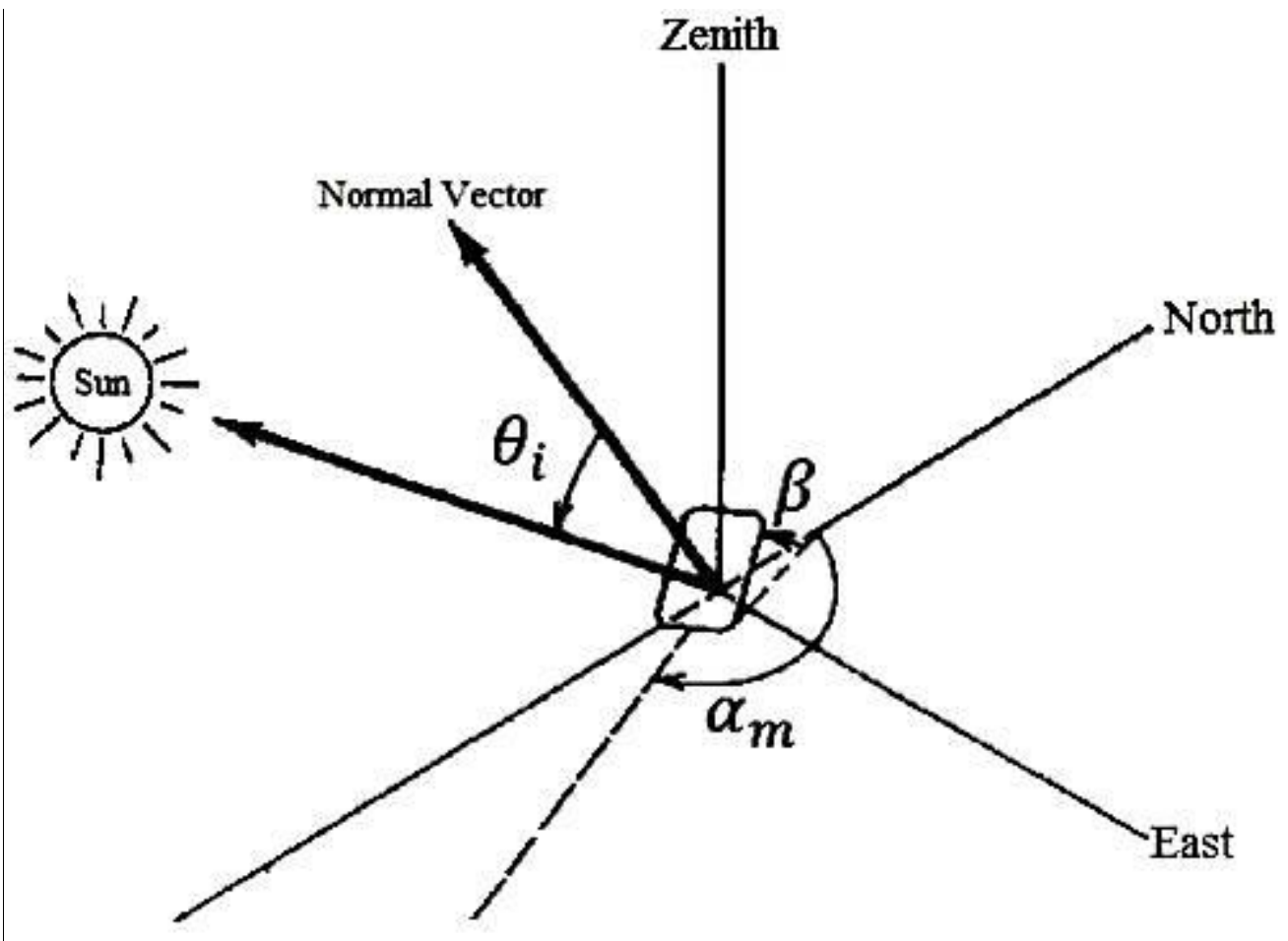

Figure 4.3. Solar Angle of Incidence [4]

The Solar Angle of Incidance can be calculated according to the following formula,

$$
\theta_{i}=\cos ^{-1}\left[\cos (\beta) \cos \left(Z_{s}\right)+\sin (\beta) \sin \left(Z_{s}\right) \cos \left(\alpha_{s}-\alpha_{m}\right)\right]
$$

Where,

$\beta \quad$ : Tilt angle of the solar collector $\left(\right.$ Horizontal $=0^{\circ}$ )

$Z_{s} \quad:$ Zenith Angle of the Sun

$\alpha_{m} \quad$ : Module azimuth angle $\left(\right.$ North $=0^{\circ}$, East $\left.=90^{\circ}\right)$

Where,

$$
Z_{s}=90-\gamma_{s}, \text { degrees }
$$

\subsection{Sunset Hour Angle}

The sunset hour angle is used to define the daylength. The sunset hour angle is represented as :

$$
\omega_{s s}=\cos ^{-1}(-\tan \varphi \tan \delta) \text { degrees }
$$

The sunrise hour angle is calculated using the following equation, 


$$
\omega_{s r}=-\cos ^{-1}(-\tan \varphi \tan \delta) \text { degrees }
$$

The time of sunrise is defined as, $\left(12-\frac{\cos ^{-1}(-\tan \varphi \tan \delta)}{15}\right)$ hours L.A.T. and the sunset time can be obtained as $\left(12+\frac{\cos ^{-1}(-\tan \varphi \tan \delta)}{15}\right)$ hours L.A.T. The astronomical daylength also can be calculated using the following relation,

$$
S_{o d}=\cos ^{-1}(-\tan \varphi \tan \delta) / 7.5
$$




\section{Chapter 5}

\section{BASIC CONCEPTS OF ARTIFICIAL NEURAL NETWORK THEORY}

The human brain acts like a highly complex machine. Although nowadays some basic mechanisms of the brain is discovered, the entire operations that drive this complex machine and makes it capable of solving very complex problems are still unknown. In order to describe the Artificial Neural Network (ANN) theory, it is better to start with describing some basics about human brain. The human brain consists of a large network of natural neurons. The architecture of a natural neuron is shown in Figure 5.1.

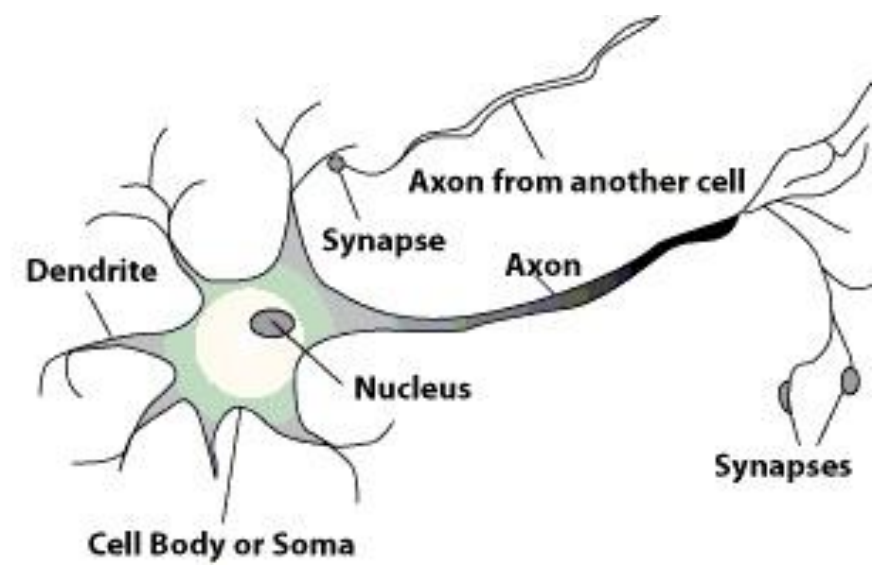

Figure 5.1.A Natural Neuron [19]

The Nucleus which is the main part of a neuron is connected to other neuron centers to form a neural network. The connection between nucleuses is made by Dendrites and Axon and is called a Synaptic connection. The nucleus can receive electric pulses fired by other nucleuses through Synapses which are located on the dendrites. The 
neuron is activated when the signals (electric pulses) received surpass a certain threshold. In this case the activated neuron emits an electric pulse through its axon. Such a pulse may be received by other neurons through their dendrites. Figure 5.2 shows the simplified form of the same neuron of the previous figure.

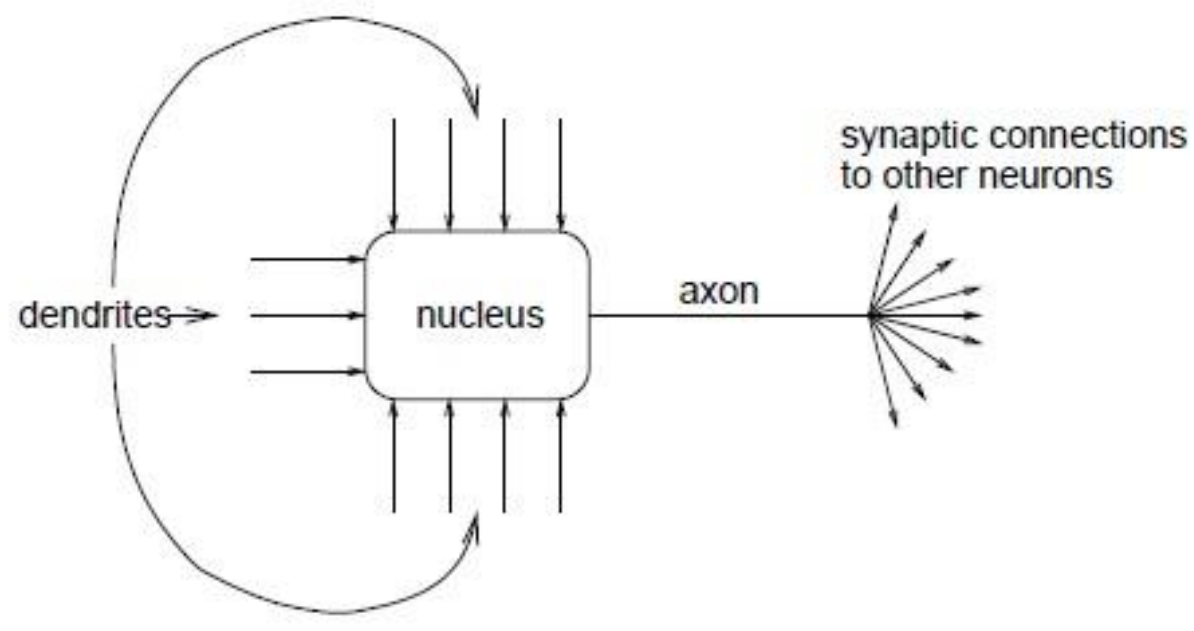

Figure 5.2.A Simplified Neuron [8]

The synaptic connections between neurons may change during the life time of a neuron. As a sequence of changing the synaptic connections and also the threshold required to activate a neuron the learning process of the neural network becomes possible.

Although it is not possible to create an artificial brain, it is possible to make a computational model inspired by the natural neural network. Simplified artificial neurons come together to form an artificial neural network which has learning capabilities by making generalizations from training data sets and make rules to solve very complex problems. It means that the ANN is capable of making future generalization about a fact by deriving rules and algorithms. What makes the ANN very desirable is that it finds out what it takes to solve a problem by itself without any need to predefinitions. 
The mathematical definition used to implement the artificial neuron of interest of this study is expressed in equation 5.1.

$$
y(x)=g\left(\sum_{i=0}^{n} w_{i} x_{i}\right)
$$

Here $\left(\mathrm{x}_{0} \ldots \mathrm{x}_{\mathrm{n}}\right)$ represent the input dendrites to the neuron $\mathrm{x}$ which was illustrated in the Figure 5.3. $y(x)$ represents the output axon and $\left(\mathrm{w}_{0} \ldots \mathrm{w}_{\mathrm{n}}\right)$ are the weights to be assigned to inputs. The activation function that determines the output based on sum of the weighted inputs is represented by g. Figure 5.3 illustrates this artificial neuron.

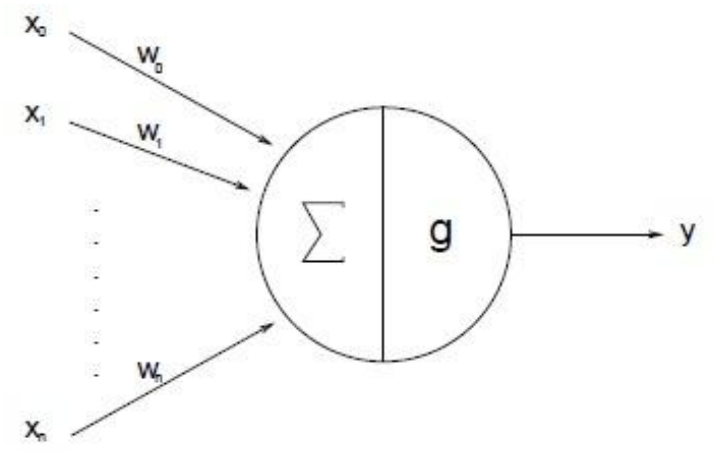

Figure 5.3.An Artificial Neuron [8]

As indicated above for the natural neurons, the neuron is activated when the receiving signal (electric pulse) is strong enough. Therefore if the case of interest was only simulating a natural neuron it would be enough to have a simple threshold function to activate the artificial neuron. Such a function would return a 0 or 1 according to the value of weighted inputs. But the threshold function is not the activation function of interest in many real cases of artificial neuron implementations. Instead of the simple threshold function (5.2), the sigmoid (5.3) and hyperbolic tangent (5.4) functions which are smooth and differentiable are commonly used in artificial neuron implementations. Equations below represent the mathematical expressions of these fuctions. 


$$
\begin{gathered}
g(x)=\left\{\begin{array}{l}
1 \text { if } x+t>0 \\
0 \text { if } x+t \leq 0
\end{array}\right. \\
g(x)=\frac{1}{1+e^{-2 s(x+t)}} \\
g(x)=\tanh (s(x+t))=\frac{\sinh (s(x+t))}{\cosh (s(x+t))}=\frac{e^{s(x+t)}-e^{-s(x+t)}}{e^{s(x+t)}+e^{-s(x+t)}}=\frac{e^{2(s(x+t))}-1}{e^{2(s(x+t))}+1}
\end{gathered}
$$

The steepness parameter is represented by $\mathrm{s}$ in above equations and the shift value of the center of activation functions from zero is represented by t. The graphs of the sigmoid and hyperbolic tangent functions are similar in sense of smoothness and differentiability and the only difference between these two function is their ranges. The sigmoid function with steepness parameter 0.5 is given in Figure 5.4.

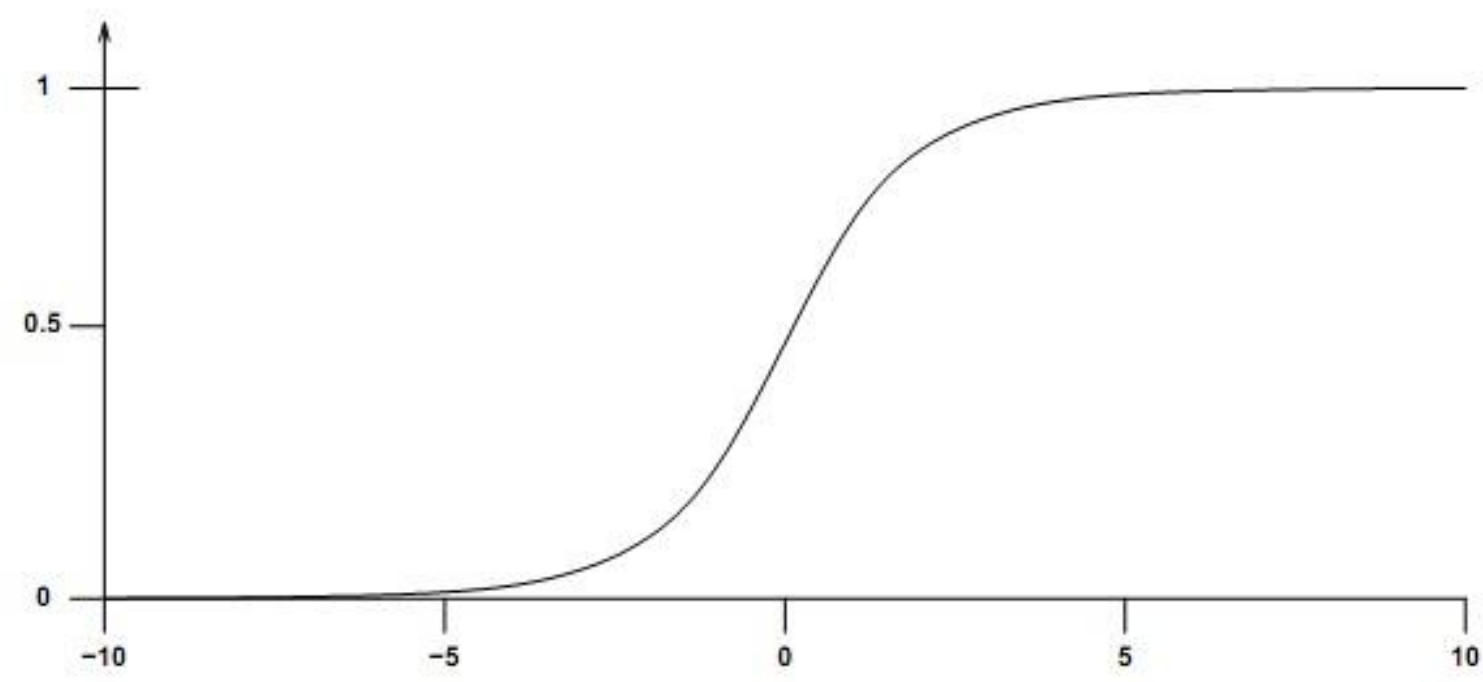

Figure 5.4.Sigmoid Function with Steepness Parameter 0.5 [8]

Multilayer feed forward artificial neural network is the type of ANN architecture of interest of this study. In a multilayer feed forward ANN which is the most common architecture, layers containing neurons start from input layer, continue with hidden layers and end up with output layer. In this architecture each layer can only connect to the next layer. 
Two different phases that form a multilayer feed forward artificial neural network are training and execution phases. In the training or learning procedure, the ANN is desired to turn out certain outputs for certain inputs, after being trained on a training data set.

The execution process of a feed forward ANN is being completed when a given input passes all the layers and output is turned out. The propagation of a neuron through network layers is done using equation 5.1. Since the connections between layers in a feed forward network are only allowed in one direction and neurons in each layer can only connect to neurons in the next layer, an input can easily propagate through different layers of the network until reaching the output layer. Having connections not only in one direction, but in all directions makes a network very complicated (like the human brain) since it creates loops. Computing a clear output using such complicated networks with loops is very difficult. Such systems are used in situations that deal with time dependencies. Therefore feed forward networks which have only one way connections are a better choice for solving time independent problems. Figure 5.5 illustrates such a network. 


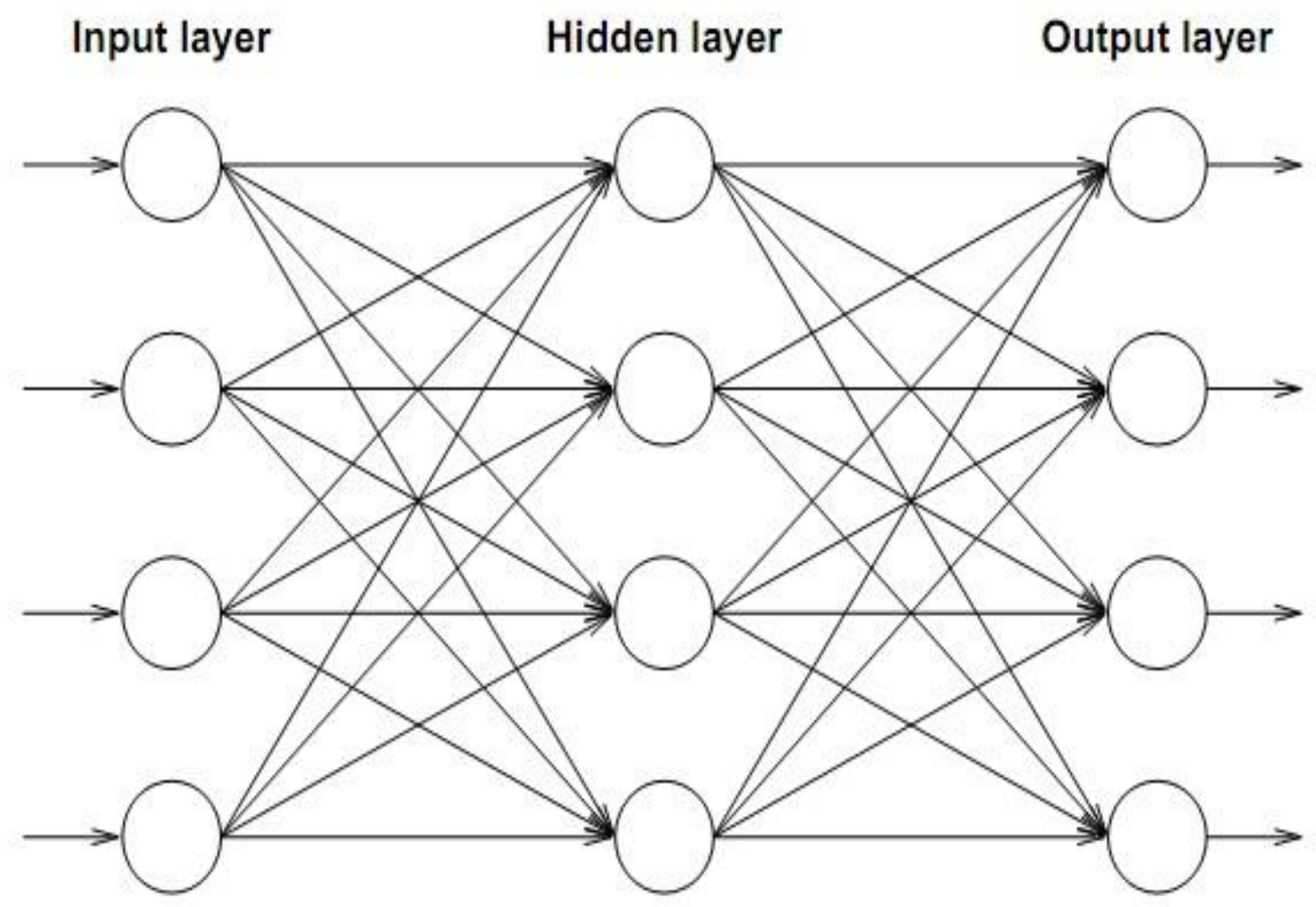

Figure 5.5.A Multilayer Feed Forward Network [8]

The network shown in Figure 5.5 consists of three different layers: An Input layer with four neurons, a hidden layer with four neurons and an output layer with four neurons. As it was indicated earlier the network is feed forward and each layer is only allowed to connect the next layer. Also as it is obvious from Figure 5.5, each layer is connected to the next layer. In real cases artificial neural networks may or may not be fully connected.

As mentioned before, in training phase the artificial neural network is desired to be trained to give appropriate outputs for given inputs. The training process is done by a set of training data which contains different inputs and their corresponding outputs and when the ANN is trained on such a data set, the weights of neurons are adjusted to make the network turn out the outputs similar to the outputs in the data sets prepared for training process. On the other hand if the training process is too rigorous 
it makes the ANN too specific that would give correct outputs only for the inputs seen in the training data set and incorrect outputs for new inputs. Such a situation is called over-fitting and should be avoided when training the ANN.

The overall goal of the training process is to minimize the mean square error between inputs and outputs in the training data set. Such a goal maybe achieved by different optimization approaches among which the backpropagation approach is the method of interest in most ANNs.

The name backpropagation describes the working principle of the algorithm pretty well. The algorithm suggests that after an input is propagated through the network to the output layer, the error between input and output is calculated and propagated back through the network while adjusting the weights on neurons to make the error smaller. The algorithm may be applied both on fully or sparse connected artificial neural networks.

Up to this point, the main issues related to implementation of a multilayer feed forward artificial neural network and the backpropagation algorithm is covered. The mathematical details regarding the above subjects are out of the scope of this study and will be left. The next chapters will continue with utilization of the ANN in a real case study of implementation an intelligent fault detection system for solar panels. 


\section{Chapter 6}

\section{ENERGY CONSUMPTION PROFILE AND SOLAR ENERGY DEVELOPMENT IN TRNC}

During this part of study some general information on the energy profile of the Turkish Republic of Northern Cyprus and the situation of solar energy development in this region is given. The importance of solar energy studies in TRNC rises from the fact that due to the geographical position of the island lots of sunshine is available during a long period of the year. This situation makes TRNC a very suitable region for solar energy studies although currently these kinds of studies are not satisfactorily developed in the island. It is hoped that the current study will contribute to the development of solar energy researches in TRNC.

The mentioned factors also have formed a basis for the experimental study on the intelligent monitoring and fault detection system for solar panel which is described in detail within the next chapter.

\subsection{Geographical Characteristics and Climate in TRNC}

Cyprus is the $3^{\text {rd }}$ largest island in the Mediterranean which is situated at $33^{\circ}$ east of Greenwich and $35^{\circ}$ north of the equator. The geographical position of the island causes it become one of the countries with the highest potential of solar energy usage. The climate characteristic of Cyprus is Mediterranean with hot dry summers and mild winters. On elevated ground the temperatures are $5^{\circ} \mathrm{C}$ lowered per $1000 \mathrm{~m}$ [9]. 


\subsection{Solar Irradiance Profile}

The daily sunshine duration in Cyprus is about $\% 75$ which is among the highest rates in world and which causes an incidence average solar radiation of about 5.4 $\mathrm{kWh} / \mathrm{m}^{2} /$ day on a horizontal surface. [9]. All these characteristics and information clearly show that Cyprus is one of the most suitable locations for solar energy applications.

The daily sunshine duration varies from 5.5 hours in winter to 12 hours in summer in lowlands. There is an average of nearly 4 hours of sunshine per day in the cloudiest months on the mountains. In July this amount reaches to about 12 hours per day [9]. Mean daily global solar radiation varies from $2.3 \mathrm{kWh} / \mathrm{m}^{2}$ in the cloudiest months, December and January to $7.2 \mathrm{kWh} / \mathrm{m}^{2}$ in July [9]. The amount of global solar radiation which is received on a horizontal surface is $1725 \mathrm{kWh} / \mathrm{m}^{2}$ per year where $\% 69$ of this amount is direct solar radiation and \%31 of that is representing diffuse solar radiation [9].

The variation of daylong solar radiation on horizontal, vertical and inclined surfaces facing south is shown in Figure 6.1 for Cyprus. 


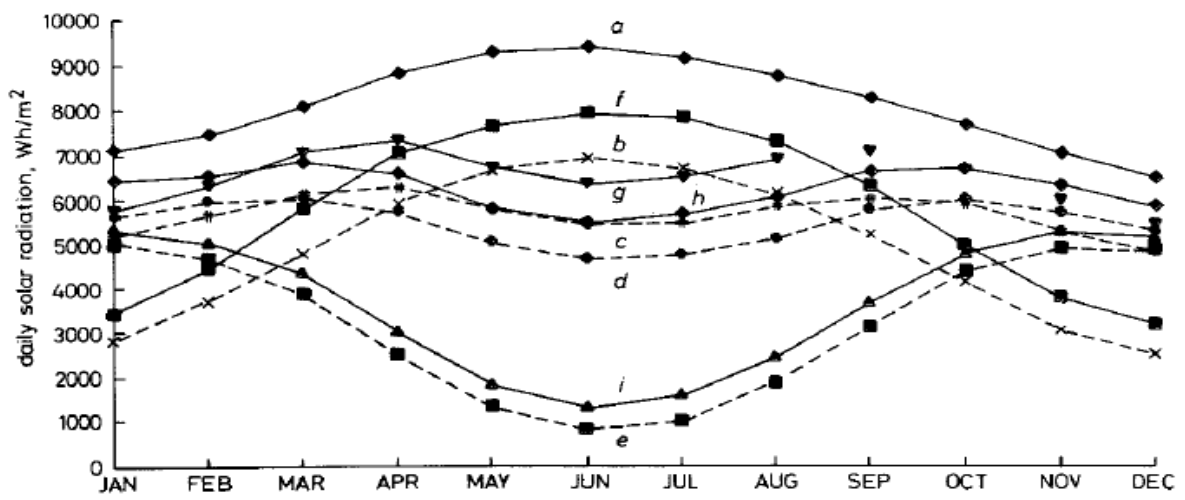

Figure 6.1.Mean Daily Solar Radiation in Cyprus. (a) Normal Incidence, Direct; (b) Horizontal Incidence, Direct; (c) Surface Tilted $35^{\circ}$, Direct; (d) Surface Tilted 50, Direct; (e) Vertical Surface, Direct; (f) Horizontal Surface, Global; (g) Surface Tilted $50^{\circ}$, Global; (h) Surface Tilted 50 , Global; (j) Vertical Surface, Global [9]

\subsection{Energy Production and Consumption Profile in TRNC}

The energy consumption profile of TRNC is presented in Figure 6.2. As it is clearly seen from the graphics the largest amount of energy (\%32) is used in houses. The most of the energy is consumed in houses for space and water heating applications.

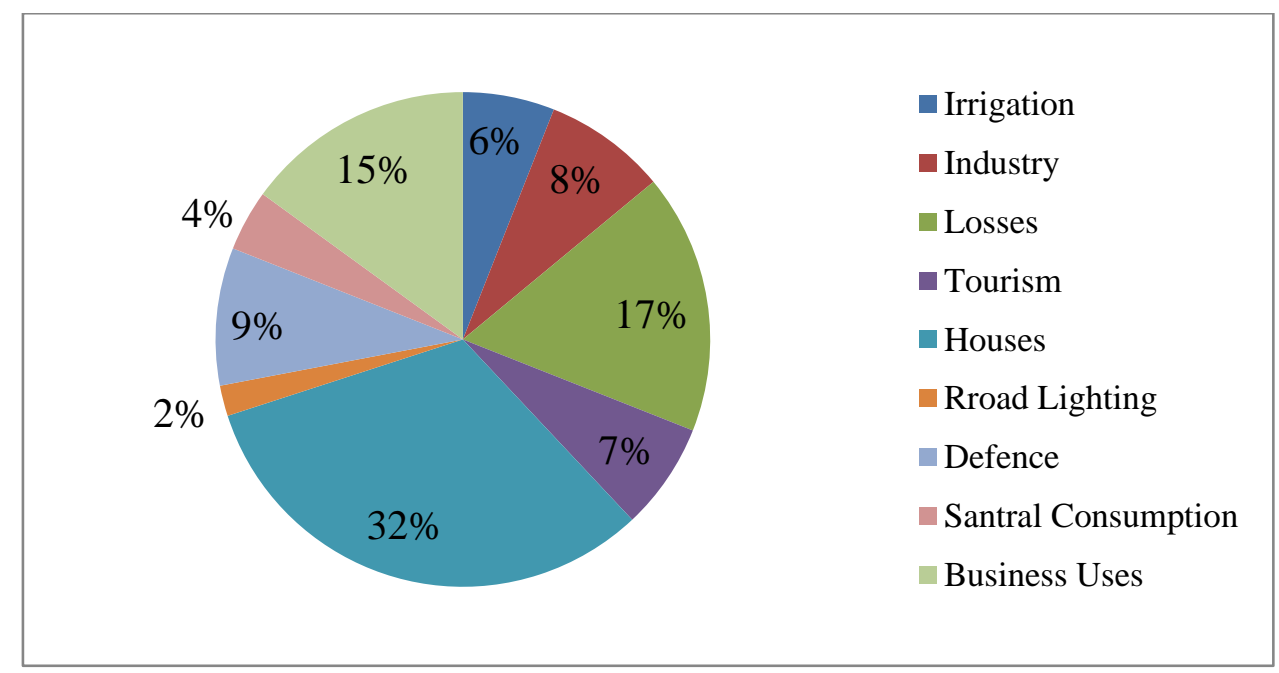

Figure 6.2.Energy Consumption Profile in TRNC

Due to a forecast made by [10] the growth rate of PV energy production in TRNC is $\% 20$ in 2010 which is followed by $\% 13$ up to $2020, \% 6$ up to 2030 and $\% 3$ up to 2040. 
A direct normal irradiance map of Cyprus is shown in Figure 6.3. It is clearly visible that due to suitable geographic and climatic conditions, the large amounts of solar irradiance and long sunshine durations, TRNC is one of the most suitable countries for investments in the filed of solar enrgy.

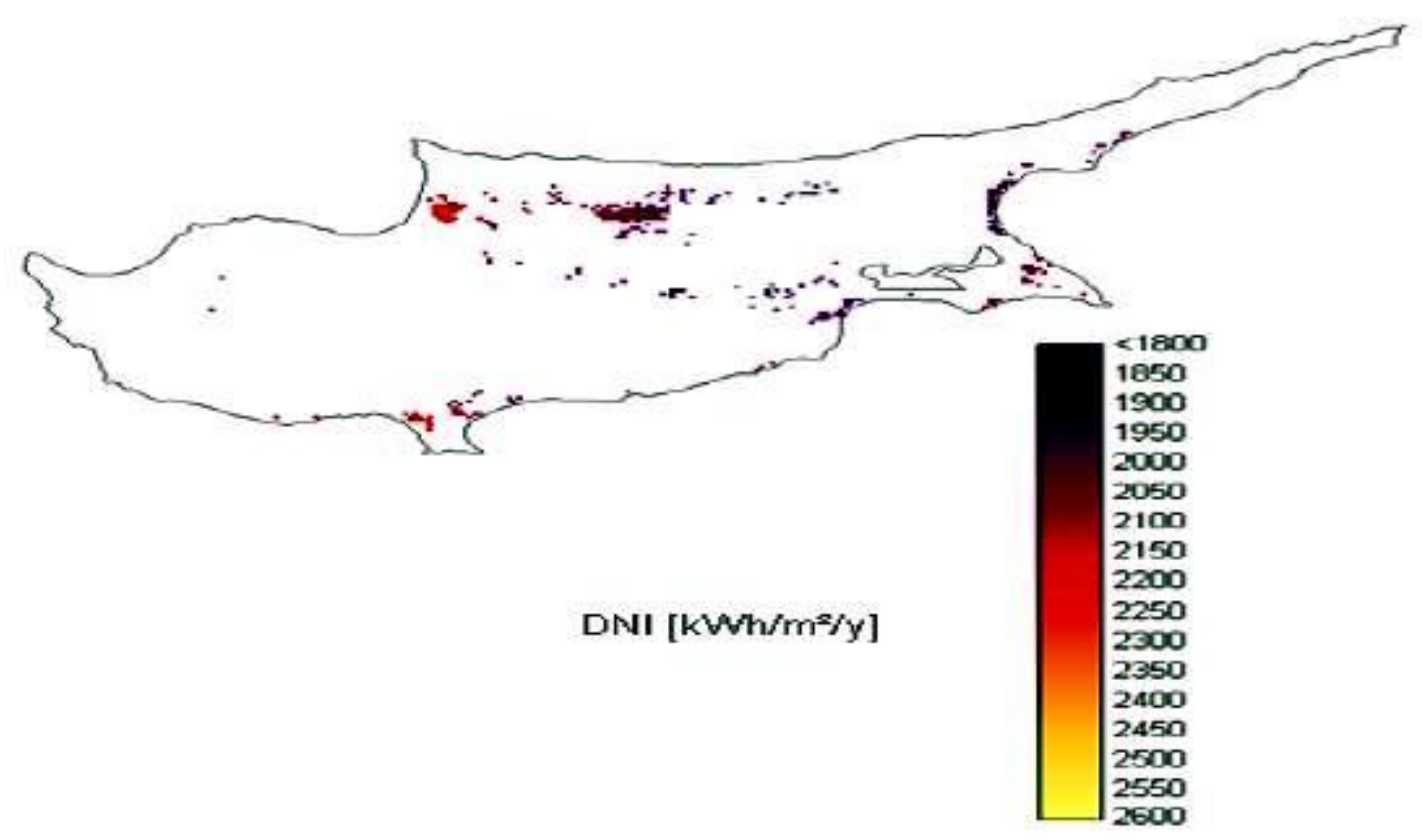

Figure 6.3.Direct Normal Irradiance Map of Cyprus [10] 


\section{Chapter 7}

\section{EXPERIMENTAL INTELLIGENT SOLAR PANEL \\ FAULT DETECTION SYSTEM BASED ON ARTIFICIAL \\ NEURAL NETWORK}

The intelligent solar panel fault detection system is developed to provide real time monitoring and fault detection possibilities for solar panels. The system perceives sun's position in the sky using certain algorithms and feeds the values describing this position to an artificial neural network. The artificial neural network which is trained to derive the relationship between the output power of a solar panel and the position of sun in the sky, estimates the expected output power corresponding to the given position for sun. If the root mean square error between the estimated power and the actually measured power exceeds some preset threshold, the system returns a fault report along with the error value. Such a fault may be caused by defective solar cells, shadows etc.

The solar panel fault detection system is developed using $\mathrm{C}$ programming language and the artificial neural network utilized in the system is implemented using the Fast Artificial Neural Network Library (FANN) Copyright (C) 2003-2006 Steffen Nissen (lukesky@diku.dk), which is an open source library used to implement multilayer artificial neural networks in $\mathrm{C}$. 
In the following parts the details about data collection, implementation, training and execution of the artificial neural network along with the overall system performance analysis will be given.

\subsection{Solar Data Collection Procedures}

In the following parts the details about collection and normalization of the solar data used to prepare the artificial neural network (ANN) training data sets will be given. When the ANN is implemented and trained, the solar data will also be used in execution of the fault detection system.

\subsubsection{Sun's Position Data}

As mentioned before, the sun's position in the sky is expressed by three different angles which are the Solar Altitude Angle, the Solar Azimuth Angle and the Solar Angle of Incidence. These three values are fed as inputs to the artificial neural network which will be utilized in the solar panel fault detection system. The methods of calculation and normalization of each of the angles in order to make them ready to be fed as inputs to the ANN is described below in details.

The Solar Altitude angle $\gamma_{\mathrm{s}}$ indicates sun's elevation from earth's surface and is calculated by the equation (7.1):

$$
\gamma_{s}=\sin ^{-1}(\sin \varphi \sin \delta+\cos \varphi \cos \delta \cos \omega) \text { Degrees }
$$

Where,

$\varphi \quad$ : The latitude of the observation point

$\delta \quad:$ The solar declination angle

$\omega \quad:$ The solar hour angle 
It is observed that the solar altitude angle ranges between -40 degrees to 90 degrees during a 24-hour period. The highest value of the solar altitude angle which optimally affects the performance of the solar panel is reached at 12:00 and is referred to the sun's highest elevation.

Before feeding the value as an input to the $\mathrm{ANN}$ it is aimed to normalize it between 0 and 1 . The value 0 refers to the value of the solar altitude angle that has the least effect on the performance of the solar panel. The value 1 refers to the angle value that has the most effect on panel's power output, which is 90 degrees and is reached at noon.

The normalization formula (7.2) is used to modify equation (7.1) in form of equation (7.3):

$$
\begin{gathered}
\text { Normalized Value }=\frac{\text { Value-Minimum }}{\text { Max-Minimum }} \\
\gamma_{s, \text { input }}=\frac{\gamma_{s}+40}{130}
\end{gathered}
$$

$\gamma_{\text {s,input }}$, Which is expressed in equation (7.3) is passed as the first input to the artificial neural network.

As discussed earlier the factor $j$ indicates the effect of the Julian day number in the declination angle $(\delta)$ calculation. Figure 7.1 shows the results of per minute calculations of $\gamma_{s, \text { input }}$ for constant latitude and different time angles over a 24-hour period. Figure 7.1 shows $\gamma_{s, \text { input }}$ calculation for Julian day number 182 which refers 
to July $1^{\text {st }}$. As it is obvious from the figure, $\gamma_{s, \text { input }}$ almost reaches its optimal value 1 which refers to 90 degrees for $\gamma_{s}$ at 12:00 on July $1^{\text {st }}$.

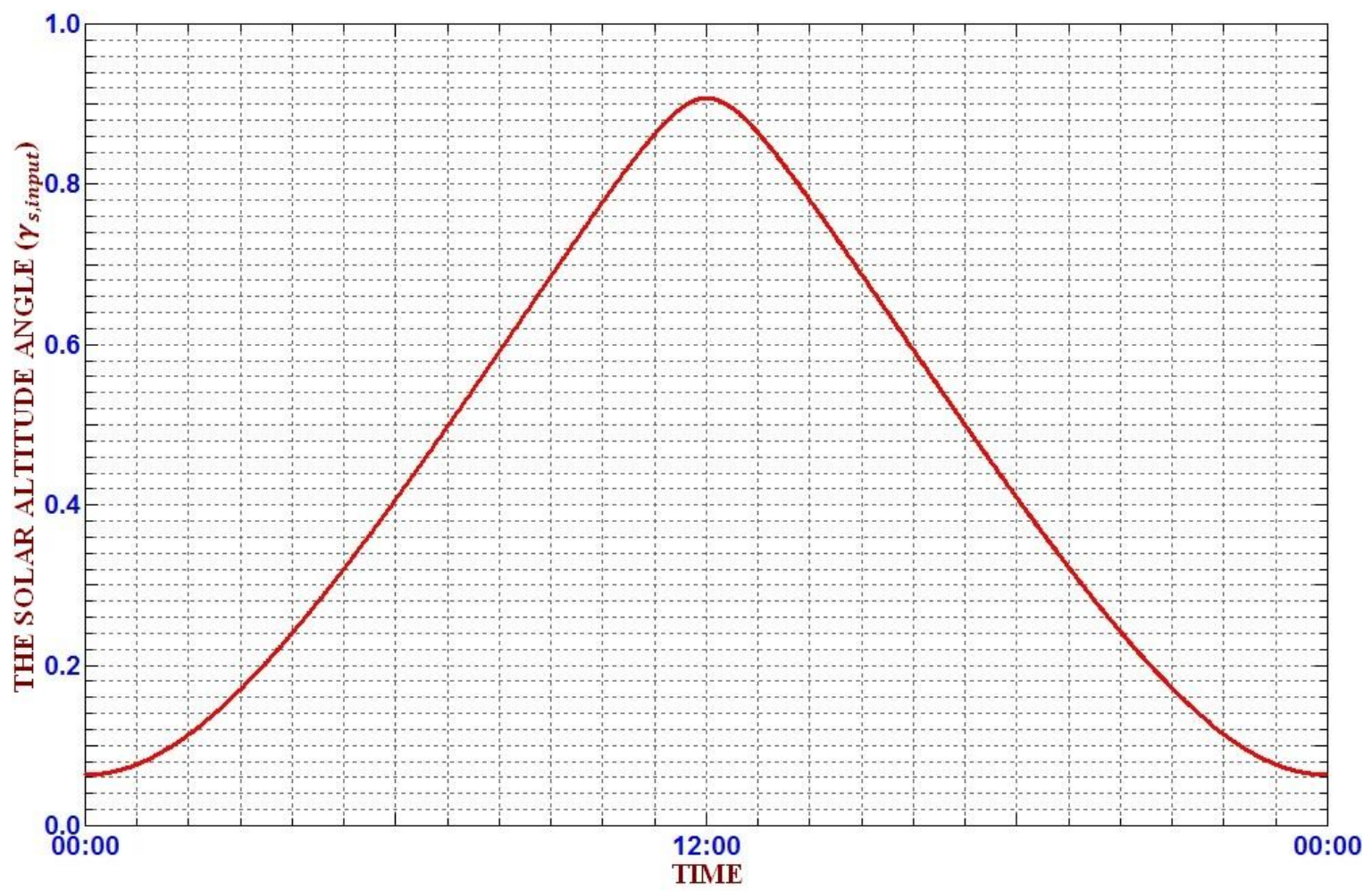

Figure 7.1.The Solar Altitude Angle Calculations over a 24-Hour Period on July $1^{\text {st }}, 2012$

The second value which is fed as input to the artificial neural network is the Solar Azimuth Angle. As discussed before the solar azimuth angle indicates sun's deviation from north direction and is represented by the equation below:

$$
\begin{cases}\alpha_{s}=180-\cos ^{-1}\left(\cos \alpha_{s}\right) & \text { If } \sin \alpha_{s}<0 \\ \alpha_{s}=180+\cos ^{-1}\left(\cos \alpha_{s}\right) & \text { If } \sin \alpha_{s}<0\end{cases}
$$

Where,

$$
\begin{aligned}
& \cos \alpha_{s}=\left(\sin \varphi \sin \gamma_{s}-\sin \delta\right) / \cos \varphi \cos \gamma_{s} \\
& \sin \alpha_{s}=\cos \alpha_{s} \sin \omega / \cos \gamma_{s}
\end{aligned}
$$


The effect of time angle $(\omega)$ makes $\left(\sin \alpha_{s}\right)$ take on positive values for 12:00 to 00:00 and negative values for 00:00 to 12:00, therefore the equation (7.4) is modified in data collection system to calculate the solar azimuth angle $\left(\sin \alpha_{s}\right)$ for these two different periods of time.

The solar panel used for data collection is headed in south direction, therefore the values of the solar azimuth angle which represent the location of sun in south direction mostly affects the performance of the panel. Since the equation (7.4) represents sun's deviation from north direction, it takes on 0 and 180 degrees when sun is located in north and south directions respectively. Therefore again using normalization equation (7.2) to modify equation (7.4) in form of equation (7.7) and (7.8):

For $\alpha_{s}<180$

$$
\alpha_{s, \text { input }}=1-\frac{180-\alpha_{s}}{180}
$$

For $\alpha_{s}>180$,

$$
\alpha_{s, \text { input }}=1-\frac{\alpha_{s}-180}{180}
$$

Figure 7.2 shows the results of per minute calculations of $\alpha_{\text {s,input }}$ over a 24-hour period for July $1^{\text {st }}$ using equations (7.7) and (7.8). As it is obvious from the figure $\alpha_{\text {s,input }}$ takes on its highest value 1 at 12:00 which shows that the sun is located in south direction at noon. Since the solar panel is also headed in south direction, the value of $\alpha_{\text {s,input }}$ at noon refers to the situation in which the panel is located in front of sun and is expected to work with its maximum performance. 


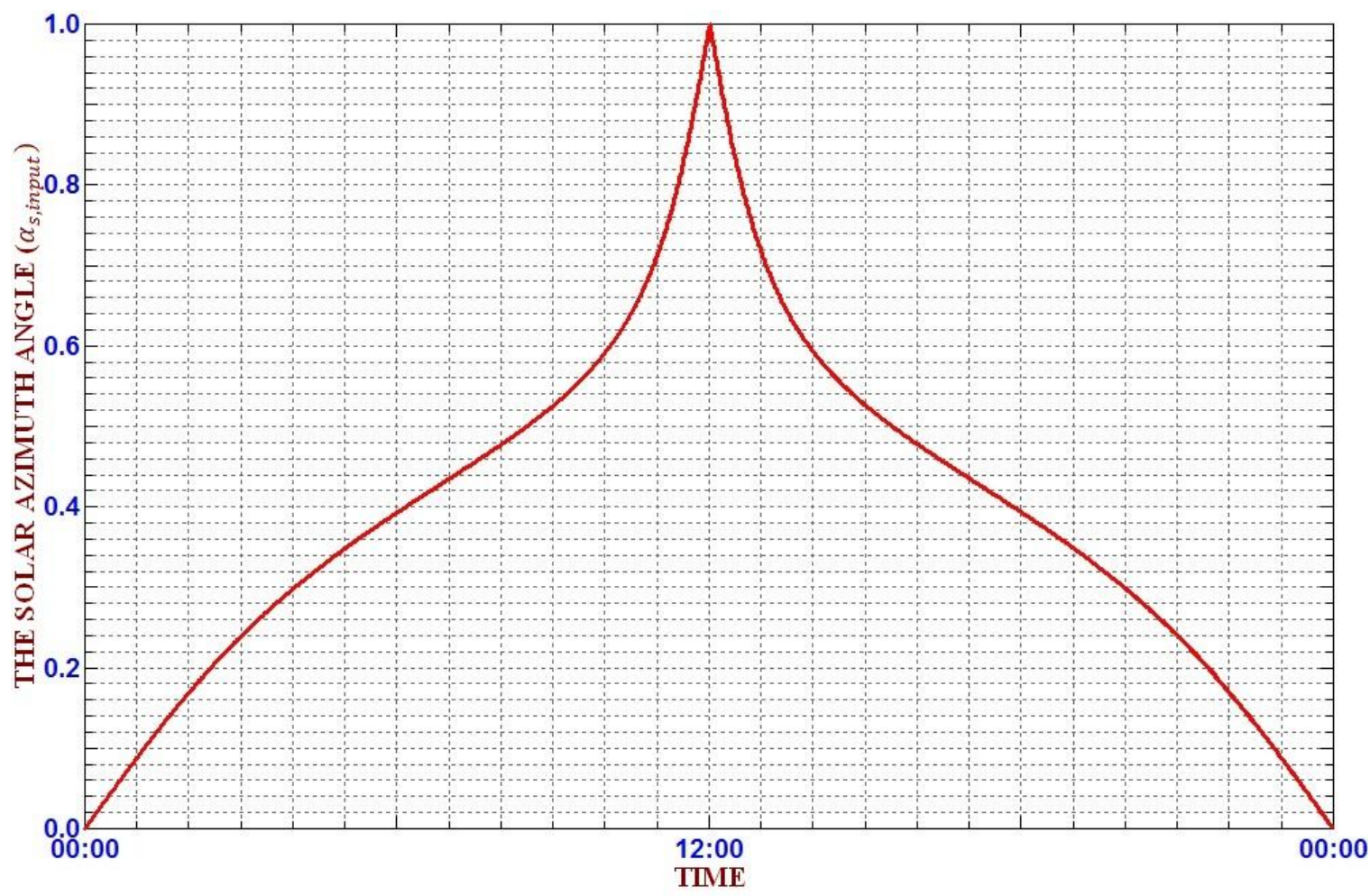

Figure 7.2.The Solar Azimuth Angle Calculations over a 24-Hour Period on July $1^{\text {st }}, 2012$

The third and last value to be passed as input to the artificial neural network (ANN) is the Solar Angle of Incidence $(\theta)$. The solar angle of incidence is the angle between the sun's radiations and a vector perpendicular to the solar panel's surface. When the sun's radiation are perpendicularly received on solar panel's surface, $\theta$ takes on its optimal value 0 degree. Like the solar altitude and azimuth angles, the solar angle of incidence which is represented by the equation (7.9) has a major role in solar panel output power estimations.

$$
\theta=\cos ^{-1}\left[\cos (\beta) \cos \left(Z_{s}\right)+\sin (\beta) \sin \left(Z_{s}\right) \cos \left(\alpha_{s}-\alpha_{m}\right)\right]
$$

Where,

$\beta \quad$ : Tilt angle of the solar panels $\left(45^{\circ}\right.$ In this case $)$

$Z_{s} \quad:$ Zenith Angle of the Sun

$\alpha_{m} \quad$ : Module azimuth angle (In this case: South $=180^{\circ}$ )

And, 


$$
Z_{s}=90-\gamma_{s}
$$

Similar to the first two inputs $\left(\gamma_{s, \text { input }}\right.$ and $\left.\alpha_{s, \text { input }}\right)$, it is desired to normalize the value of the solar angle of incidence between 0 and 1 before feeding it as the third input to the ANN. The normalized input value takes on 1 corresponding to $0^{\circ}$ which is the optimal value of the angle of incidence and as this value moves towards $180^{\circ}$, the normalized input value decrease down to 0 .

Again the normalization equation (7.2) is used to modify equation (7.9) in form of equation (7.10):

$$
\theta_{\text {input }}=1-\frac{\theta}{180}
$$

Figure 7.3 shows the results of per minute calculations of $\theta_{\text {input }}$ over a 24-hour period, again for the Julian day number 182 which refers to July $1^{\text {st }}$. As it is obvious from the figure, $\theta_{\text {input }}$ takes on its maximum value on 12:00 which indicates that sun's radiations are perpendicularly received on solar panel's surface at noon, and decreases down to its minimum value at midnight. 


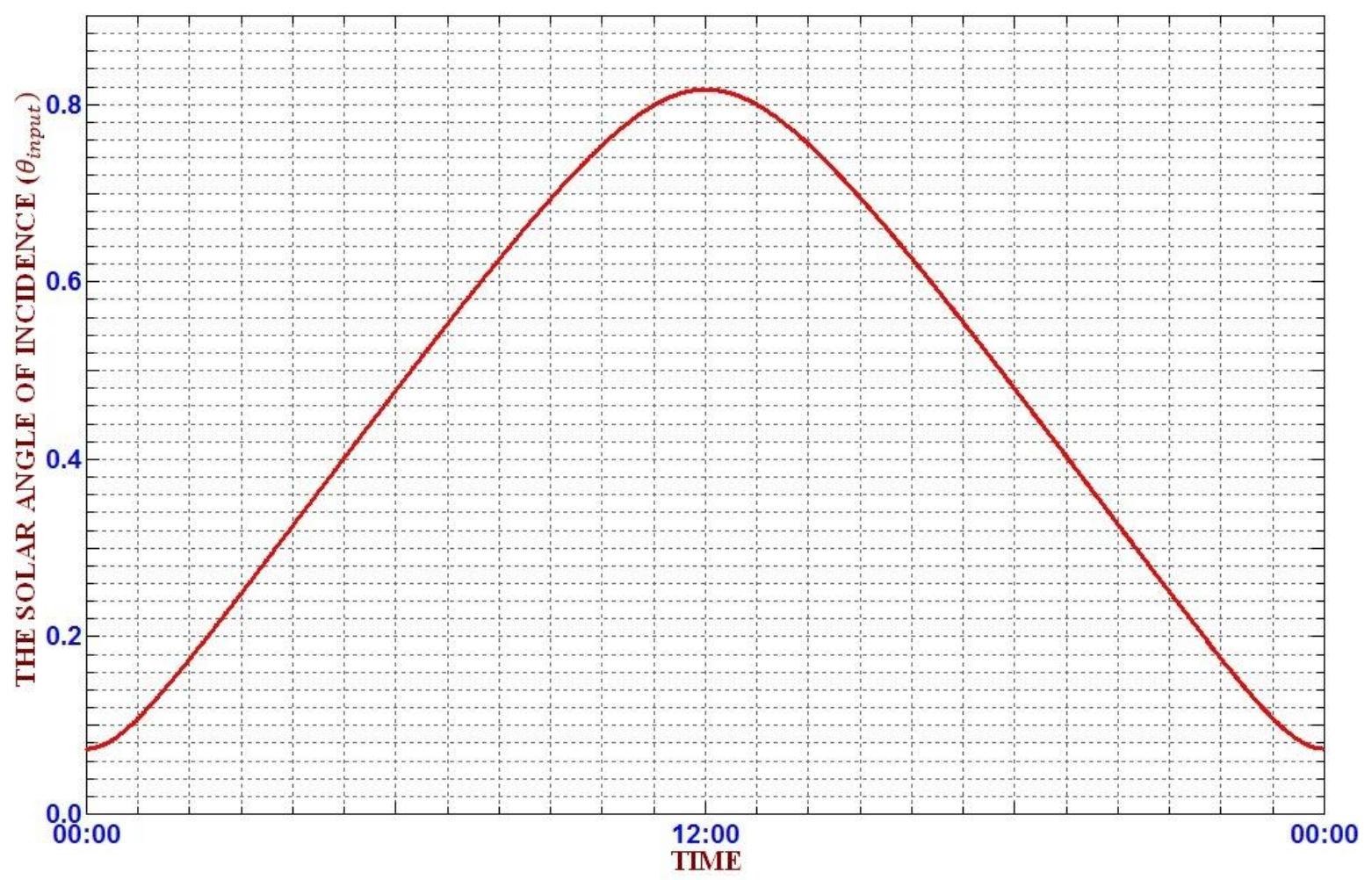

Figure 7.3.The Solar Angle Of Incidence Calculations over a 24-Hour Period on July $1^{\text {st }}, 2012$

\subsubsection{Solar Panel Output Power}

The solar panel used to collect data for the fault detection system is a $50 \times 60 \mathrm{~cm}$ monocrystalline silicon solar panel located 17 meters above sea level, at $35^{\circ} 8^{\prime} 51^{\prime \prime} \mathrm{N}$, $33^{\circ} 53^{\prime} 58^{\prime \prime}$ E. Figure 7.4 shows the solar panel headed in south direction which is used for data collection. 


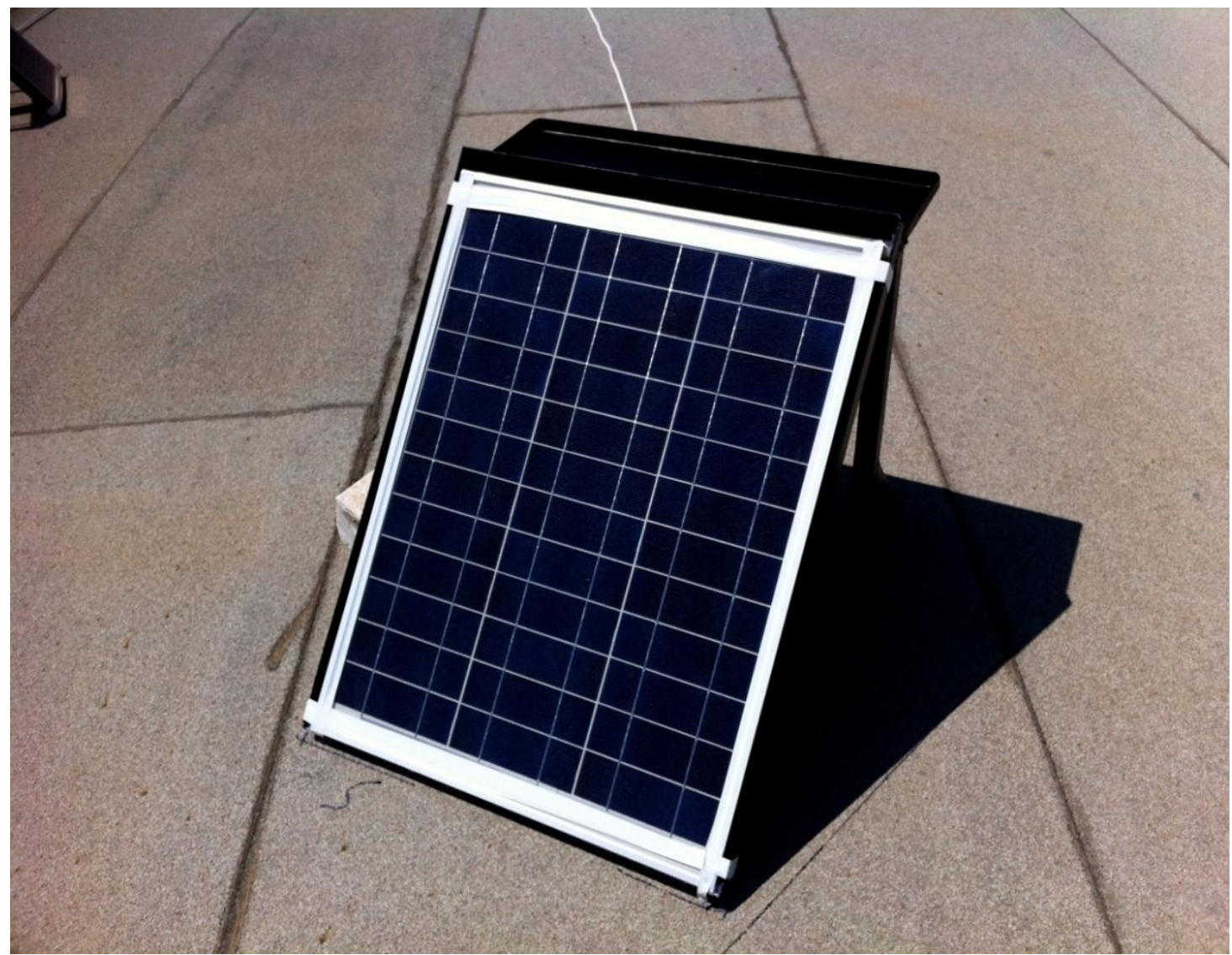

Figure 7.4.The Solar Panel Used for Data Collection

The solar panel is connected to a $2.2 \mathrm{~K}$ Ohms/ 5 Watts power resistor (Figure 7.5 ) in order to measure its output power. The output power is firstly used while the training data sets for the artificial neural network (ANN) are being prepared and then it is used to compare with the estimated output power after each execution of the ANN in the fault detection system (the details about training and execution of the ANN will be given in further parts). 


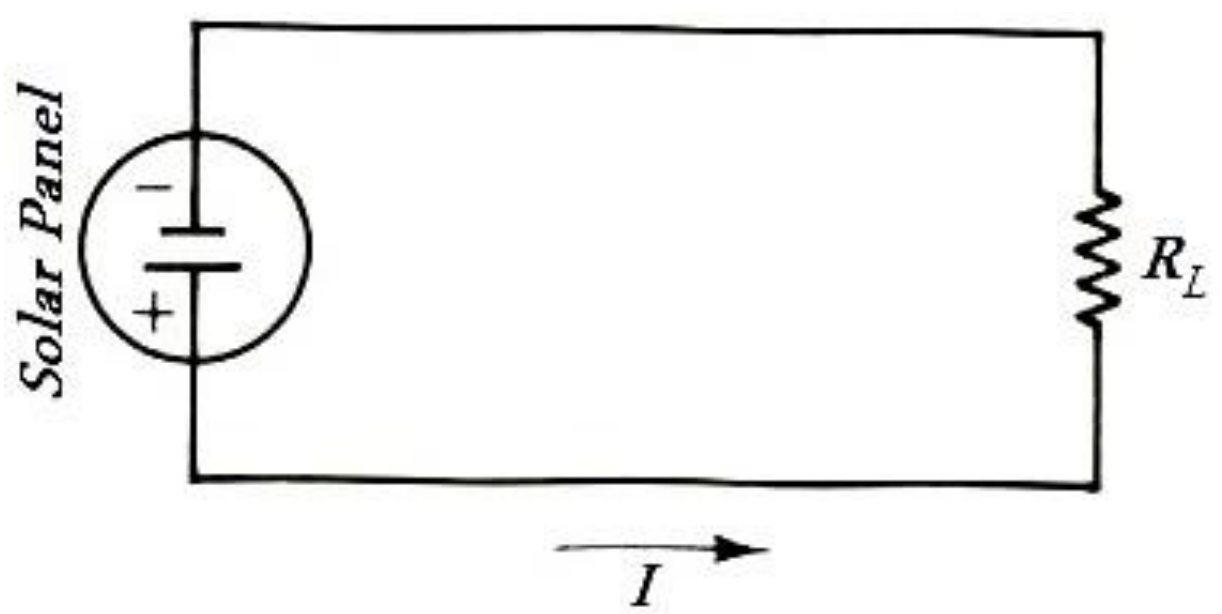

Figure 7.5.The Circuit Connection between the Solar Panel and the Power Resistor

A circuit containing an ATMEGA microprocessor and a MAX232 chip to measure the output power of the solar panel and send the value of the measured power to the computer is constructed. The voltage across the power resistor $\left(\mathrm{R}_{\mathrm{L}}\right)$ is fed into the microprocessor after passing through a voltage divider consisting of 5 resistors. The microprocessor is programmed to calculate the current in the power resistor and the output power of the solar panel every 5 seconds and send the values of voltage, current and power to the MAX232 chip. The values of voltage and current are also sent to a display on board every 5 seconds. The MAX232 sends the received data from the microprocessor to a 15-pin VGA connector, which feeds the measured data to the computer through a RS232 to USB adapter. The computer receives the values of voltage, current and power through its serial port.

The different parts of the solar panel output power measurement circuit consisting of (a)Microprocessor, (b)Max232, (c)Power Resistor and (d)5-Resistor Voltage Divider along with their connections are shown and labeled in Figure 7.6. 


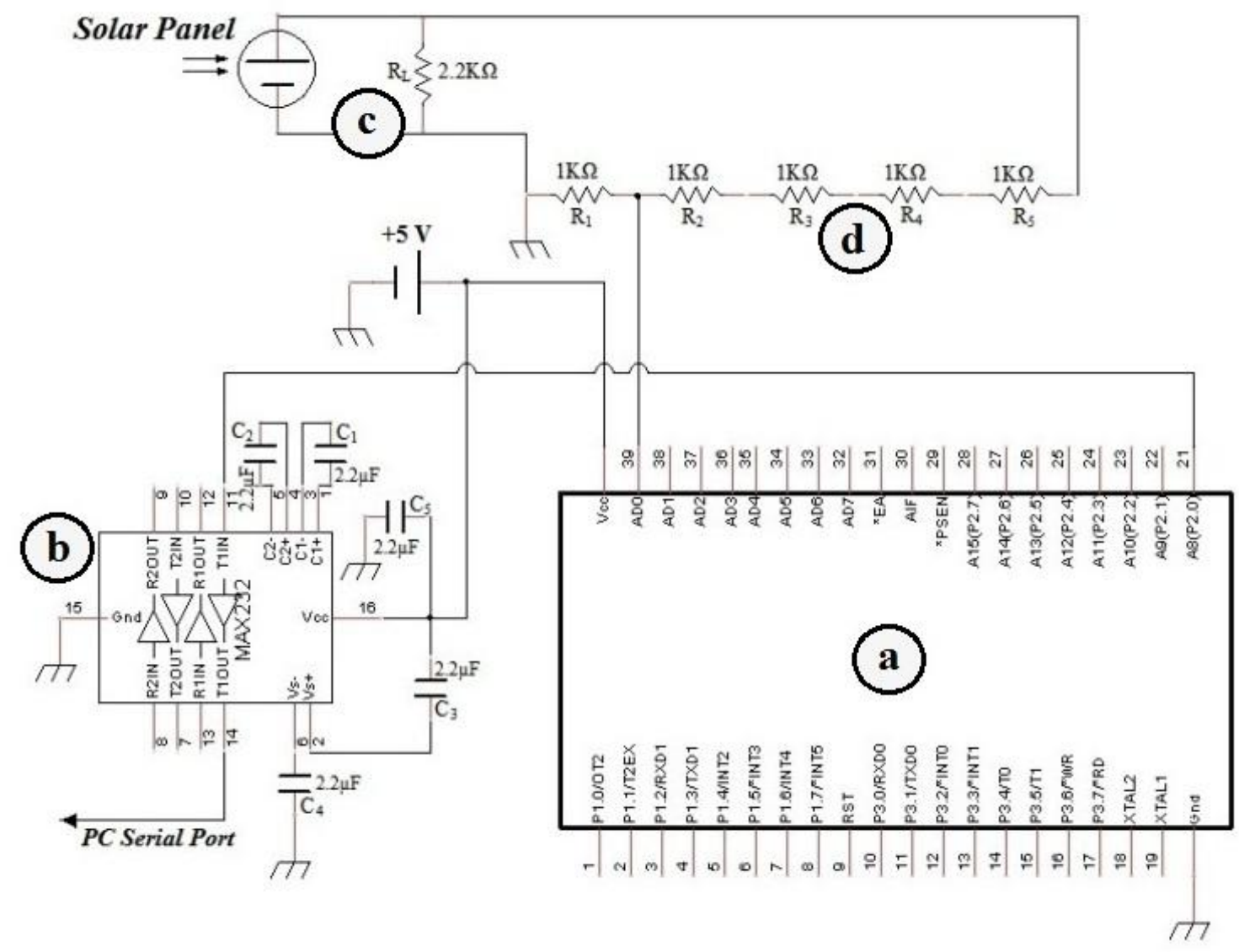

Figure 7.6.The Circuit Used for the Output Power Measurement of the Solar Panel

The output power of the solar panel was firstly tracked and logged over a 24-hour period with sample rate of 1 reading per minute. The system was designed to read the computer's serial port which was connected to the circuit in Figure 7.6, log the data referred to the output power of the solar panel together with the time of reading the port and wait for 60 seconds. The result of about 1400 times reading and logging the value of solar panel's output power over a 24-hour period starting from 00:00 (including delay effects) on July $3^{\text {rd }}$ is show in Figure 7.7. 


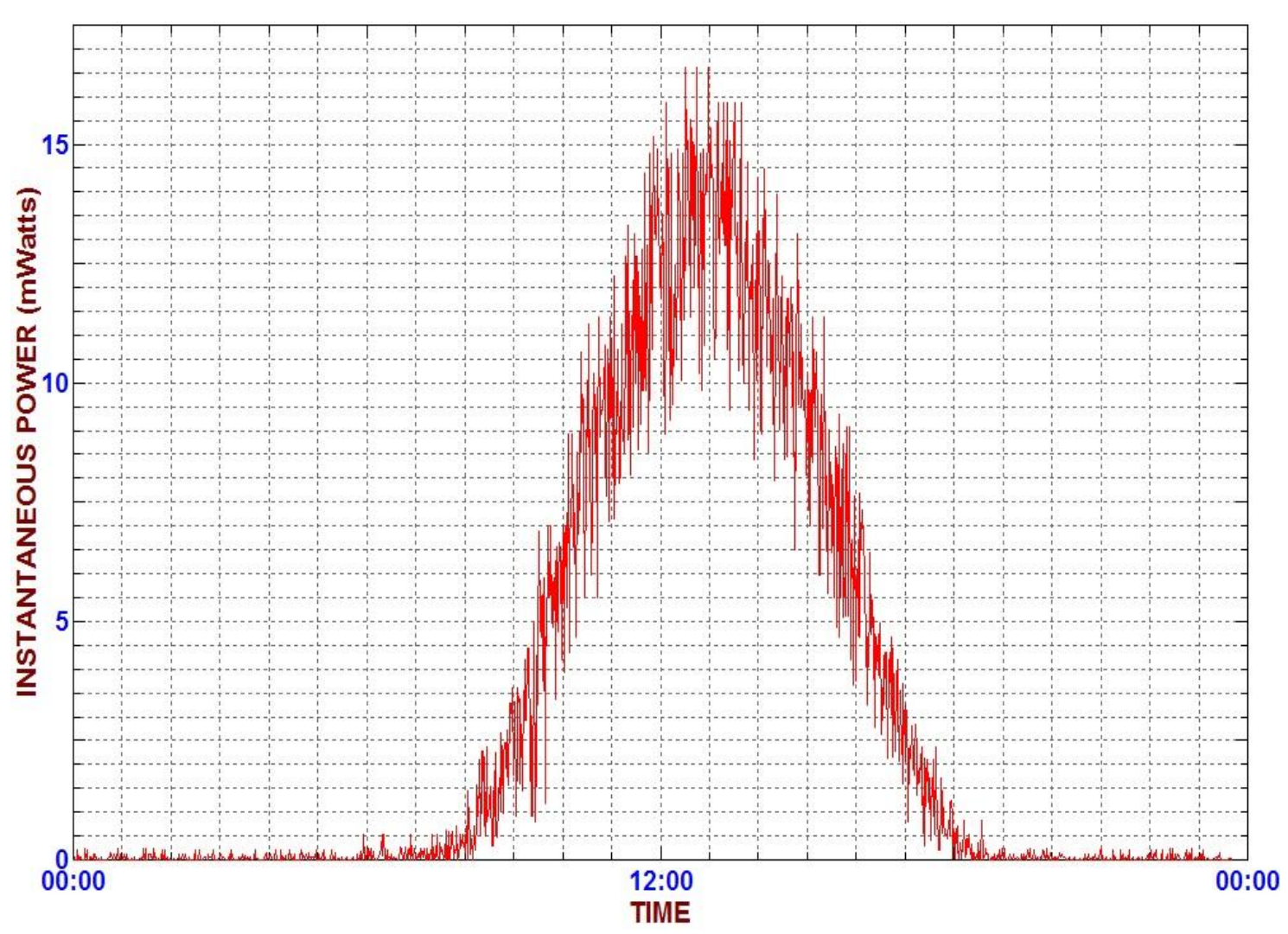

Figure 7.7. Output Power Measured with 1 Sample per Minute for a $50 x 60 \mathrm{~cm}$ Monocrystalline Silicon Solar Panel over a 24-Hour Period on July 3 ${ }^{\text {rd }}, 2012$

As it is obvious from Figure 7.7, solar panel's output power measured with 1 sample per minute is highly fluctuating. Logging the fluctuating power value in the artificial neural network training data sets would decrease the efficiency of the training process of the ANN and increase its training error. The solution to this problem is to increase the averaging rate of the measured output power.

At this point the system is modified to read the output power of the solar panel through computer's serial port in 5 second intervals. After 12 readings is completed (which corresponds to 60 seconds reading time), the average value of the last 12 samples is logged along with exact time at the moment. 
Figure 7.8 shows the results of about 1400 measurements of the solar panel's output power with sampling rate of 12 readings per minute over a 24-hour period on July $3^{\text {rd }}$.

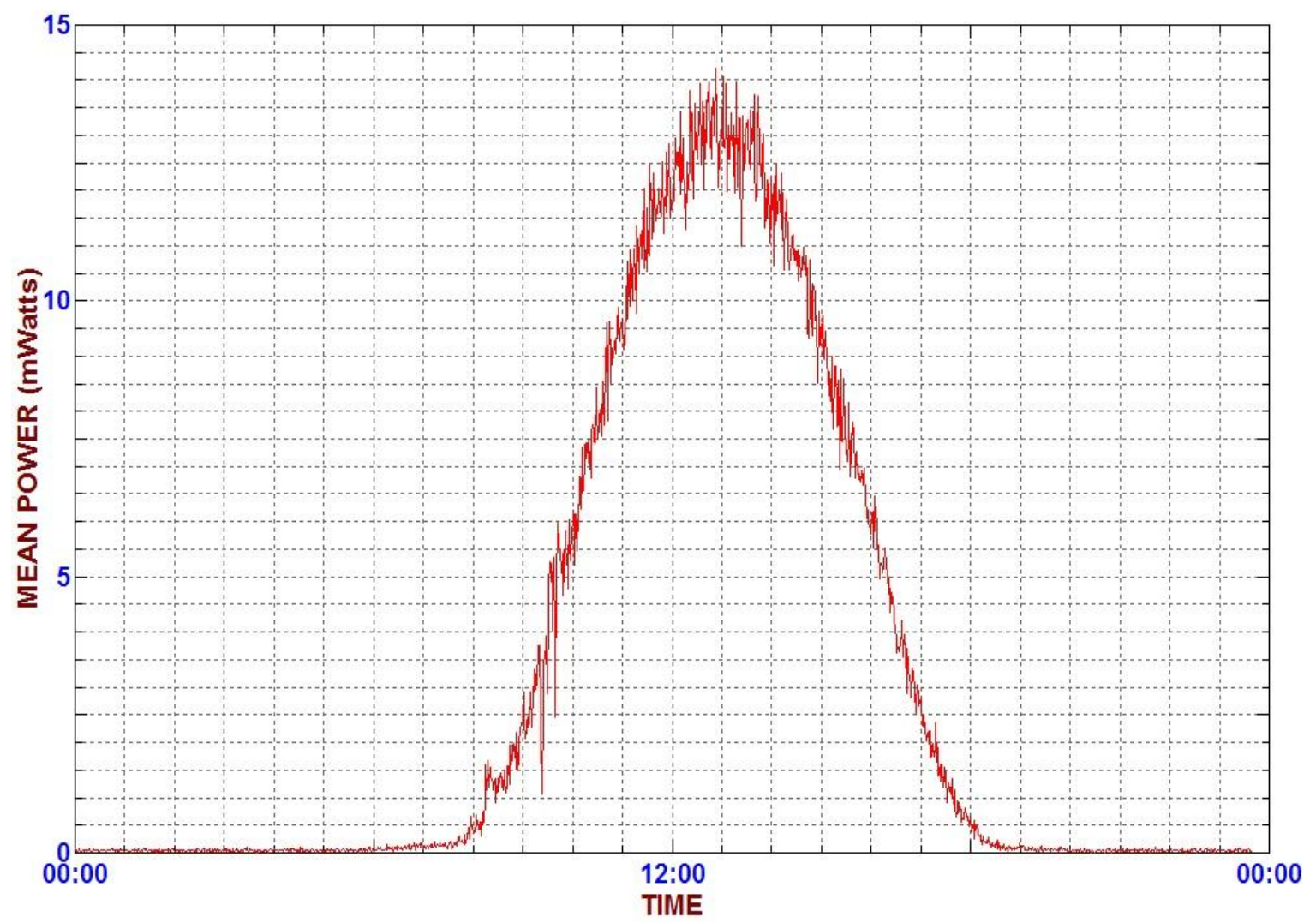

Figure 7.8.Output Power Measured with 12 Samples per Minute for a 50x60 cm Monocrystalline Silicon Solar Panel over a 24-Hour Period on July 3 ${ }^{\text {rd }}, 2012$

As shown in Figure 7.8, increasing the averaging rate of the solar panel's output power measurement decreases the fluctuations in the logged data and makes it ready to be passed into the artificial neural network training data sets. Similar to the input values, the output value also has to be normalized before being passed to the training data set. Normalization of output power (observing its peak value to be less than 15 $\mathrm{mW}$ ) is done by equation (7.11).

$$
P_{\text {output }}=\text { Mean Power } / 15
$$

At this point it is observed that there is a 1-hour shift between the expected and the actually measured output power of the solar panel. In instance it is shown in Figures 
7.1, 7.2 and 7.3 that the sun is in its optimal position in terms of its effect on the solar panel performance at 12:00, but it is observed from the Figures 7.7 and 7.8 that the solar panel's output power reaches its maximum at 13:00. The 1-hour shift is also valid for all other values of the solar panel's output power during daylight. For the time being it is thought that this shift is caused by the activation processes of the solar cells.

Training the artificial neural network with the present data would decrease its training efficiency. Therefore a temporary 1-hour shift is applied to the inputs in data collection phase to sync the input and output graphs and prevent the displacement effects on the artificial neural network training process.

\subsection{Artificial Neural Network Training Process}

As previously mentioned, it is aimed to develop an artificial neural network (ANN) which receives the values of the solar altitude angle, the solar azimuth angle and the solar angle of incidence as inputs and derive the estimated solar panel output power corresponding to each set of input. The ANN needs to be trained with inputs and outputs collected before. After the training process completed, the ANN gets ready to derive proper outputs for the inputs given in training data set as well as generalizations for new inputs. The training process is done on a data training file which is shown in Figure 7.9. 


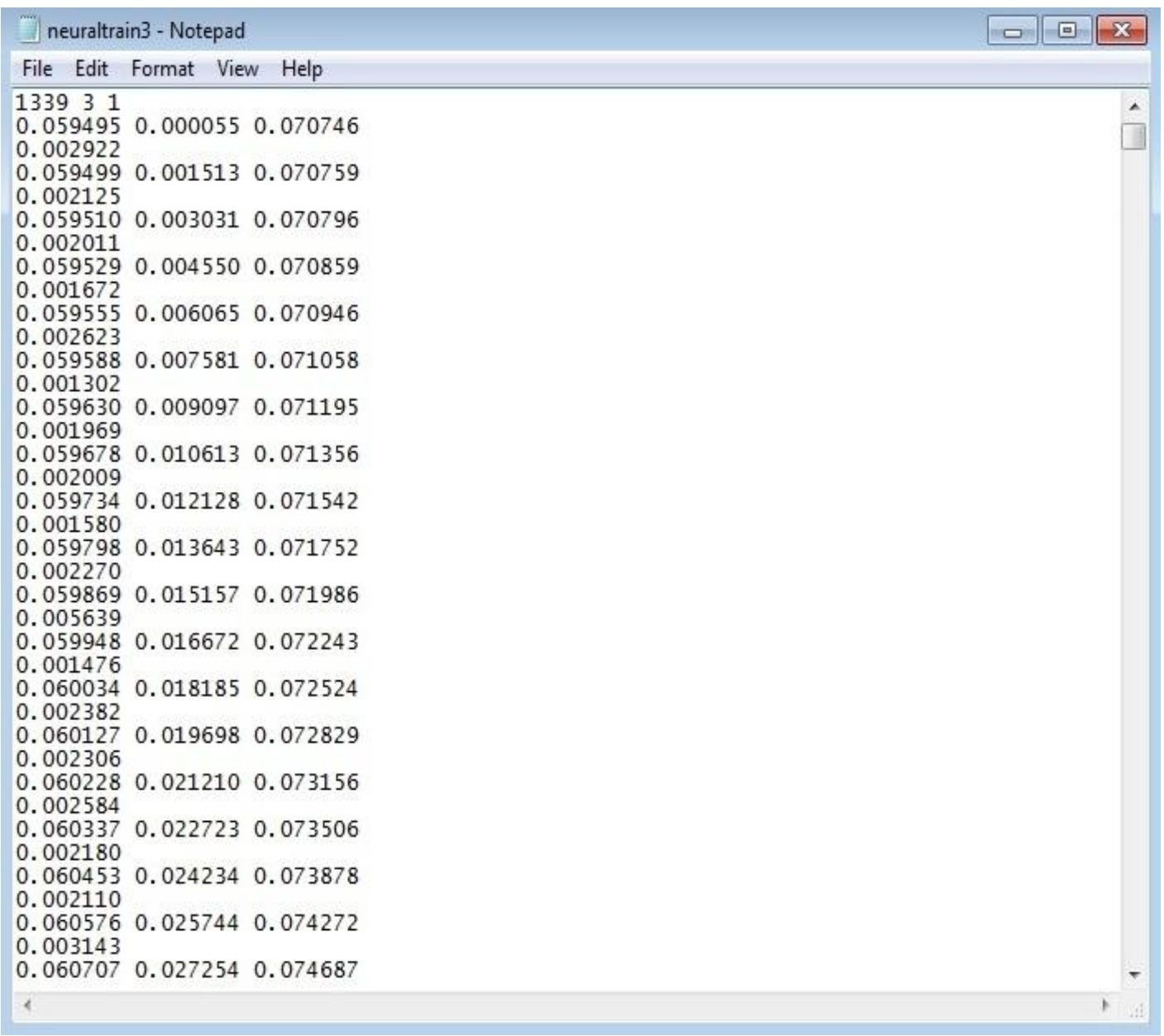

Figure 7.9.Artificial Neural Network Training Data Set

The first line in the training file indicates that the ANN goes through 1339 training paths with 3 inputs and 1 output. The next couple of lines consist of the input values which are $\gamma_{\text {s,input }}(7.3), \alpha_{\text {s,input }}(7.7,7.8)$ and $\theta_{\text {input }}(7.10)$ in the first line and the output value $P_{\text {output }}(7.11)$ in the second line. These two lines represent the first training path for the ANN and are followed by 1338 other paths which are all formed in the same way with different input and output values.

As discussed before, the artificial neural network utilized in the solar panel fault detection system has multilayer feedforward architecture with backpropagation algorithm. During the training process each training path is processed separately and inputs of each path are propagated through different layers of the network until they 
reach to the output layer. At this point the error of the training process is calculated with respect to the output specified to each input array in the training data set. After all the training paths are processed, the backpropagation algorithm is applied to adjust the weights on neurons in different layers of the network. The procedure continues until the training error falls below a preset threshold. The architecture of the multilayer fully connected artificial neural network shown in Figure 7.10 consists of an input layer, two hidden layers and an output layer. This ANN architecture with symmetric sigmoid activation function with steepness factor 1 is selected to be utilized in the solar panel fault detection system since it provided the lowest error during the training and execution phases. The execution window of the training process of the artificial neural network is shown in Figure 7.11. As it is obvious from the figure, the ANN falls below the preset training error threshold after 15215 epochs of backpropagation and at this point a net file is created to be used for execution of the ANN with future inputs. 


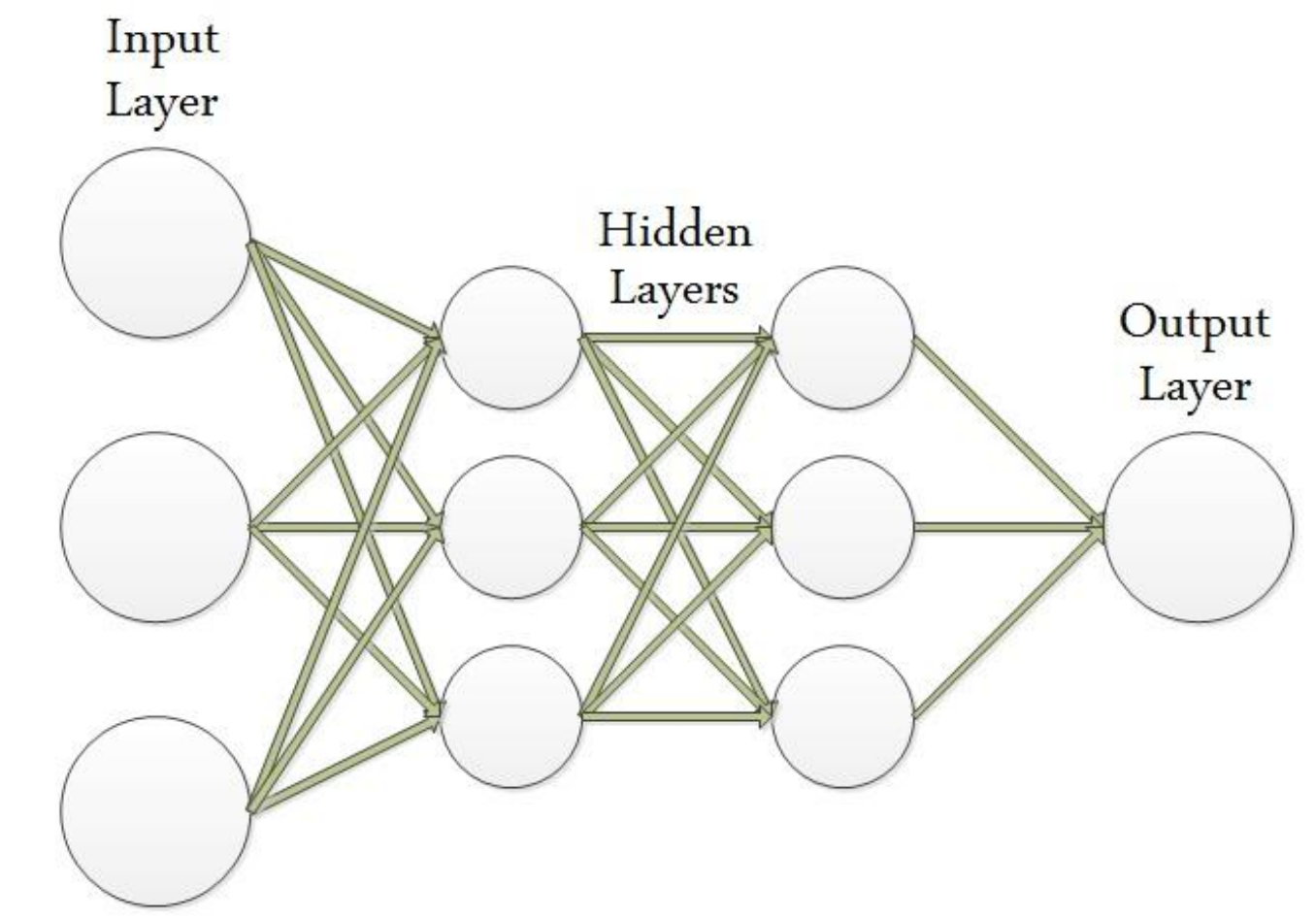

Figure 7.10.The Artificial Neural Network Architecture Utilized in the Solar Panel Fault Detection System

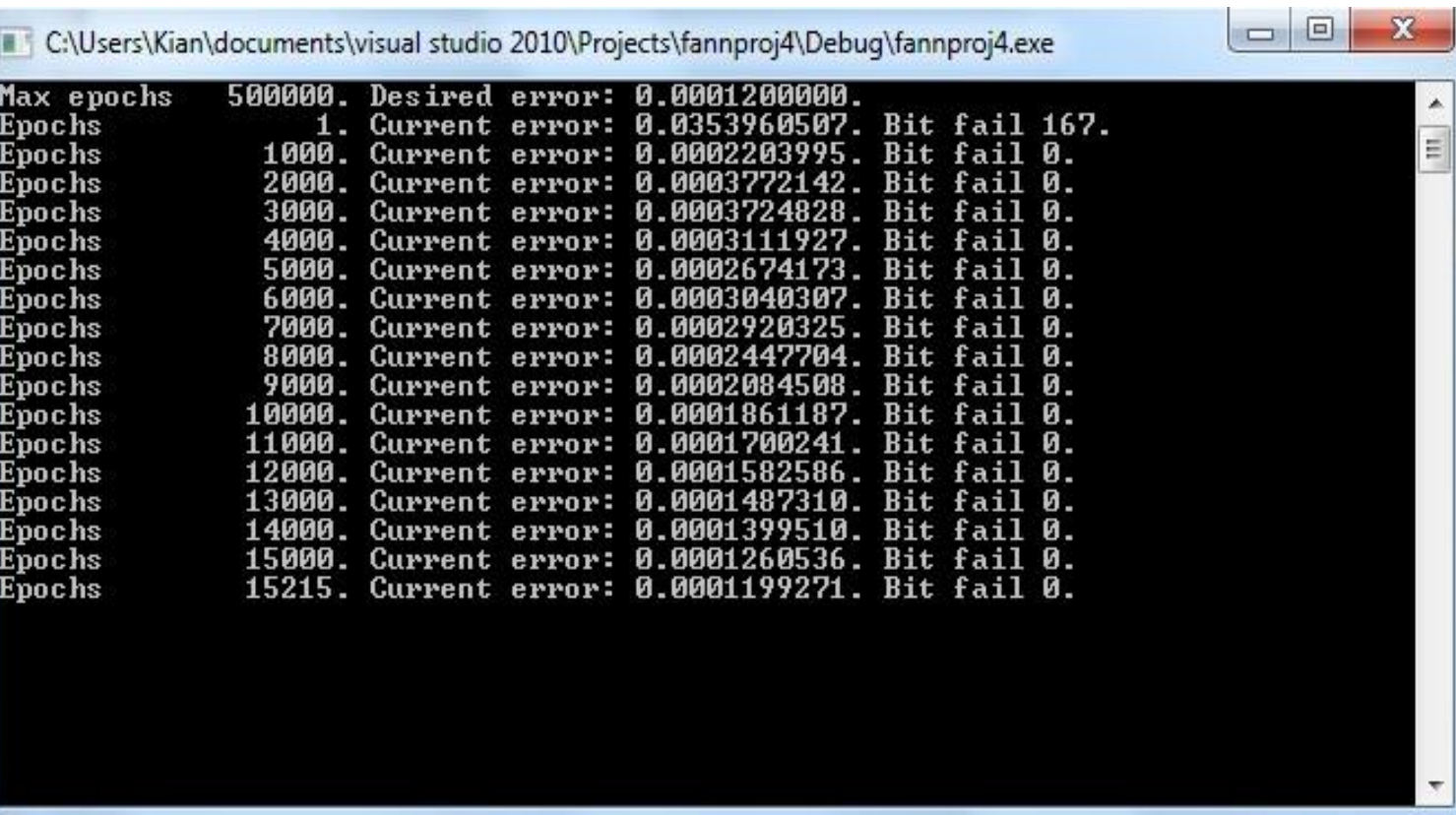

Figure 7.11.The Execution Window of the Training Process of the Artificial Neural Network 


\section{Chapter 8}

\section{EXECUTION RESULTS OF INTELLIGENT SOLAR}

\section{PANEL FAULT DETECTION SYSTEM}

At this point, having the artificial neural network trained with collected solar data, the solar panel fault detection system is ready to be executed. When the system is run, it connects to the computer's serial port to gets the value of the solar panel output power every 5 seconds and calculates the average output power with 12 samples per minute. After calculating the average power for each minute, the system gets the time and calculates the values of $\gamma_{\text {s,input }}(7.3), \alpha_{s, \text { input }}(7.7,7.8)$ and $\theta_{\text {input }}(7.10)$ and feeds them as inputs to the artificial neural network (ANN) shown in Figure 7.10.

The inputs propagate through the network layers as described before to reach the output layer. After the execution of the ANN is completed the output value is reconstructed from the normalized form and logged as the estimated output power for the corresponding time. At this point the root mean square error between the estimated and the actually measured output power values are calculated and logged as a percent error with respect to the measured output power value.

If the calculated percent error value falls below a preset threshold, the execution window of the fault detection system prints the message "System Performance Check: Successful" along with the exact time, measured power value, estimated 
power value and the root mean square error value. On the other hand, if the percent error value exceeds the threshold, the system prints "System Performance Check: Fault Detected" again together with the previously mentioned values.

Figure 7.12 shows the graph of the measured output power versus the graph of the estimated output power over a 24 -hour period on a clear, sunny day (July $\left.6^{\text {th }}, 2012\right)$ and Figure 7.13 shows the same graph for another day with partly cloudy morning and clear afternoon (August $3^{\text {rd }}, 2012$ ). The effect of cloudy weather on the solar panel output power is obvious from the Figure 7.13.

Figure 7.14 shows the root mean square error between the measured and the estimated solar panel output power values over a 24-hour period on August $3^{\text {rd }}, 2012$. As seen from the graph, the RMSE values for the partly cloudy morning are very high and fluctuating but the RMSE values for the clear afternoon are lower and smoother. 


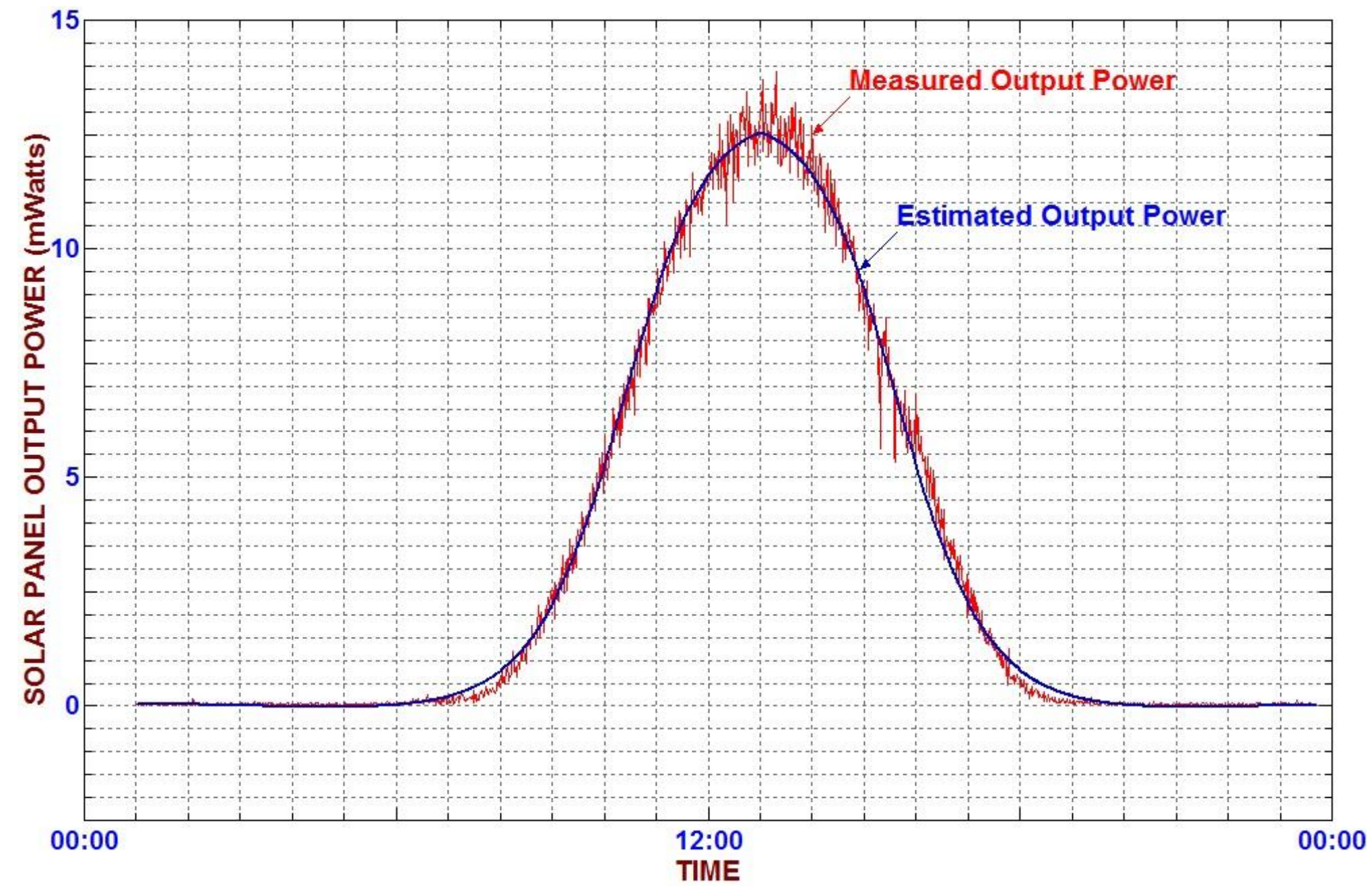

Figure 7.12.Output Power Values (Measured vs. Estimated) for a 50x60 cm Monocrystalline Silicon Solar Panel over a 24-Hour Period on July $6^{\text {th }}, 2012$ 


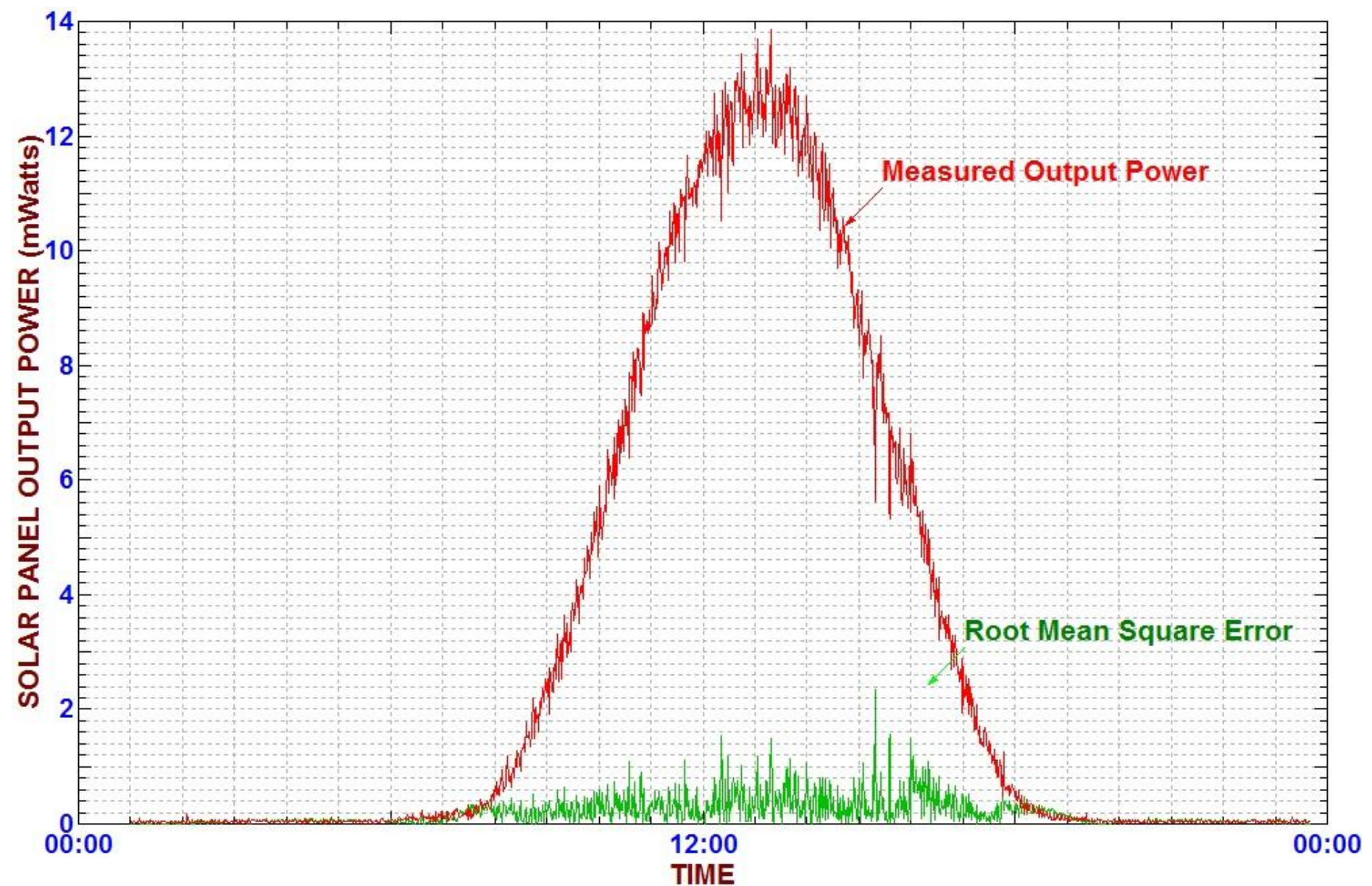

Figure7.13.The Root Mean Square Error between the Measured and the Estimated Output Power Values for a $50 x 60 \mathrm{~cm}$ Monocrystalline Silicon Solar Panel on July $6^{\text {th }}, 2012$ 


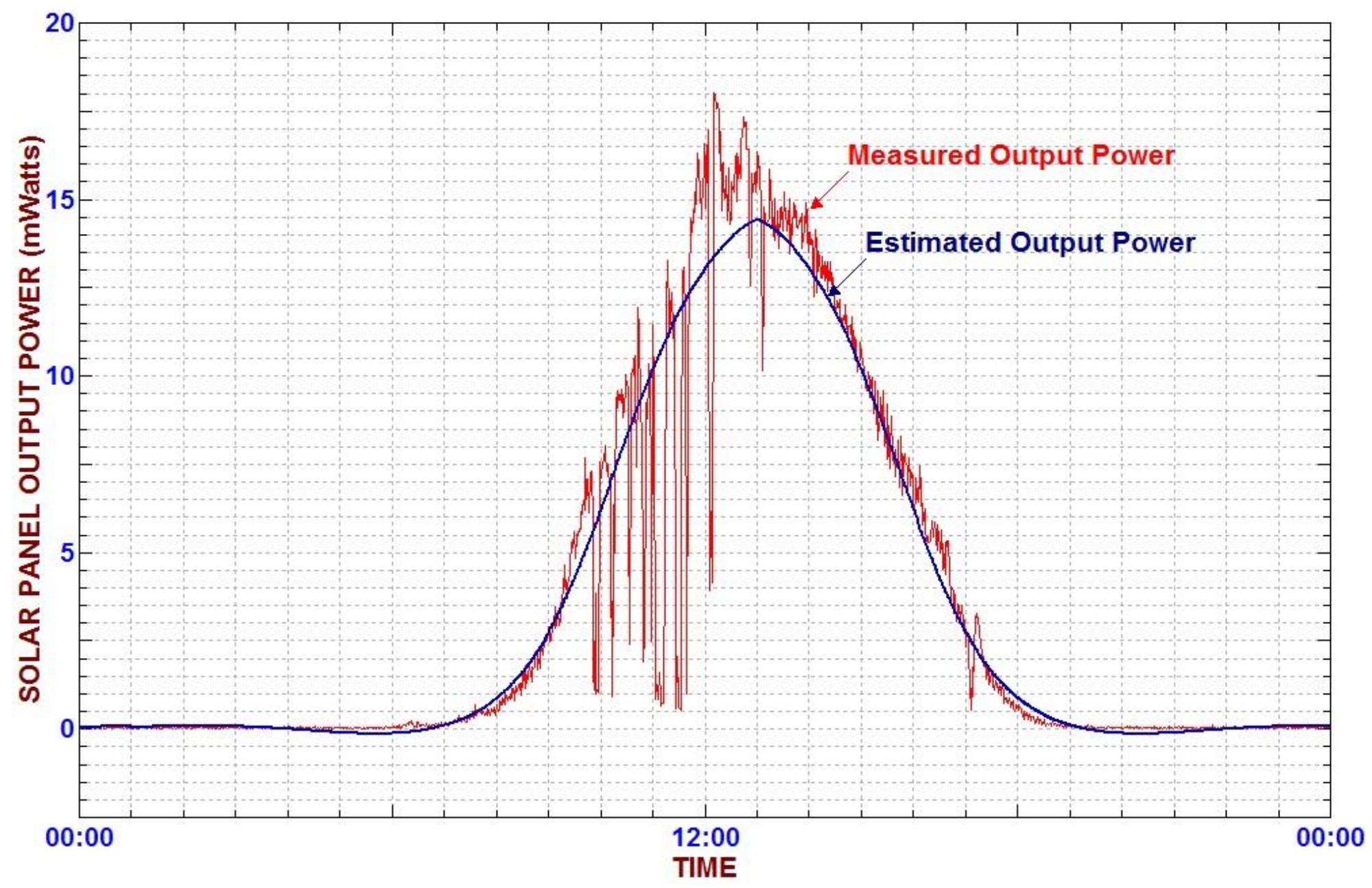

Figure 7.14.Output Power Values (Measured vs. Estimated) for a 50x60 cm Monocrystalline Silicon Solar Panel over a 24-Hour Period on August $3^{\text {rd }}, 2012$ 


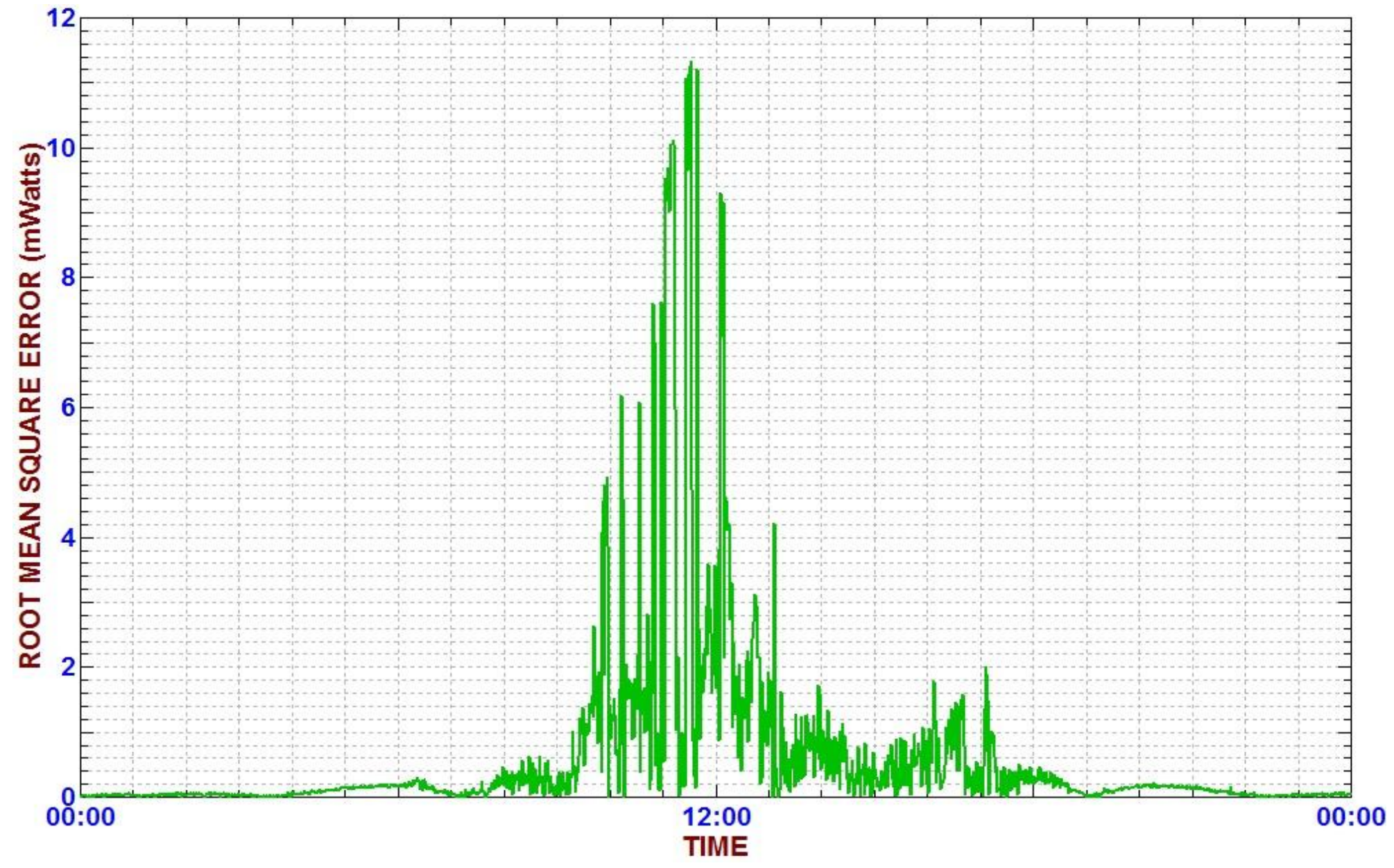

Figure 7.15.The Root Mean Square Error between the Measured and the Estimated Output Power Values for a 50x60 cm Monocrystalline Silicon Solar Panel on August $3^{\text {rd }}, 2012$ 
The table below shows the different values of the average percent RMSE between the measured and the estimated solar panel output power for different daylight time intervals from 1 up to 12 hours on a clear, sunny day (July $\left.6^{\text {th }}, 2012\right)$.

Table 8.1: Average Percent RMSE between the Measured and the Estimated output Power Values of a 50x60 Monocrystalline Silicon Solar Panel for different daylight time intervals on July $6^{\text {th }}, 2012$

\begin{tabular}{|c|c|}
\hline DAYLIGHT TIME INTERVAL & AVERAGE \% RMSE \\
\hline $12: 30-13: 30$ & 3.309906 \\
\hline $12: 00-14: 00$ & 3.420657 \\
\hline $11: 30-14: 30$ & 3.188346 \\
\hline $11: 00-15: 00$ & 3.175156 \\
\hline $10: 30-15: 30$ & 3.57076 \\
\hline $10: 00-16: 00$ & 3.950062 \\
\hline $9: 30-16: 30$ & 4.602882 \\
\hline $9: 00-17: 00$ & 5.207249 \\
\hline $8: 30-17: 30$ & 5.554695 \\
\hline $8: 00-18: 00$ & 8.405882 \\
\hline $7: 30-18: 30$ & 17.34585 \\
\hline $7: 00-19: 00$ & 29.37761 \\
\hline
\end{tabular}

As indicated in Table 8.1 the average RMSE between the measured and the estimated solar panel output power values varies from $\% 3.17$ to $\% 29.37$ for different daylight time intervals between 7:00 and 19:00. The \%RMSE between the measured and the estimated solar panel output power is high and fluctuating during morning and evening hours especially between 7:00-8:00 and 18:00-19:00 intervals. On the 
other hand the lowest \%RMSE value refers to the 4-hour time interval from 11:00 to 15:00 which is \%3.17. These values may be compared to the RMSE values for 15 different models of irradiance estimation introduced by Notton et al [20]. In these models the global irradiation on inclined planes (which is directly proportional to the output power generated by solar panels) is estimated and each estimation model is associated with a different RMSE value that varies from \%6.05 to \%26.72. Comparing with \%RMSE values for different estimation models introduced in [20] and also respecting solar panel power loss percentages due to shaded or damaged cells addressed in [2], which will be covered briefly, the solar panel fault detection system is executed in 8:00 to 18:00 time interval which corresponds to overall $\%$ RMSE values between \%3.17 and \%8.40.

As mentioned earlier, Nguyen [2] indicates that in a solar panel/module consisting of 10 sub-modules each containing 10 solar cells interconnected by 2 different connection types (Simple Series-Parallel and Total-Cross-Tied), the effect of 6 solar cells being shaded or damaged results in $\% 17$ to $\% 48$ overall power loss based on the locations and connection types of the shaded/damaged solar cells. Respecting the above, the \% 15 RMSE value between the measured and the estimated output power is decided as threshold for the solar panel fault detection system.

Setting the RMSE threshold for the solar panel fault detection system to $\% 15$ provides the possibility of detecting any failure higher than $\% 6$ in a solar panel's surface [2]. The power losses in solar panels may be due to real failures caused by damaged solar cells or superficial failures caused by meteorological conditions. At this point it is not possible to distinguish between real and superficial failures due to 
lack of equipment of sensing or simulating meteorological factors (clouds, dust, aerosols, etc.).

As a future work it is planned to expand the artificial neural network utilized in the solar panel fault detection system to include inputs provided by irradiance sensor, aerosol and cloud simulation data. Having the ANN trained with additional irradiance sensor, aerosol and cloud simulation data will provide the possibility of distinguishing between solar panel output power losses due to damaged cells and the output power losses due to meteorological conditions. 


\section{Chapter 9}

\section{CONCLUSIONS}

The artificial neural network based intelligent fault detection system provides the possibilities of 24-hour monitoring and real time fault detection of solar panels. The mechanism of the fault detection system relies on the position of sun in the sky. During the data collection procedure, sun's position is calculated and recorded along with the corresponding solar panel output power in the artificial neural network (ANN) training data sets. The ANN is trained with the solar training data sets and derives the algorithms that relate the solar panel output power to the position of sun in the sky.

At this point the artificial neural network is capable of estimating the output power of the solar panel with respect to sun's position. The fault detection system is designed to measure the average output power of the solar panel with 12 samples per minute and compare it with the output power estimated by the ANN. If the root mean square error (RMSE) between the measured and the estimated output powers exceeds some preset threshold an error message is produced to report the RMSE value along with the measured and estimated output power values and system time.

Utilizing the solar panel intelligent fault detection system, any power losses due to damaged cells, shadows etc. is detected and reported immediately which increases 
the efficiency of the solar power stations and decreases the maintenance and support costs in long terms. 


\section{REFERENCES}

[1] P.A. Lynn, Electricity from Sunlight: An Introduction to Photovoltaics, John Wiley \& Sons, Ltd., 2010.

[2] D. D. Nguyen, "Modeling And Reconfiguration Of Solar Photovoltaic Arrays Under Non-Uniform Shadow Conditions", Ph.D. dissertation, Northeastern University, Dept. of Electrical and Computer engineering, Boston, Mass., 2008.

[3] http://www.infinitepower.org/pdf/FactSheet-11.pdf, Retrieved on July $5^{\text {th }}$, 2012.

[4] http://www.en.wikipedia.org, Retrieved on July $3^{\text {rd }}, 2012$.

[5] C.S. Solanski, Solar Photovoltaics: Fundamentals, Technologies and Applications, $2^{\text {nd }}$ ed., PHI Learning Private Limited, 2011.

[6] "A Guide to Photovoltaic (PV) System Design and Installation", Endecon Engineering, California Energy Commission, 2001.

[7] K. Scharmer, and J. Greif, "Fundamentals and Maps" in The European Solar Radiation Atlas Vol.1, Les Presses de l`Ecole des Mines, Paris, 2000. 
[8] S. Nissen, "Implementation of A Fast Artificial Neural Network Library (FANN)", University of Copenhagen, Department of Computer Science, 2003.

[9] J.M. Michaelides and P.P. Votsis, "Energy analysis and solar energy development in Cyprus", in Computing and Control Engineering Journal, pp.211-215, Sept.1991.

[10] "Concentrating Solar Power for the Mediterranean Region", Technical Report, Institute of Technical Thermodynamics, Section Systems Analysis and Technology Assessment, German Aerospace Center (DLR), Stutgart, 2005.

[11] A. Peraiah, An Introduction to Radiative Transfer : Methods and Applications in Astrophysics, Cambridge University Press, 2004.

[12] W. Shen, Y. Ding, F.H. Choo, P. Wang, P.C. Loh and K.K. Tan, "Mathematical model of a solar module for energy yield simulation in photovoltaic systems", Technical Report, School of Electrical \& Electronic Engineering, Nanyang Technological University, 2009.

[13] J. Machacek, Z. Prochazka and J. Drapela, "System for measuring and collecting data from solar-cell systems", Technical Report, Dept. of Electrical and Power Eng., FEEC, Brno University of Technology, Czech Republic, 2007. 
[14] M. Suri, T. Huld, T. Cebecauer and E. Dunlop, "Geographic aspects of photovoltaics in Europe: contribution of the PVGIS website", IEEE Journal of Selected Topics in Applied Earth Observations and Remote Sensing, Vol. 1, No.1, 2008.

[15] E. Lorenz, J. Hurka, D. Heinemann and H.G. Beyer, "Irradiance forecasting for the power prediction of grid-connected photovoltaic systems", IEEE Journal of Selected Topics in Applied Earth Observations and Remote Sensing, Vol. 2, No.1, 2009.

[16] A. Luque and S. Hegedus, Handbook of Photovoltaic Science and Engineering. Wiley \& Sons Ltd., 2003.

[17] http://www.mpoweruk.com/solar_power.htm, Retrieved on July $10^{\text {th }}, 2012$.

[18] http://solar.sdsu.edu, Retrieved on July $10^{\text {th }}, 2012$.

[19] http://www.neuralpower.com/technology.htm, Retrieved on July $15^{\text {th }}, 2012$.

[20] G. Notton, C. Cristofari, M. Muselli, P. Poggi and N. Heraud, "Hourly solar irradiations estimation: from horizontal measurements to inclined data", in ISEIM, 2006. 